\title{
Vorläuferzellen des lymphatischen Endothels
}

\author{
Dissertation \\ zur Erlangung des Doktorgrades \\ der Mathematisch-Naturwissenschaftlichen Fakultäten \\ der Georg-August-Universität zu Göttingen
}

vorgelegt von

Kerstin Buttler

aus Hamburg

Göttingen 2008 
D 7

Referent: $\quad$ Prof. Dr. E. A. Wimmer

Korreferent: Prof. Dr. T. Pieler

Tag der mündlichen Prüfung: 23.10.2008 


\section{Inhaltsverzeichnis}

Abkürzungsverzeichnis

1 Einleitung _ 1

1.1 Bau und Funktion des Lymphgefäßsystems___ 1

1.2 Ontogenese von Blut- und Lymphgefäßen __ 3

1.3 Phylogenese des Lymphgefäßsystems _ 6

1.4 Molekulare Charakteristika des Lymphendothels ___ 6

1.4.1 Vascular Endothelial Growth Factor (VEGF)___ 6

1.4.2 Proxl__ 8

1.4.3 Lyve-1 8

1.4.4 Podoplanin _ 8

1.5 Vorläuferzellen bei der Lymphgefäßentwicklung __ 9

1.6 Zielsetzung der Arbeit ___ 13

2 Material __ 14

$2.1 \quad$ Geräte

2.2 Chemikalien und Biochemikalien__ 15

$2.3 \quad$ Verbrauchsmaterialien 16

$2.4 \quad$ Antikörper 17

2.4.1 Primärantikörper _ 18

2.4.2 Sekundärantikörper _ 19

$2.5 \quad$ Enzyme

$2.6 \quad$ Oligonukleotidprimer 19

$2.7 \quad$ Lösungen und Puffer____ 21

$2.8 \quad$ Anderes___ 22

2.9 Zellinien 23

2.10 Blutproben _ 23 
3.1 Immunhistologische Methoden 25

3.1.1 Isolierung von Mausembryonen aus dem Uterus des Muttertieres 25

3.1.2 Fixierung, Einbettung und Schnittanfertigung der Mausembryonen 25

3.1.2.1 Fixierung mittels Paraformaldehyd- (PFA) Lösung für Kryopräparate_ 25

3.1.2.2 Fixierung mittels Ethanol-Eisessig-Lösung und Einbettung in Paraffin 25

3.1.2.3 Unfixiertes Gewebe für Kryopräparate 26

3.1.3 Hämatoxylin-Eosin- (HE) Färbung 26

3.1.4 Immunhistologische Färbungen 26

3.1.4.1 Immunhistochemischer Nachweis von Lyve-1 an Paraffinpräparaten mittels Peroxidasereaktion 27

3.1.4.2 Immunfluoreszenzfärbungen an Kryopräparaten 27

3.1.4.3 Immunhistologischer Nachweis von Lyve-1 und Prox1 an Kryopräparaten 28

3.1.4.4 Immunhistologischer Nachweis von Lyve-1 und Ki-67 an Paraffinpräparaten nach Demaskierung (Antigen Retrieval) 28

3.1.4.5 Immunhistologischer Nachweis von Lyve-1 und CD31 an transgenen PPAR $\gamma$-Mausembryonen 29

3.2 Etablierung einer Schnittkultur von Mausembryonen 29

3.2.1 Gewebekultur ohne Zusatz von VEGF-C 29

3.2.2 Gewebekultur mit Zugabe von Wachstumsfaktor VEGF-C 30

3.2.3 Gewebekultur an PPAR $\gamma$-knock-out Mausembryonen 31

\subsection{Zellbiologische Methoden} 31

3.3.1 Anfertigung von Blutausstrichen und Immunfluoreszenzfärbungen 31

3.3.2 Isolierung mononukleärer Zellen aus peripherem humanem Blut mittels Dichtegradientenzentrifugation 32

3.3.3 Bestimmung der Zellzahl 32

3.3.4 Anfertigung von Zytospins und Immunfluoreszenzfärbungen 33 
3.3.5 Isolierung von Lyve-1-positiven Zellen aus mononukleären Zellen mittels magnetischer Zellseparation (MACS) __ 33

3.3.6 Durchflusszytometrie (FACS)___ 34

3.3.7 Kultivierung von Blutendothelzellen (HUVECs) __ 34

3.3.8 Kultivierung von Lymphendothelzellen __ 34

3.3.9 Kryokonservierung und Rekultivierung von Zellen __ 35

3.4 Molekularbiologische Methoden__ 35

3.4.1 Isolierung und Quantifizierung von gesamt-RNA aus peripheren mononukleären Blutzellen (PBMCs) _ 35

3.4.2 Isolierung von DNA aus embryonalem Mausgewebe___ 36

3.4.3 Polymerase-Ketten-Reaktion (PCR)__ 36

3.4.4 Agarose-Gelelektrophorese __ 37

3.4.5 Reverse Transkription- (RT) PCR 38

3.4.6 Reverse Transkription-PCR mittels Qiagen OneStep RT-PCR Kit __ 39

3.4.7 Real-Time-PCR__ 40

4 Ergebnisse

4.1 Lymphangiogenese im Jugularbereich von Mausembryonen__ 42

4.1.1 Expression des Lymphendothelmarkers Lyve-1 __ 44

4.1.1.1 Koexpression der Lymphendothelmarker Lyve-1 und LA102__ 46

4.1.1.2 Differenzierung zwischen Blut- und Lymphgefäßendothel ___ 47

4.1.1.3 Lyve-1-positive Einzelzellen koexprimieren den Leukozytenmarker

CD45_ 49

4.1.2 Expression des Lymphendothelmarkers Proxl__ 50

4.1.2.1 Koexpression der Lymphendothelmarker Lyve-1 und Prox $1 \_50$

4.1.2.2 Koexpression der Lymphendothelmarker Prox1 und LA102___ 51

4.1.2.3 Differenzierung zwischen Blut- und Lymphgefäßendothel __ 52

4.1.2.4 Prox1-positive Einzelzellen koexprimieren den Leukozytenmarker

CD45

4.1.3 Koexpression lymphendothelialer Marker mit dem Makrophagenmarker

$C D 11 b$

4.1.4 Koexpression lymphendothelialer Marker mit dem Makrophagenmarker

F4/80 
4.1.5 Untersuchungen mit dem Proliferationsmarker Ki-67 58

4.1.6 Proliferation Prox1- und Lyve-1-positiver Zellen 60

4.1.7 Quantitative Analyse proliferierender Lymphendothelzellen 60

4.2 Untersuchung der lymphangiogenen Potenz an Schnittkulturen von

Mausembryonen 63

4.2.1 Untersuchungen der lymphangiogenen Potenz an Schnittkulturen unter Zugabe des Wachstumsfaktors VEGF-C 65

\subsection{Untersuchungen mononukleärer Zellen aus peripherem Blut von}

Erwachsenen und Kindern 66

4.3.1 Reinheitsbestimmung und Quantifizierung der isolierten RNA aus PBMCs_67

4.3.2 Expressionsnachweis von Lyve-1, Proxl und Podoplanin auf mRNA-Ebene 68

4.3.3 Lyve-1-positive PBMCs von Erwachsenen 69

4.3.4 Untersuchungen von kindlichen PBMCs mit Lyve-1, Prox1 und CD31 Antikörpern 70

4.3.5 Untersuchungen von kindlichen PBMCs mit Lyve-1, Prox1 und CD45 Antikörpern 71

4.3.6 Untersuchungen von kindlichen PBMCs mit Lyve-1 und Podoplanin Antikörpern 72

4.3.7 Untersuchungen von kindlichen PBMCs mit Lyve-1 und CD34 Antikörpern 73

\subsection{Suche nach neuen Lymphangiogenese-Genen} 74

4.4.1 Vergleich humaner Lymphendothelzellen mit venösen Blutendothelzellen_ 74

4.4.2 Quantifizierung der RNA-Expression von PPAR in LECs und HUVECs_ 76

\subsection{Lymphgefäßentwicklung bei PPAR $\gamma$-knock-out-Mäusen _ 76}

4.5.1 Genotypisierung der Mausembryonen __ 77

4.5.2 Untersuchung der lymphangiogenen Potenz, von Wildtyp und heterozygoten Mausembryonen an Schnittkulturen 78

4.5.3 Makroskopische und immunhistologische Untersuchungen von Wildtyp und heterozygoten Mausembryonen

5 Diskussion 82

5.1 Lymphangiogenese 82

5.2 Entwicklung des Lymphgefäßsystems in der Ontogenese von Vertebraten 83 
5.2.1 Lyve-1-Expression bei der Lymphgefäßentwicklung von Mäusen 84

5.2.2 Proxl-Expression bei der Lymphgefäßentwicklung von Mäusen 85

5.2.3 Lymphangioblasten im Mesenchym von Mausembryonen 87

5.2.4 Lymphgefäßentwicklung bei Zebrafischen 89

5.2.5 Lymphgefäßentwicklung bei Xenopus laevis 90

5.2.6 Lymphgefäßentwicklung bei Vogelembryonen 90

5.2.7 Leukozyten bei der Lymphgefäßentwicklung von Mäusen 91

5.3 Makrophagen in der Lymphangiogenese 92

5.4 Lymphangiogenese in der Phylogenese 93

5.5 Pathologische Lymphangiogenese 94

5.5.1 Mesenchymale Zellen bei der Lymphgefäßregeneration 96

5.5.2 Zirkulierende Vorläuferzellen bei der pathologischen Lymphangiogenese_ 96

5.5.3 Zirkulierende Vorläuferzellen beim Kaposi-Sarkom 98

5.6 PPAR $\gamma$ in der Lymphangiogenese 99

5.7 Ausblick 100

6 Zusammenfassung 102

$7 \quad$ Literaturverzeichnis 105

8 Anhang 117

8.1 Abbildungs- und Tabellenverzeichnis 117

8.2 Publikationen 119

8.2.1 Originalpublikationen 119

8.2.2 Buchbeiträge 119

8.2.3 Abstracts 119

8.2.4 Posterpräsentationen 119

8.2.5 Vorträge 120

8.3 Danksagung 121 


\section{Abkürzungsverzeichnis}

$\alpha$

Abb.

AK

Aqua bidest. $\left(\mathrm{ddH}_{2} \mathrm{O}\right)$

BECs

bp

BrdU

BSA

bzw.

${ }^{\circ} \mathrm{C}$

ca.

$\mathrm{CD}$

cDNA

$\mathrm{CFU}$

$\mathrm{CO}_{2}$

$\mathrm{C}_{\mathrm{T}}$

DAB

Dapi

DiI

DMEM

DMSO

DNA

dATP

dCTP

dGTP

dNTP

dTTP

EDTA

ET

et al. anti

Abbildung

Antikörper

doppelt destilliertes Wasser

Blutendothelzellen

Basenpaare

Bromdesoxy-Uridin

Rinder-Serum-Albumin

beziehungsweise

Grad Celsius

circa

engl.: Cluster of Differentiation

komplementäre DNA (engl.: comlementary DNA)

engl.: Colony Forming Units

Kohlendioxid

Schwellenwert-Zyklus (engl.: Threshold Cycle)

3,3'-Diaminobenzidin-Tetrahydrochlorid

4',6-Diamidin-2-phenylindoldihydrochlorid

1,1'-Dioctadecyl-3,3,3',3'-tetramethyl-indocarbocyanine perchlorate

Dulbecco's modifiziertes Eagle's Medium

Dimethylsulfoxid

Desoxyribonukleinsäure

Desoxyadenintriphosphat

Desoxycytosintriphosphat

Desoxyguanosintriphosphat

Desoxynukleotidtriphosphat

Desoxythymidintriphosphat

Ethylendiamintetraessigsäure

Embryonaltag(e)

und andere (lat.: et alii) 


\begin{tabular}{|c|c|}
\hline $\mathrm{EtOH}$ & Ethanol \\
\hline FACS & engl.: Fluorescence Activated Cell Sorting \\
\hline FBS & fötales Rinderserum (engl.: Fetal Bovine Serum) \\
\hline FGF2 & engl.: Fibroblast Growth Factor 2 \\
\hline FITC & Fluoreszeinisothiocyanat \\
\hline FoxC2 & engl.: Forkhead box $\mathrm{C} 2$ \\
\hline GAPDH & Glycerinaldehyd-3-phosphat-dehydrogenase \\
\hline GATA & engl.: Globin Transcription Factor \\
\hline GFPSlp-76 & Grünes Fluoreszenz-Protein Slp-76 \\
\hline h & Stunde(n) \\
\hline $\mathrm{HE}$ & Hämatoxylin-Eosin \\
\hline HHV-8 & Humanes Herpesvirus 8 \\
\hline HIV & Humanes Immundefizienzvirus \\
\hline HRP & Meerrettichperoxidase (engl.: Horseradish Peroxidase) \\
\hline HUVECs & engl.: Human Umbilical Vein Endothelial Cells \\
\hline JLS & juguläre(r) Lymphsack (-säcke) \\
\hline $\mathrm{kb}$ & Kilobasen \\
\hline $\mathrm{kDa}$ & Kilodalton \\
\hline KPP & Kaliumphosphatpuffer \\
\hline $\mathrm{KS}$ & Kaposi-Sarkom \\
\hline Lyve-1 & Lymphgefäß-Hyaluronsäure-Rezeptor-1 \\
\hline LECs & Lymphendothelzellen \\
\hline M & molar \\
\hline m- & milli \\
\hline MACS & Magnetische Zellseparation (engl.: Magnetic Cell Sorting) \\
\hline $\min$ & Minute(n) \\
\hline $\mathrm{ml}$ & Milliliter \\
\hline$\mu l$ & Mikroliter \\
\hline mRNA & Boten-RNA (engl.: messenger RNA) \\
\hline $\mathrm{N}$ & normal \\
\hline $\mathrm{n}$ & Anzahl \\
\hline $\mathrm{Na}$ & Natrium \\
\hline ng & Nanogramm \\
\hline
\end{tabular}


NK-Zellen

NMRI

$\mathrm{Nr}$.

OD

o.g.

PBMCs

PBS

PCR

PDGF

PE

PECAM-1

Pen/Strep

PFA

$\mathrm{pH}$

PlGF

PPAR

PVR

RNA

RT

RT-PCR

$\mathrm{s}$

SCL/Tal-1

SD

SDS

$\mathrm{SH} 2$

SLC

Slp76

SYK

TAE-Puffer

U
Natürliche Killerzellen

Naval Medical Research Institute

Nummer

optische Dichte

oben genannte

Periphere mononukleäre Blutzellen

Phosphat-gepufferte Salzlösung (engl.: phosphate buffered saline)

Polymerase-Ketten-Reaktion (engl.: Polymerase Chain

Reaction)

engl.: Platelet-derived Growth Factor

Phycoerythrin

engl.: Platelet Endothelial Cell Adhesion Molecule-1

Penicillin / Steptomycin

Paraformaldehyd

negativer dekadischer Logarithmus der

Wasserstoffionen-Konzentration

engl.: Placenta Growth Factor

engl.: Peroxisome Proliferator-activated Receptor

engl.: PDGF/VEGF Receptor

Ribonukleinsäure

Reverse Transkription

Reverse Transkription-Polymerase-Ketten-Reaktion

Sekunde(n)

engl.: T-cell acute lymphocytic leukemia-1

Standardabweichung

Sodium-Dodecyl-Sulfat

engl.: Src-homology 2

engl.: Secondary Lymphoid Chemokine

engl.: SH2 domain-containing Leukocyte Protein of $76 \mathrm{kDa}$

engl.: Spleen Tyrosine Kinase

Tris-Acetat-EDTA-Puffer

Einheiten (engl.: Units) 
u.a.

VE-Cadherin

VEGF

VEGFR-2

VEGFR-3

VEGF-C

VEGF-D

z.B. unter anderem

engl.: Vascular Endothelial Cadherin

engl.: Vascular Endothelial Growth Factor

engl.: Vascular Endothelial Growth Factor Receptor-2

engl.: Vascular Endothelial Growth Factor Receptor-3

engl.: Vascular Endothelial Growth Factor-C

engl.: Vascular Endothelial Growth Factor-D

zum Beispiel 


\section{$1 \quad$ Einleitung}

Bau, Entwicklung und Pathologie des Lymphgefäßsystems sind im Vergleich zum Blutgefäßsystem wenig untersucht worden, obwohl die Lymphgefäße für die Zirkulation von Leukozyten und beim Metastasieren von Karzinomen die entscheidende Leitstruktur darstellen. Für die Versorgung der einzelnen Gewebe und Organe benötigen Vertebraten aufgrund ihrer komplexen Körperstruktur ein effizientes Transportsystem. Das Blutgefäßsystem versorgt den Organismus mit Sauerstoff, Nährstoffen und Hormonen und entsorgt Metabolite. Es ist ein geschlossenes Zirkulationssystem aus arteriellen und venösen Gefäßstrecken. Das Lymphgefäßsystem ist für die Aufrechterhaltung der Flüssigkeits-Homöostase der Gewebe zuständig. Es nimmt interstitielle Flüssigkeit (und Zellen) aus dem Gewebe auf und transportiert Lymphe zu den lympho-venösen Anastomosen des rechten und linken Venenwinkels in das Blut der Vena jugularis bzw. Vena subclavia. Die Lymphe besteht aus interstitieller Flüssigkeit, Proteinen, Leukozyten, Lipiden, Enzymen und Ionen und kann pathogene Organismen, wie z.B. Bakterien oder Viren, enthalten, die in den Körper eingedrungen sind. Funktionelle Störungen der Flüssigkeits-Homöostase resultieren in Beschwerden, die den Gesundheitszustand und die Lebensqualität erheblich beeinträchtigen. Fehlentwicklungen oder Verletzungen von Lymphgefäßen rufen Lymphödeme hervor. Lymphangiome, Lymphangiosarkome und Kaposi Sarkome sind tumuröse Entartungen von Lymphendothelzellen. Obwohl in den letzten 100 Jahren das Wissen über Struktur und Funktion des Lymphgefäßsystems erheblich gewachsen ist, bleiben die Ursachen der genannten Pathologien und die Mechanismen der embryonalen Lymphgefäßentwicklung bis heute weitgehend unklar. Ein besseres Verständnis der Lymphgefäßbildung (Lymphangiogenese) könnte helfen, diagnostische Methoden und therapeutische Maßnahmen bei Erkrankungen und Verletzungen zu optimieren bzw. zu ergänzen (Wilting et al., 1999; Kubik et al., 2003; Oliver und Alitalo, 2005).

\subsection{Bau und Funktion des Lymphgefäßsystems}

Lymphgefäße sind neben den primären und sekundären lymphatischen Organen wie Thymus, Knochenmark, Milz und Lymphknoten ein Teil des lymphatischen Systems. Sie 
kommen in allen Geweben und Organen vor, ausgenommen hiervon sind das Zentralnervensystem, die Kornea, das Knochenmark und avaskuläre Gewebe wie Knorpel und Epidermis (Alitalo et al., 2005). Es gibt ein oberflächliches (epifasziales) und ein tiefes Lymphgefäßsystem, das die Körperwand und die inneren Organe drainiert. Lymphgefäße wie auch Blutgefäße sind mit einer Endothelzellschicht ausgekleidet und bilden ein Gefäßnetz aus Kapillaren, Präkollektoren, Kollektoren und Lymphstämmen. Lymphkapillaren (Durchmesser bis zu $70 \mu \mathrm{m}$ ), auch initiale Lymphgefäße genannt, liegen oft in Begleitung großer Blutgefäße und sind blind-endend. Im Gegensatz zu den meisten Blutkapillaren besitzen sie keine kontinuierliche Basallamina, dafür aber interendotheliale Klappen (Casley-Smith, 1980; Barsky et al., 1983; Ezaki et al., 1990). Das Lumen der Kapillaren wird durch Ankerfilamente stabilisiert, welche die Endothelzellen mit dem Elastin der extrazellulären Matrix verbinden (Casley-Smith, 1980). Die Endothelklappen werden bei erhöhtem interstitiellen Druck geöffnet, so dass Flüssigkeit, Zellen und Makromoleküle in die Lymphkapillaren eintreten können. Interstitielle Flüssigkeit ensteht, indem Blutplasma aus dem arteriellen Gefäßschenkel in das Körpergewebe abgepresst wird und anschließend nur ca. 90\% wieder von den Venulen (kleinste venöse Gefäße) kolloidosmotisch reabsorbiert werden. Ein Weitertransport der restlichen $10 \%$ erfolgt über die Lymphkapillaren. Sobald die initialen Lymphgefäße Lymphe enthalten, erhöht sich der Innendruck und schließt die Klappen der Endothelzellen wieder. Lymphe wird weiter zu den Präkollektoren (Durchmesser ca. $150 \mu \mathrm{m}$ ) und Kollektoren (Durchmesser ca. 100 $600 \mu \mathrm{m})$ transportiert. Lymphkollektoren besitzen eine Basalmembran, eine kontraktile Tunica media und eine Tunica adventitia (Berens von Rautenfeld und Drenckhahn, 1994). Es wurden unterschiedliche Segmente an Präkollektoren beschrieben, die kollagenes Bindegewebe und einige glatte Muskelzellen aufweisen, während andere Segmente des selben Gefäßes ähnliche Wandstrukturen wie Lymphkapillaren zeigen. Kollektoren besitzen zusätzlich intraluminale Taschenklappen, um einen Rückfluss der Lymphe zu verhindern. Der Transport der Lymphflüssigkeit in den Kollektoren geschieht durch aktive Kontraktionen der Media von distal nach proximal. Dabei werden die Klappen geöffnet und die Lymphe weiter in die Lymphstämme geleitet. Diese besitzen dickere Wandschichten als die Kollektoren. Der größte Lymphstamm ist der Ductus thoracicus. Er drainiert Lymphe der unteren Körperregion (unterhalb des Herzens), sowie den oberen linken Quadranten des Körpers. Der Ductus thoracicus mündet schließlich in den linken Venenwinkel zwischen Vena subclavia sinistra und Vena jugularis interna sinistra. Der 
obere rechte Körperquadrant wird über den Ductus lymphaticus dexter in den rechten Venenwinkel drainiert, der zwischen der Vena jugularis interna dextra und Vena subclavia dextra liegt. Auf diese Weise werden täglich 2-4 Liter Lymphflüssigkeit dem Blutkreislauf wieder zugeführt. Auf dem Weg von den Lymphkapillaren bis zum Wiedereintritt in das Blutgefäßsystem passiert die Lymphe mehrere Lymphknoten, von denen es ca. 600 - 700 im Menschen gibt (Kubik et al., 2003).

\subsection{Ontogenese von Blut- und Lymphgefäßen}

Das Lymphgefäßsystem wurde 1627 erstmals von Gasparo Aselli beschrieben (Asellius, 1627). Die meisten morphologischen Studien wurden Ende des 19. und Anfang des 20. Jahrhunderts mit Hilfe von Injektionstechniken und seriellen Schnitten an verschiedenen Tieren durchgeführt (Budge, 1880; Sala, 1900; Sabin, 1909; Kampmeier, 1912b). Lymphgefäße, aber auch Blutgefäße, Blutzellen sowie Bindegewebe (und weitere Gewebe) entstehen aus dem Mesoderm. Das Mesoderm bezeichnet als Ganzes das mittlere Keimblatt des Embryos. Bei der Gastrulation bildet sich beiderseits der Mittellinie paraxiales Mesoderm aus, die lateralen Bereiche werden als Seitenplatten bezeichnet (Abb. 1A). Das paraxiale Mesoderm gliedert sich gegen Ende der 3. Woche (beim Menschen) beiderseits des Neuralrohrs in einzelne Segmente, die als Somiten bezeichnet werden (Abb. 1B). Die Somiten sind für die Ausbildung der Grundform des embryonalen Körpers und die segmentale Gliederung des mesodermalen Anlagematerials zuständig. Anfang der 4. Woche beginnt die Auflösung der Somiten in der ventro-medialen Wand (Abb. 1B). Diese Zellen, sogenannte Sklerotomzellen, bilden einen lockeren Gewebeverband, der als Mesenchym bezeichnet wird (Abb. 1C). Die Mesenchymzellen können in verschiedener Weise differenzieren, u.a. auch in Blut- und Lymphendothelzellen. Aus jedem Somiten entwickelt sich ein Sklerotom (bildet u.a. die Anlage der Wirbelsäule und Meningen), ein Myotom (segmentale Muskulatur) und ein Dermatom (segmentaler Hautabschnitt, in dem später oberflächliche Lymphkapillaren auftreten) (Sadler, 2003). 


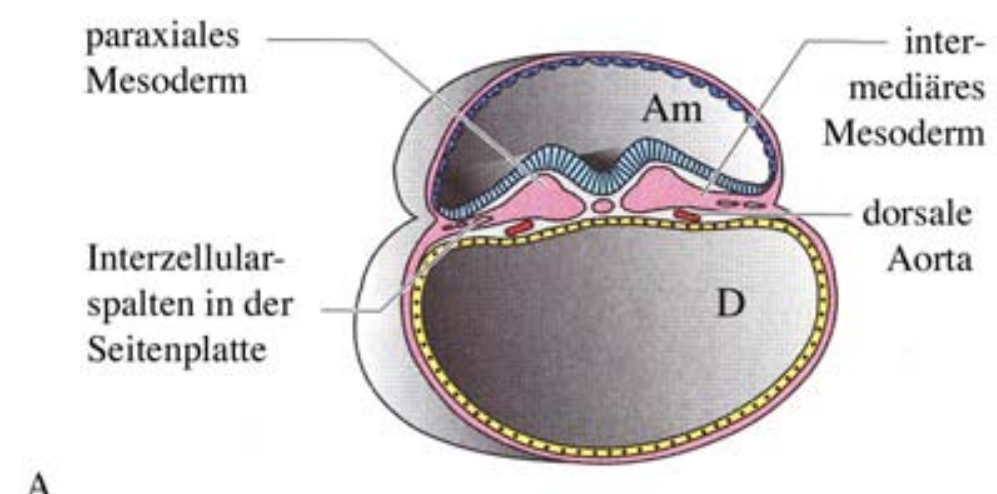

A

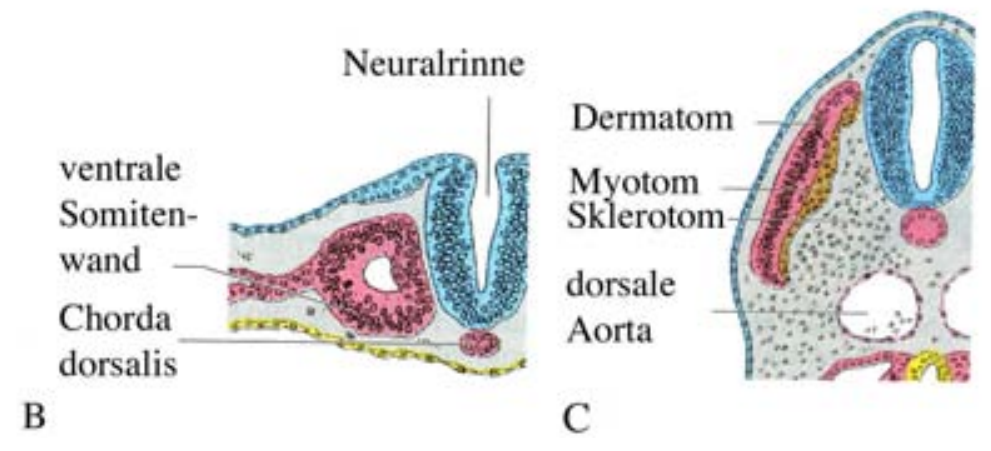

Abb. 1: Querschnitte verschiedener Entwicklungsstadien des Mesoderms / der Somiten beim Menschen. A) Aus dem paraxialen Mesoderm entwickeln sich die Somiten. Am = Amnionhöhle (blau $=$ Ektoderm) $; \mathrm{D}=$ Dottersack $($ gelb $=$ entodermale Wand des Dottersacks $)$. B) Die Mesodermzellen (rosa) ordnen sich epithelartig um eine kleine Höhle an. C) Aus der dorsalen Somitenwand entwickelt sich das Dermatom (rosa; spätere Dermis) und darunter das Myotom (gelb), das die Muskelanlagen enthält. Zellen der ventralen und medialen Somitenwand wandern auf die Chrorda dorsalis zu und werden als Sklerotom bezeichnet. Verändert nach Sadler (2003).

Erste Blutgefäße differenzieren sich im Mesoderm in der Mitte der 3. Woche (Abb. 2). Hämangioblasten, das sind aus dem Mesoderm abstammende Vorläuferzellen, aggregieren zu Zellnestern und bilden primäre Blutinseln im Dottersack (Sabin, 1920; Sadler, 2003). Die äußeren Zellen differenzieren sich $\mathrm{zu}$ Endothelzellen und die inneren $\mathrm{zu}$ hämatopoetischen Zellen. Die Blutinseln verbinden sich durch aussprossende Endothelzellen miteinander und formen einen primitiven (primären) kapillar-ähnlichen Plexus. Kurze Zeit später entwickeln sich intraembryonal Blutgefäße aus Hämangioblasten und Angioblasten (Vorläuferzellen des Endothels), die in verschiedenen mesodermalen Abschnitten des Embryos lokalisiert sind. 


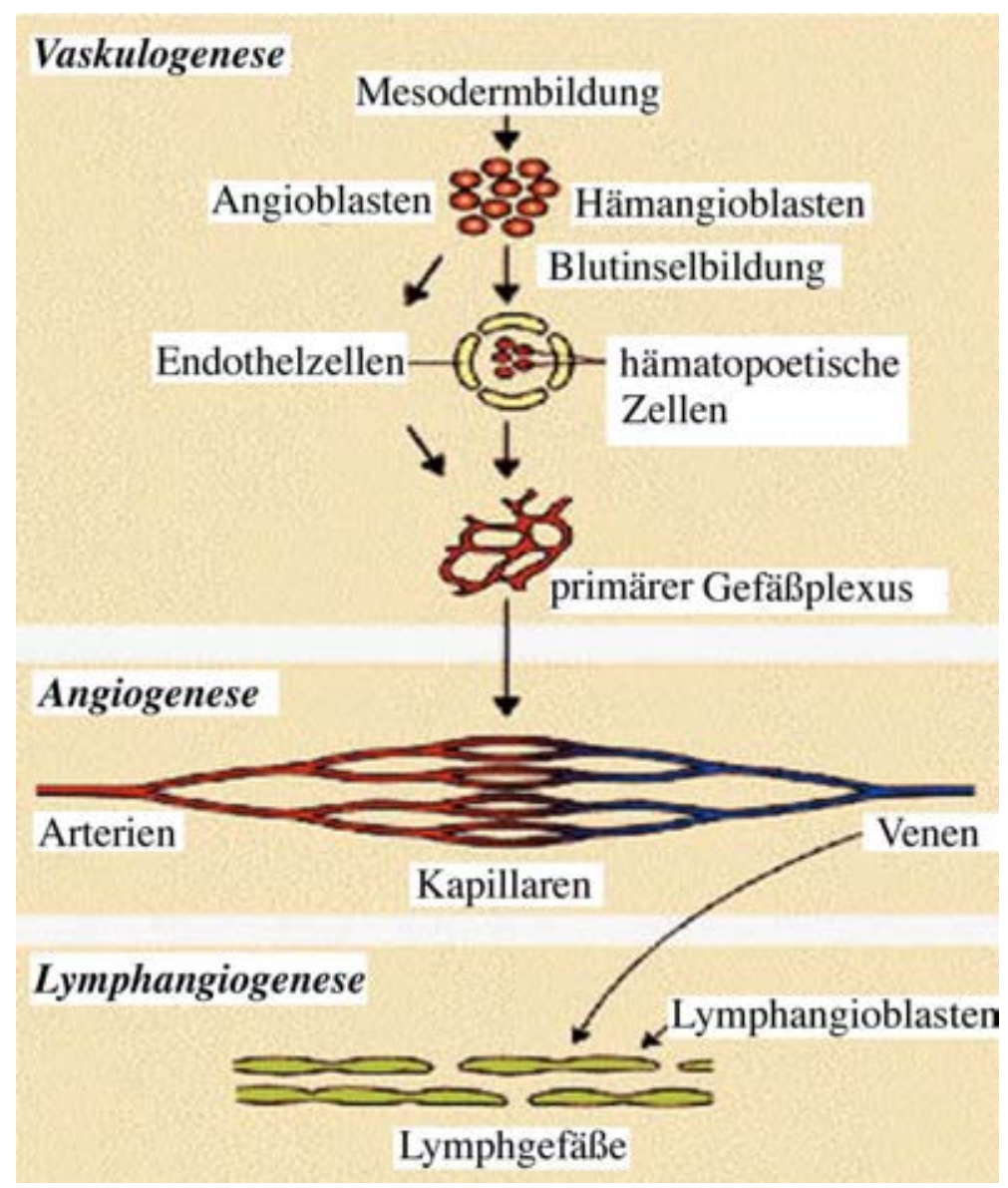

Abb. 2: Schema der Gefäßentwicklung. Die Vaskulogenese beschreibt die ersten Entwicklungsschritte von Blut und Blutgefäßen aus dem Mesoderm bis zu einem primitiven Gefäßplexus. Die Ausbildung des Gefäßsystems zu einem verzweigten Netz durch Sprossung und Intussuszeption aus den primitiven Gefäßen wird Angiogenese genannt. Während der Lymphangiogenese entstehen Lymphgefäße durch Sprossung aus bereits vorhandenen Venen oder mit Hilfe von Lymphangioblasten. Verändert nach Wilting et al. (2003a).

Die Bildung von Gefäßen aus Vorläuferzellen wird Vaskulogenese genannt (Risau und Flamme, 1995). Die anschließende Angiogenese beschreibt das Wachstum und die Umgestaltung des initialen Gefäßnetzes durch Sprossung der Endothelzellen, Teilung der vorhandenen, großlumigen Gefäße (Intussuszeption) und durch Vergrößerung von Gefäßen (Risau, 1997; Yancopoulos et al., 2000). Erst sehr viel später bildet sich das Lymphgefäßsystem in Vertebraten aus. Im Menschen treten die ersten sichtbaren Zeichen des Lymphgefäßsystems, die jugulären Lymphsäcke, etwa einen Monat nach der Entwicklung der ersten Blutgefäße auf (van der Putte, 1975a). Lymphgefäße sind meistens in unmittelbarer Nähe von Blutgefäßen lokalisiert. Diese Beobachtung führte zu der Annahme, dass Blutgefäße für die sich entwickelnden Lymphgefäße als Wegweiser fungieren. 


\subsection{Phylogenese des Lymphgefäßsystems}

In der phylogenetischen Reihe erscheinen Lymphgefäße relativ spät (erstmals bei den Vertebraten). Mollusken und Arthropoden besitzen ein offenes Zirkulationssystem, welches die Funktionen des lymphatischen Systems und des Blutes übernimmt (Alitalo et al., 2005). Auch bei den Insekten ist das Kreislaufsystem noch undifferenziert und wird als hämolymphatisches System bezeichnet. Tiere mit einem geschlossenen Blutkreislauf (Vertebraten und einige Invertebraten) benötigen für die Flüssigkeits-Homöostase ein Lymphgefäßsystem. Die Komplexität des Lymphgefäßsystems wächst mit der Phylogenese von Vertebraten (Rusznyák et al., 1969). Die Klasse der Chondrichthyes (Knorpelfische) besitzt, mit wenigen Ausnahmen, keine Lymphgefäße. Teleostei (höhere Knochenfische) dagegen entwickeln ein primitives Lymphgefäßsystem (Hoyer und Michalski, 1922; Yaniv et al., 2006), welches in Amphibien und Reptilien komplexere Strukturen aufweist (Clark, 1909; Ny et al., 2005). Für den Transport der Lymphflüssigkeit besitzen diese Tiere kontraktile Lymphherzen sowie Lymphklappen, die einen Rückfluss der Lymphe verhindern. Weiter entwickelte Formen der Lymphgefäße mit kontraktilen Kollektoren zeigen Vögel (Budge, 1882; Fülleborn, 1895) und schließlich die Säugetiere (Ranvier, 1895; Sabin, 1909). Der Hauptunterschied zwischen Vögeln und Säugetieren, speziell dem Menschen, besteht in der höheren Anzahl von Lymphknoten. Wasservögel besitzen nur zwei Paare von Lymphknoten, ein Paar in der Becken- und ein Paar in der Jugularregion (Nickel et al., 1992; Wilting et al., 1997). Die Zahl der Lymphklappen ist bei Vögeln geringer, dafür weisen sie, im Gegensatz zu Säugetieren, Lymphherzen auf, die zum Teil nur transient, zum Teil aber auch permanent auftreten.

\subsection{Molekulare Charakteristika des Lymphendothels}

\subsubsection{Vascular Endothelial Growth Factor (VEGF)}

In den letzten Jahren wurden Moleküle identifiziert, die bei der Entwicklung von Lymphendothelzellen im Rahmen der Entstehung von Lymphgefäßen eine wichtige Rolle spielen. Bedeutend für die Angiogeneseforschung ist die Vascular Endothelial Growth Factor (VEGF) Familie, die bisher aus fünf Mitgliedern besteht: VEGF-A (ursprünglich als VEGF bezeichnet), -B, -C, -D und der Placenta Growth Factor (PlGF) (Neufeld et al., 
1999). Die Funktionen dieser Wachstumsfaktoren werden über ihre Rezeptoren 1, 2 und 3 (VEGFR-1, -2, -3) sowie die Ko-Rezeptoren Neuropilin-1 und -2 vermittelt. VEGF-A, VEGF-B und PIGF binden mit hoher Affinität an VEGFR-1, VEGF-A, -C und -D an VEGFR-2 und VEGF-C und -D an VEGFR-3 (Flt4). Es ist bekannt, dass VEGF-A ausschließlich hämangiogene (blutgefäßbildende) Wirkung besitzt (Wilting et al., 1992; Wilting und Christ, 1996). Ich möchte hier nur auf VEGF-C und -D sowie deren Rezeptoren VEGFR-2 und -3 näher eingehen, da diese Moleküle in der Lymphangiogenese eine wichtige Rolle spielen. Sie stimulieren in geringerem Umfang ebenfalls die Hämangiogenese (Joukov et al., 1996; Lee et al., 1996; Jeltsch et al., 1997; Oh et al., 1997). Sowohl die unreife als auch die proteolytisch prozessierte Form von VEGF-C binden VEGFR-3 mit hoher Affinität, aber nur letztere bindet VEGFR-2 (Joukov et al., 1996; Lee et al., 1996). Hohe Expressionsraten von VEGF-C können in Bereichen mit hohem lymphangiogenen Potential nachgewiesen werden wie z.B. der Jugularregion von Embryonaltag (ET) 12,5 Mausembryonen (Kukk et al., 1996). Die homozygote Deletion des VEGF-C-Gens in Mäusen führt zu einem Verlust von Lymphgefäßen, während heterozygote Mäuse lymphatische Hypoplasien entwickeln (Karkkainen et al., 2004). Im Gegensatz dazu beeinträchtigt die VEGF-D-Deletion nicht die Entwicklung des Lymphgefäßsystems. Der Wachstumsfaktor übt aber einen lymphangiogenen Effekt in VEGF-C-knock-out-Mäusen aus (Baldwin et al., 2005). In der Embryonalentwicklung von Mäusen und Vögeln wird VEGFR-3 stadienspezifisch reguliert. In frühen Entwicklungsstadien exprimieren Blut- und Lymphendothelzellen den Rezeptor. Bei fortschreitender Gewebereifung wird die Expression in Blutgefäßen herunterreguliert und bleibt nur in Lymphendothelzellen ausdifferenzierter Gewebe erhalten (Kaipainen et al., 1995; Wilting et al., 1997). Nur einige nicht-endotheliale Zelltypen wie die Podozyten und eine Subpopulation von Gallengangszellen sind ebenfalls VEGFR-3-positiv. Die Inaktivierung von VEGFR-3 führt $\mathrm{zu}$ Fehlbildungen der Blutgefäße und einem frühembryonalen Sterben des Keims (Dumont et al., 1998). VEGFR-2 ist ein früher Marker in der Entwicklung von Blut- und Endothelzellen (siehe 1.5) und wird auf Hämangioblasten, Angioblasten, Blut- und Lymphendothelzellen exprimiert (Eichmann et al., 1993; Yamaguchi et al., 1993; Wilting et al., 1997). VEGFR-2-knock-out-Mäuse sterben zwischen ET 8,5 und 9,5 aufgrund von Entwicklungsdefekten hämatopoetischer Zellen und Endothelzellen. Luminisierte Blutgefäße sind im Embryo und Dottersack nicht vorhanden (Shalaby et al., 1995). 


\subsubsection{Prox1}

Prox1 ist ein Homeobox-Transkriptionsfaktor, der in Mäusen als Homolog des Drosophila Gens Prospero kloniert wurde. Neben Kardiomyozyten, Hepatozyten und neuronalen Zellen, wird Prox 1 in Lymphendothelzellen, nicht aber in Blutendothelzellen bei Mäusen, Vögeln und Menschen exprimiert (Wigle und Oliver, 1999; Rodriguez-Niedenfuhr et al., 2001). Eine frühe Prox1-Expression konnte während der Embryonalentwicklung von Mäusen und Vögeln in dem Bereich des Gefäßsystems nachgewiesen werden, wo sich die kraniale und kaudale Kardinalvene vereinigen (siehe Abb. 4G). In dieser Region bilden sich später die jugulären Lymphsäcke. Die Inaktivierung von Prox1 führt zum Absterben der Mausembryonen an ET 14,5 mit phänotypischen Veränderungen der Linsen, Leber und der Lymphgefäße. Selbst bei heterozygoten Proxl defizienten Mäusen kommt es zur Flüssigkeitsakkumulation im Abdomen. Wenige Tage nach der Geburt sterben die Mäuse. Nur wenige Tiere eines bestimmten Stammes überleben (Wigle und Oliver, 1999).

\subsubsection{Lyve-1}

Lyve-1 (Lymphgefäß-Hyaluronsäure-Rezeptor-1) ist ein transmembranes Glykoprotein, das auf Lymphendothelzellen und Makrophagen exprimiert wird. Es ist homolog zu dem Hyaluronsäure-Rezeptor CD44 (Banerji et al., 1999; Prevo et al., 2001). Leber-, Milzsinusoide und hoch-endotheliale Venulen sind die einzigen Blutendothelzellen, die eine Lyve-1-Expression zeigen (Mouta Carreira et al., 2001). Der Rezeptor scheint am Transport der Hyaluronsäure durch das lymphatische Endothel in die Lymphe beteiligt zu sein, da er luminal und abluminal lokalisiert ist (Prevo et al., 2001). Lyve-1 reguliert möglicherweise auch den Eintritt von Leukozyten oder Tumorzellen in das Lumen von Lymphkapillaren (Jackson et al., 2001). Mäuse, denen der Rezeptor fehlt, zeigen jedoch keine Veränderungen in der Entwicklung und Funktion von Lymphgefäßen (Gale et al., 2007).

\subsubsection{Podoplanin}

Ein weiteres Molekül, das auf Lymphendothelzellen, nicht aber auf Blutendothelzellen nachgewiesen werden konnte, ist Podoplanin. Es ist ein integrales Membranprotein, das auf Osteoblasten, Osteozyten, Epithelzellen des Plexus choroideus, Typ-1-Pneumozyten 
und glomerulären Epithelzellen (Podozyten) exprimiert wird (Rishi et al., 1995; Wetterwald et al., 1996). Es gibt Hinweise darauf, dass Podoplanin für die Bildung, Formgestaltung und Permeabilität von Podozyten eine wichtige Rolle spielt (BreitenederGeleff et al., 1997; Matsui et al., 1998; Breiteneder-Geleff et al., 1999; Matsui et al., 1999; Kriehuber et al., 2001). Die Funktionen von Podoplanin wurden an Knock-out-Mäusen untersucht. Die Mäuse sterben bei der Geburt aufgrund von respiratorischen Defekten. Sie zeigen ebenfalls Malformationen der Lymphgefäße, nicht aber der Blutgefäße. Assoziiert hiermit waren ein reduzierter Lymphtransport, angeborene Lymphödeme und dilatierte Lymphgefäße (Schacht et al., 2003). Die genaue Funktion von Podoplanin für LECs ist bisher aber nicht charakterisiert.

\subsection{Vorläuferzellen bei der Lymphgefäßentwicklung}

In frühen Stadien der Embryonalentwicklung treten bei der Bildung von Blutinseln hämatopoetische Zellen und Endothelzellen gemeinsam in Erscheinung. Ihre räumliche Nähe zueinander führte $\mathrm{zu}$ der Hypothese einer gemeinsamen Vorläuferzelle, dem Hämangioblasten (Sabin, 1920; Murray, 1932; Eichmann et al., 1997). Unterstützt wurde diese Theorie durch die Tatsache, dass hämatopoetische Zellen und Endothelzellen gemeinsame Oberflächenproteine und Transkriptionsfaktoren wie CD31, CD34, VECadherin, GATA1 und -2 und SCL/Tal-1 besitzen (Kubo und Alitalo, 2003; Wilting et al., 2003a). Ein Schlüsselmolekül scheint hierbei auch VEGFR-2 zu sein, da der Rezeptor auf Hämangioblasten, Angioblasten, Blut- und Lymphendothelzellen exprimiert wird (Eichmann et al., 1993; Yamaguchi et al., 1993). In Mäusen sind VEGFR-2-positive embryonale Stammzellen in der Lage, Endothelzellen und hämatopoetische Zellen zu bilden, was auf die Existenz von Hämangioblasten hinweist. Knock-out-Experimente bei Mäusen haben gezeigt, dass aufgrund von Entwicklungsdefekten hämatopoetischer Zellen und Endothelzellen keine Blutinseln und somit auch keine Blutgefäße gebildet werden. Die Embryonen sterben noch vor der Geburt (Shalaby et al., 1995; Huber et al., 2004). Es ist bisher aber nicht geklärt, in welchem Entwicklungsstadium sich die hämatopoetische von der endothelialen Zelllinie trennt. 


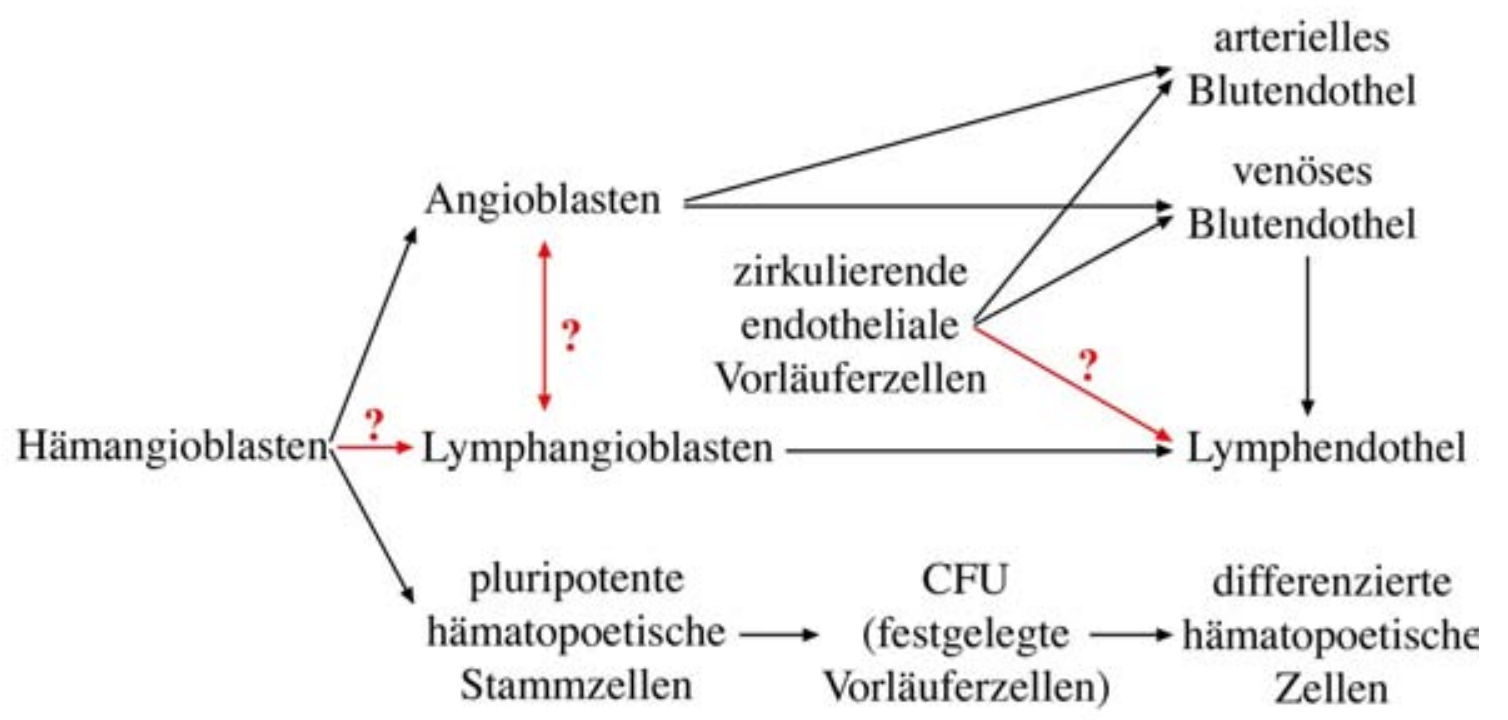

Abb. 3: Entwicklung von Endothelzellen und Zellen der hämatopoetischen Reihe. Die Verwandtschaft zwischen Hämangioblasten, Angioblasten und Lymphangioblasten ist angedeutet. Es besteht ein Zusammenhang zwischen zirkulierenden endothelialen Vorläuferzellen und der Entwicklung von Blutendothel, eine Korrelation zum Lymphendothel ist bisher jedoch nicht bekannt. CFU, colony forming units.

Aus den Vorläuferzellen des Endothels (Angioblasten) entwickeln sich arterielle und venöse Blutendothelzellen (Abb. 3). Die venösen Blutendothelzellen können wiederum zu Lymphendothel differenzieren. Ob Lymphangioblasten als spezifische Vorläuferzellen des Lymphendothels unmittelbar aus Hämangioblasten bzw. Angioblasten hervorgehen und damit eine weitere Quelle für Lymphendothelzellen darstellen, ist bisher nicht bekannt. In der pathologischen Angiogenese sind auch zirkulierende endotheliale Vorläuferzellen beschrieben worden. Jedoch ist nicht geklärt, ob ein direkter Zusammenhang zur Entwicklung des Lymphendothels besteht. Zellen der hämatopoetischen Reihe (Erythrozyten, Granulozyten, Monozyten, Lymphozyten, Thrombozyten) bzw. deren Vorläufer (CFU) stammen von pluripotenten hämatopoetischen Stammzellen ab, deren Vorläuferzelle der Hämangioblast ist.

Die sukzessive Entwicklung von Blut- und Lymphendothel führte vor mehr als 100 Jahren zu der Hypothese, dass das Lymphendothel aus spezifischen Bereichen venöser Blutgefäße hervorgeht. Erste morphologisch sichtbare Zeichen der Lymphgefäßentwicklung bei Vögeln, Säugetieren und beim Menschen sind die jugulären Lymphsäcke. Die Lymphsäcke 
entstehen vornehmlich durch Sprossung aus bestimmten Segmenten der Kardinalvenen. Die ursprüngliche Theorie von Florence Sabin (1902) über die weitere Entwicklung des Lymphgefäßsystems besagt, dass alle Lymphgefäße der Gewebe und Organe in einem Organismus von sprossenden Endothelzellen der Lymphsäcke abstammen (Zentrifugaltheorie, Abb. 4A,B). Alternativ hierzu postulierten Huntington und McClure ein Modell, wonach sich die Lymphgefäße und Lymphsäcke aus mesenchymalen Zellen entwickeln. Vorläuferzellen des lymphatischen Endothels sollen endothelial ausgekleidete Spalten bilden, die schließlich zu einem Gefäßsystem konfluieren. Erst danach werden Verbindungen zum venösen System etabliert (Abb. 4C-F). Dieses Modell wird Zentripetaltheorie genannt (Huntington und Mc Clure, 1910). Andere Autoren des vorigen Jahrhunderts vertraten einen intermediären Standpunkt, der beide Theorien vereinte (Kampmeier, 1912a). Unterstützt wurde die Zentrifugaltheorie durch neuere Studien an Mäusen und Zebrafischen (Wigle und Oliver, 1999; Yaniv et al., 2006). Bei Mäusen wurden Prox-1-positive Endothelzellen bereits vor der Bildung der Lymphsäcke in jugulären Segmenten der Kardinalvenen nachgewiesen (Wigle et al., 2002; Srinivasan et al., 2007). Andere Arbeiten hingegen zeigten an Vögeln und Fröschen zusätzlich einen mesenchymalen Ursprung von Lymphendothelzellen (Schneider et al., 1999; Ny et al., 2005; Wilting et al., 2006). In großer Distanz zu den tiefen embryonalen Venen konnten im Dermatom entlang der Körperachse von Vogelembryonen verstreute Prox-1-positive Zellen nachgewiesen werden (Abb. 4G) (Wilting et al., 2003b). 
A

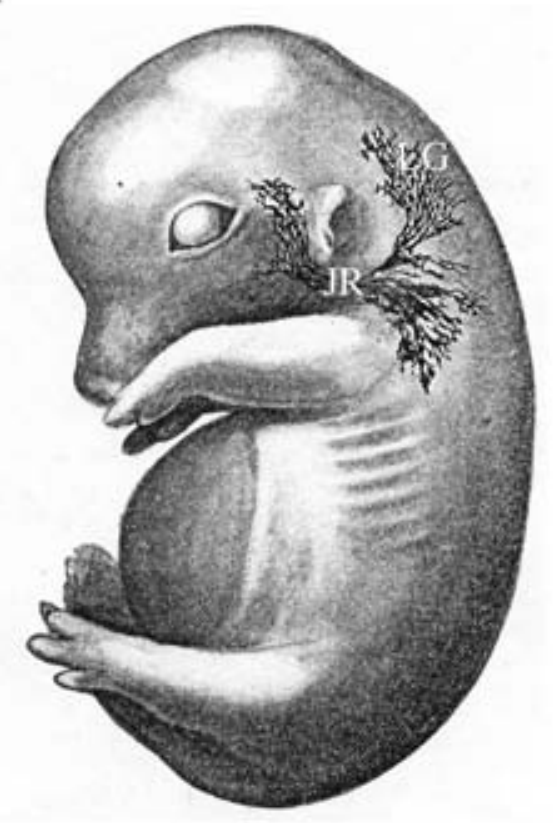

B
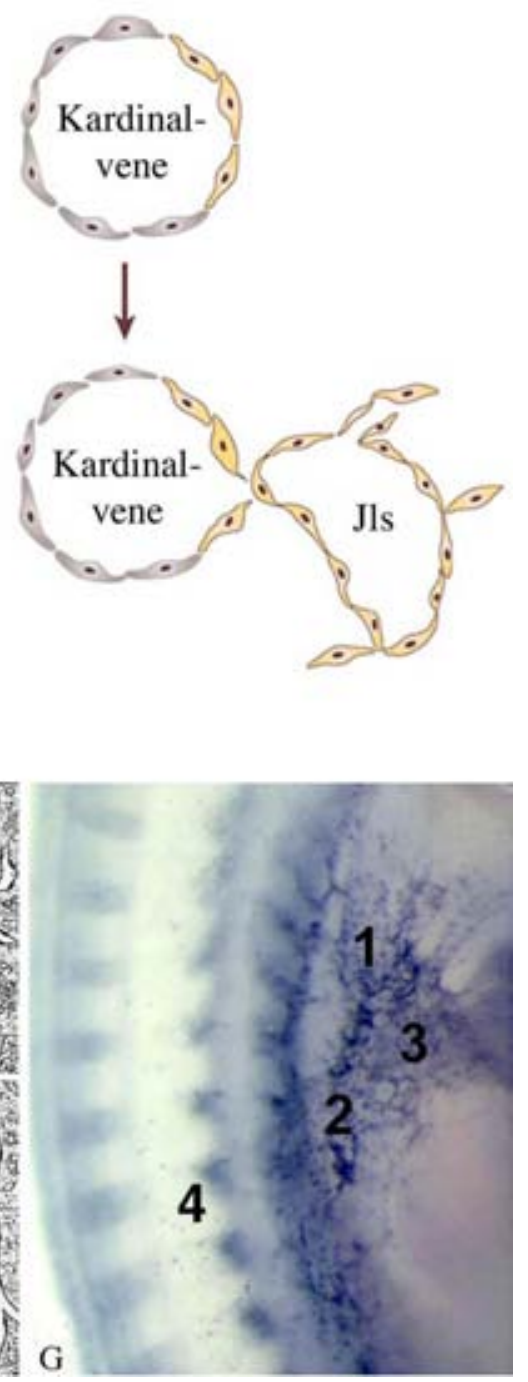

Abb. 4: Theorien über die Entstehung von Lymphgefäßen (A,B - Zentrifugaltheorie; C-F Zentripetaltheorie; G - Kombination beider Theorien). A) Mittels Tusche-Injektion sind Lymphgefäße der Jugularregion (JR) und der Hautanlage (LG) eines $3 \mathrm{~cm}$ großen Schweineembryos dargestellt. Lymphgefäße befinden sich an der Rückseite des Kopfes hinter dem Ohr, in der Schulterregion und zwischen Auge und Ohr. Verändert nach Sabin (1904). B) Endothelzellen der Kardinalvene sprossen aus und bilden die jugulären Lymphsäcke (Jls). Aus den Jls entwickeln sich alle weiteren Lymphgefäße. Verändert nach Alitalo et al. (2005). C) Im Mesenchym (M) werden Blutinseln (Pfeile) sichtbar. D-F) Mesenchymale Einzelzellen bilden Spalten (Pfeile), die sich zu Gefäßen $\left(^{*}\right)$ vereinigen und schließlich Verbindungen zum Venensystem (Pfeil in F) aufbauen. Verändert nach Huntington (1914). G) Im Jugularbereich eines Vogelembryos ET 4 vereinigen sich die kraniale (1) und kaudale (2) Kardinalvene zur gemeinsamen (3) Kardinalvene. Die In-situ-Hybridisierung zeigt Prox1-positive Zellen in diesem Segment der Kardinalvenen. In den Dermatomen (4) entlang der Längsachse befinden sich Prox1positive mesenchymale Einzelzellen. Verändert nach Wilting et al. (2006). 


\subsection{Zielsetzung der Arbeit}

Die Mechanismen der Lymphangiogenese und die daran beteiligten Gene sind bei der Embryonalentwicklung und bei Erwachsenen nicht hinreichend geklärt. Seit vielen Jahren wird der Ursprung von Lymphendothelzellen kontrovers diskutiert, und es ist unklar, ob mehrere Mechanismen an der Lymphangiogenese beteiligt sind. Das Sprossen von Lymphgefäßen aus venösen Blutgefäßen ist ein weitgehend akzeptierter Mechanismus, auf der anderen Seite sind möglicherweise mesenchymale Vorläuferzellen an der Bildung von Lymphgefäßen beteiligt. Die zweite Hypothese wurde bisher nicht eingehend bei der Klasse der Mammalia untersucht. Ein Ziel meiner Arbeit besteht darin, mesenchymale Lymphangioblasten in Mausembryonen, als Vertreter der Mammalia, anhand von Lymphendothelmarkern zu identifizieren. Mit Hilfe verschiedener immunhistologischer Marker sollen potentielle Vorläuferzellen charakterisiert und mit Lymphendothelzellen verglichen werden. Dabei soll auch der Ursprung der Lymphgefäße aus den embryonalen Venen und die Proliferationsaktivität der verschiedenen Anlagen untersucht werden. Weiterhin stellt sich die Frage, welche Bereiche der Mausembryonen lymphangiogenes Potential besitzen und ob der lymphangiogene Wachstumsfaktor VEGF-C dieses Potential beeinflusst. Hierfür soll eine Methode etabliert werden, in der die Entwicklung der Mausembryonen in Schnittkultur drei Tage lang fortschreiten kann. Viele Mäuse mit Deletionen endothelialer Gene sterben frühembryonal aufgrund von Herz-KreislaufDefekten, bevor die Entwicklung der Lymphgefäße beginnt. Um eine Beteiligung dieser Gene an der Lymphangiogenese nachweisen zu können, sollen die Embryonen mit Hilfe der Schnittkultur untersucht werden. Durch Genchip-Analysen unserer Arbeitsgruppe, die Lymphendothelzellen und Blutendothelzellen miteinander verglichen hat, steht eine Auswahl an regulierten Genen zur Verfügung. Für die Schnittkulturen sollen Knock-outMäuse herangezogen werden, denen regulierte Kandidatengene fehlen. Des Weiteren soll die Übertragbarkeit der Befunde auf den Menschen untersucht werden. Es gibt Hinweise auf zirkulierende endotheliale Vorläuferzellen im Blut von Erwachsenen. Über zirkulierende lymphendotheliale Zellen ist praktisch nichts bekannt. Da Kleinkinder noch ein breites Spektrum zirkulierender Zellen besitzen, habe ich deren peripheres Blut mit lymphendothelialen Markern auf RNA- und Proteinebene untersucht. 


\section{Material}

\subsection{Geräte}

Analysewaage Sartorius excellence

Axioplan 2 LSM 510 Laser-Scanning-

Mikroskop

Beleuchtung CTR 5000 für Mikroskop

Beleuchtung KL1500LCD

Beleuchtung MTR38

Binokular Leica MZ6

$\mathrm{CO}_{2}$-Inkubator Forma Scientific

DNA Engine Opticon2

FACScan

Fluoreszenzmikroskop DM5000B

Geldokumentationsapparatur

Gelkammer für Agarosegele H5

Kamera DC300FX (Mikroskop)

Kryotom CM3050S

Mikrowelle

Mikrotom RM2165

ND-1000 Spectrophotometer

Neubauer Zählkammer

Knick Digital-pH-Meter

Rotationsrad

IKA-Combimagret

Schüttler Polymax 1040

Spannungsgerät für Gele Consort E455

Sterilbank SterilGARDIII Advance

Thermocycler T3

Thermomixer compact

T-Gradient
Sartorius, Göttingen

Zeiss, Göttingen

Leica, Wetzlar

Leica, Wetzlar

Leica, Wetzlar

Leica, Wetzlar

Labotect, Göttingen

MJ Research, Waltham, USA

Becton Dickinson, Heidelberg

Leica, Wetzlar

Intas, Göttingen

Bethesda Research Laboratories,

Gaithersburg, USA

Leica, Wetzlar

Leica, Wetzlar

Privileg, Fürth

Leica, Wetzlar

Kisker, Steinfurt

Roth, Karlsruhe

Schütt Labortechnik, Göttingen

Univeristät Lausanne, Schweiz

Janke \& Kunkel, Staufen im Breisgau

Heidolph Elektro, Kelheim

LMS Labortechnik, Dossenheim

Labotect, Göttingen

Biometra, Göttingen

Eppendorf, Hamburg

Biometra, Göttingen 
Trockenschrank Memmert

Vortex Heidolph Relax top

Wärmeschrank Memmert

Wasserbad GFC

Zentrifuge 5415R

Zentrifuge 5810R

Shandon Cytospin 2
Schütt Labortechnik, Göttingen

Oehmen Labortechnik, Essen

Schütt Labortechnik, Göttingen

Krannich, Göttingen

Eppendorf, Hamburg

Eppendorf, Hamburg

Labequip, Markham, Kanada

\subsection{Chemikalien und Biochemikalien}

Die Angaben sind pro analysis, wenn nicht anders angegeben.

3,3'-Diaminobenzidin-Tetrahydrochlorid

Aceton

Aqua ad iniectabilia

Ammoniumnickelsulfat Hexahydrat

Bromphenolblau

Chloroform

Chloroform / Isoamylalcohol 49:1

di-Kaliumhydrogenphosphat

di-Natriumhydrogenphosphat

Dimethylsulphoxid (DMSO)

Ethylendiamintetraessigsäure

Eosin

Essigsäure (Eisessig)

Ethanol 99\%

Ethidiumbromidlösung $(10 \mathrm{mg} / \mathrm{ml})$

FACSFlow

Glycerol

Mayers Hämalaunlösung

Kaliumdihydrogenphosphat

Methanol

Natriumacetat
Dako, Hamburg

Merck, Darmstadt

DeltaSelect, Dreieich

Sigma-Aldrich, München

Sigma-Aldrich, München

Sigma-Aldrich, München

Sigma-Aldrich, München

Roth, Karlsruhe

Merck, Darmstadt

Sigma-Aldrich, München

Roth, Karlsruhe

Roth, Karlsruhe

Merck, Darmstadt

GeReSo, Einbeck

Roth, Karlsruhe

Becton Dickinson, Heidelberg

Invitrogen, Karlsruhe

Roth, Karlsruhe

Merck, Darmstadt

Merck, Darmstadt

Sigma-Aldrich, München 
Natriumchlorid

Natriumcitrat

Natriumhydroxyd (-pellets)

Natrium-Hypochlorid

Natriumtetraborat

Ortho-Phosphorsäure

Paraformaldehyd

PBS

Penicillin / Streptomycin

Phenol

Propidiumjodid (200 mg/ml)

Roti-Histol

Saccharose

Salzsäure $1 \mathrm{~N}$

Seakem LE Agarose

Sodium-Dodecyl-Sulfat

Tris

Tris-HCl

Trizol Reagent

Trypan Blau

Tween 20

Wasser bidestilliert

Wasserstoffperoxid

Zitronensäure

\subsection{Verbrauchsmaterialien}

24-Well-Platten

96-Well-Platten

Bullet-Kit

Culture Plate Inserts

Deckgläser

DMEM
Roth, Karlsruhe

Merck, Darmstadt

Roth, Karlsruhe

Sigma-Aldrich, München

Sigma-Aldrich, München

Merck, Darmstadt

Sigma-Aldrich, München

Cambrex, Taufkirchen

Invitrogen, Karlsruhe

Sigma-Aldrich, München

Sigma-Aldrich, München

Roth, Karlsruhe

Merck, Darmstadt

Merck, Darmstadt

Biozym, Hessisch Oldendorf

Gerbu, Gaiberg

Roth, Karlsruhe

Roth, Karlsruhe

Invitrogen, Karlsruhe

Sigma-Aldrich, München

Roth, Karlsruhe

Universität Göttingen

Roth, Karlsruhe

Merck, Darmstadt

Sarstedt, Nümbrecht

Bio-Rad, Hercules, USA

Lonza, Köln

Millipore, Billerica, USA

Menzel, Braunschweig

Biochrom, Berlin 
DNA-Größenstandard 100 bp

Eiweißglycerin

Entellan

Reaktionsgefäße $(0,5 \mathrm{ml} ; 1,5 \mathrm{ml})$

FBS Superior

Fluoromount-G

Kryoröhrchen (2 ml)

MicroBeads (Ziege anti-Kaninchen IgG)

Kernechtrot

Lymphoprep

Microseal 'B' Film

MS-Säulen

Objektträger mit Mattrand

Paraplast Plus

Petrischalen (10 cm Durchmesser)

Random Hexamer Primer

Omniscript RT Kit

OneStep RT-PCR Kit

RPMI-1640-Medium

Superfrost Objektträger

SYBR Green JumpStart Taq ReadyMix

Tissue Tek O.C.T.

Trypsin / EDTA (200 mg/l)

Vascular Endothelial Growth Factor-C

Zentrifugenröhrchen (15 und $30 \mathrm{ml}$ )
Fermentas, St. Leon-Rot

Chroma Waldeck, Münster

Merck, Darmstadt

Sarstedt, Nümbrecht

Biochrom, Berlin

Southern Biotech, Birmingham, USA

Greiner, Solingen

Miltenyi, Bergisch Gladbach

Merck, Darmstadt

Progen Biotechnik, Heidelberg

Bio-Rad, Hercules, USA

Miltenyi, Bergisch Gladbach

Waldemar Knittel, Braunschweig

Tyco Healthcare Group, Mansfield,

USA

Greiner, Solingen

Invitrogen, Karlsruhe

Qiagen, Hilden

Qiagen, Hilden

Lonza, Köln

Menzel, Braunschweig

Sigma-Aldrich, München

Sakura Finetek Europe, Zoeterwoude,

Niederlanden

Lonza, Köln

ReliaTech, Braunschweig

Sarstedt, Nümbrecht

\subsection{Antikörper}

Die Verdünnungen der Antikörper erfolgen entsprechend mit $0,1 \mathrm{M}$ Kaliumphosphatpuffer. 


\subsubsection{Primärantikörper}

Tabelle 1: Primärantikörper für Immunhistologische Untersuchungen

\begin{tabular}{|c|c|c|c|}
\hline Antikörper & Spezies & Verdünnung & Hersteller \\
\hline$\alpha$-Maus-CD11b & Ratte & $1: 50$ & Becton Dickinson, Heidelberg \\
\hline a-Maus-CD31 (PECAM-1) & Ratte & $1: 100$ & Becton Dickinson, Heidelberg \\
\hline$\alpha$-Mensch-CD31 (PECAM-1) & Ratte & $1: 50$ & Becton Dickinson, Heidelberg \\
\hline$\alpha$-Maus-CD45 & Ratte & $1: 50$ & Becton Dickinson, Heidelberg \\
\hline$\alpha-M e n s c h-C D 45$ & Ratte & $1: 200$ & Dako, Hamburg \\
\hline$\alpha$-Maus-F4/80 & Ratte & $1: 100$ & Sanbio, Beutelsbach \\
\hline$\alpha$-Maus-Ki-67 & Ratte & $1: 100$ & Dako, Hamburg \\
\hline$\alpha$-Maus-LA102 & Ratte & unverdünnt & T. Ezaki, Tokyo, Japan \\
\hline$\alpha$-Maus-Lyve-1 & Kaninchen & $1: 100$ & Regeneron, Tarrytown, USA \\
\hline$\alpha$-Mensch-Lyve-1 & Kaninchen & $1: 500$ & ReliaTech, Braunschweig \\
\hline$\alpha$-Mensch-Podoplanin & Hamster & $1: 1000$ & $\begin{array}{l}\text { Hybridoma Bank, Iowa City, } \\
\text { USA }\end{array}$ \\
\hline$\alpha$-Mensch-Prox 1 & Kaninchen & $1: 500$ & ReliaTech, Braunschweig \\
\hline
\end{tabular}




\subsubsection{Sekundärantikörper}

Tabelle 2: Gekoppelte Sekundärantikörper für Immunhistologische Untersuchungen und FACSAnalysen

\begin{tabular}{|c|c|c|c|}
\hline Gekoppelte Antikörper & Spezies & Verdünnung & Hersteller \\
\hline$\alpha$-Kaninchen-Alexa 350 & Ziege & $1: 25$ & MobiTech, Göttingen \\
\hline$\alpha$-Hamster-Alexa 488 & Ziege & $1: 200$ & MobiTech, Göttingen \\
\hline$\alpha$-Kaninchen-Alexa 488 & Esel & $1: 200$ & MobiTech, Göttingen \\
\hline$\alpha$-Ratte-Alexa 488 & Ziege & $1: 200$ & MobiTech, Göttingen \\
\hline$\alpha$-Maus-Alexa 488 & Ziege & $1: 200$ & MobiTech, Göttingen \\
\hline a-Kaninchen-Alexa 594 & Ziege & $1: 200$ & MobiTech, Göttingen \\
\hline$\alpha$-Kaninchen-HRP & Ziege & $1: 200$ & Sigma-Aldrich, München \\
\hline$\alpha$-Ratte-HRP & Ziege & $1: 200$ & Sigma-Aldrich, München \\
\hline$\alpha$-Ratte-Isotypkontrolle-I & Maus & unverdünnt & Serotec, Düsseldorf \\
\hline
\end{tabular}

\subsection{Enzyme}

DNA-Polymerase

HotStarTaq DNA-Polymerase

Proteinase K

RNase Out $(40 \mathrm{U} / \mu \mathrm{l})$
Thermo Scientific, Dreieich

Qiagen, Hilden

Roth, Karlsruhe

Invitrogen, Karlsruhe

\subsection{Oligonukleotidprimer}

Die Oligonukleotidprimer für den Nachweis des $P P A R \gamma$-Gens wurden von der Universität Lausanne, Schweiz, zur Verfügung gestellt. 
Für PCR:

PPAR $\gamma$-Wildtyp-Allel

Sense: $\quad 5^{\prime}$ - CCCATGCACAGGTGCGATCAAAGTAGAA - 3'

Antisense: 5'-CCTCTGCAAGATCCACTGAGATGCCTC - 3'

PPAR $\gamma$-Null-Allel

Sense: $\quad 5^{\prime}$ - CCTCTGCAAGATCCACTGAGATGCCTC - 3'

Antisense: 5' - GCTGACCGCTTCCTCGTGCTTTACGGTA - 3'

Die Oligonukleotidprimer für die RT-PCR wurden von der Firma IBA, Göttingen, bezogen.

Für RT-PCR:

Lyve-1

Sense: $\quad 5^{\prime}-$ ATGGCCAGGTGCTTCAGCCTGGT - 3'

Antisense: 5' - TCCAACCCAGCCATAGCTGCAAGT - 3'

Prox 1

Sense: $\quad 5^{\prime}-$ TTCAGATGGAGAAGTACGCA - 3'

Antisense: $\quad$ 5' - GGACTGCTACTCTTCATACA - 3'

Podoplanin

Sense: 5 - CAGAAGATGACACTGAGACTA - 3'

Antisense: 5' - TGACAAACCATCTTTCTCAACT - 3'

GAPDH

Sense: $\quad 5$ - -CCACCCATGGCAAATTTCATGGCA - 3'

Antisense: $\quad 5$ ' - TCTAGACGGCAGGTCAGGTCCACC - 3'

Für Real-Time-PCR:

$\operatorname{PPAR} \alpha$

Sense: $\quad 5^{\prime}$ - GACAAGGCCTCAGGCTATCA - 3'

Antisense: $\quad$ 5' - ACCAGCTTGAGTCGAATCGT - 3' 
$\operatorname{PPAR} \beta / \delta$

Sense: $\quad 5^{\prime}$ - TCTCTGCTGGCAGGATTCTT - 3'

Antisense: 5' - GCTGTCCCTTCATAGCCTTG - 3'

PPAR $\gamma$

Sense: $\quad 5^{\prime}-$ TGAATGTGAAGCCCATTGAA - ${ }^{\prime}$,

Antisense: $\quad$ 5' - CTGTGAGGACTCAGGGTGGT - 3'

$\beta$-Aktin

Sense: $\quad$ 5'- GCATCCCCCAAAGTTCACAA - 3'

Antisense: $\quad$ 5' - AGGACTGGGCCATTCTCCTT - 3'

\subsection{Lösungen und Puffer}

Die Lösungen und Puffer wurden, wenn nicht anders angegeben, mit deminieralisiertem Wasser angesetzt.

Agarose-Gele

Ammoniumnickelsulfat-

Lösung

BSA-Lösung

Citratpuffer (pH 6,0)
1\% Agarose; 1 x TAE-Puffer; $2 \mu \mathrm{g} / \mathrm{ml}$ Ethidiumbromid $1 \%$ Ammoniumnickelsulfat; Tris- $\mathrm{HCl} ; 0,02 \%$ Wasserstoffperoxid

$1 \%$ BSA; 1 x PBS

10 mM; 9 ml Stammlösung A: 0,1 M Zitronensäure, Aqua bidest.

$41 \mathrm{ml} \mathrm{Stammlösung} \mathrm{B:} \mathrm{0,1} \mathrm{M} \mathrm{Natriumcitrat,}$ Aqua bidest.;

mit $450 \mathrm{ml}$ Aqua bidest. auffüllen.

DNA-Probenpuffer dNTP-Mix (50x)

Na-EDTA (pH 8,0)

Eosin
30\% Glycerin; 70\% Aqua bidest.; Bromphenolblau 10 mM dATP; 10 mM dCTP; 10 mM dGTP; 10 mM dTTP

0,5 M EDTA; $\mathrm{NaOH}$ (-pellets) zum Titrieren

1\% Eosin; Aqua bidest.; 1 Tropfen Essigsäure auf $100 \mathrm{ml}$ 
Ethanol-Eisessig-Lösung

FACS-Puffer

$\mathrm{KPP}(\mathrm{pH} 7,4-7,8)$

Lysepuffer (pH 8,0)

MACS-Puffer

Natriumtetraborat

$\left(\mathrm{Na}_{2} \mathrm{~B}_{4} \mathrm{O}_{7}\right),(\mathrm{pH} 8,5)$

Paraformaldehydlösung

PFA / Tween-Lösung

PBS (pH 7,2)

PBS / EDTA

PBS / Tween

Saccharose-Lösung

TAE-Puffer ( $\mathrm{pH} \mathrm{8,0)}$

Tris-HCl-Puffer (pH 7,6)

Zellkulturmedium
97\% Ethanol; 3\% Eisessig

0,5\% BSA; 1x PBS

0,2 $\mathrm{M} \mathrm{KH}_{2} \mathrm{PO}_{4} ;$ 0,2 $\mathrm{M} \mathrm{K}_{2} \mathrm{HPO}_{4}$; Gebrauchslösung 0,1 M

50 mM Tris; 100 mM EDTA; $100 \mathrm{mM} \mathrm{NaCl}$; 1\% SDS;

Aqua bidest.

0,5\% BSA in PBS; 2 mM EDTA

$0,1 \mathrm{M} \mathrm{Na}_{2} \mathrm{~B}_{4} \mathrm{O}_{7}$; Aqua bidest.

(mit Phosphorsäure auf $\mathrm{pH}$ einstellen)

4\% Paraformaldehyd; 1x PBS

4\% Paraformaldehyd; 0,1\% Tween; 1x PBS

0,01 M; 7,2\% Natriumchlorid; 1,48\% Di-Natriumhydro-

genphosphat; 0,43\% Kaliumdihydrogenphosphat;

Gebrauchslösung $1 \mathrm{mM}(1 \mathrm{x})$

1 x PBS; 2 mM EDTA

$1 \times$ PBS; $0,05 \%$ Tween

$5 \%$ Saccharose; 0,1 M KPP

15\% Saccharose; 0,1 M KPP

40 mM Tris; 1 mM EDTA, 18,8 mM Eisessig

0,05 M Tris; 3,7\% HCl; Aqua bidest.

Bullet-Kit: EBM-2-Medium; 25 ml FBS; 0,2 ml

Hydrocortison; $2 \mathrm{ml}$ hFGF-B; 0,5 ml VEGF; 0,5 ml R3-IGF-

1; 0,5 ml Ascorbinsäure; 0,5 ml hEGF; 0,5 ml GA-1000

\subsection{Anderes}

4',6-Diamidin-2-phenylindoldihydrochlorid Sigma-Aldrich, München

(Dapi), Verdünnung: 1:20.000

cDNA aus humanem

Abteilung Gastroenterologie und

Gallengangskarzinomgewebe

Endokrinologie der Universitätsmedizin

Göttingen

Einfrierbox

Nunc, Wiesbaden

Färbegestell

Schütt, Göttingen

Federscheren

Geuder, Heidelberg 
Feuchte Kammer

Glaskasten

Mikrolöffel

Pipetten

Präzisionspinzetten

Siebspatel
Universitätsklinikum Göttingen, Technik

Schütt, Göttingen

Roth, Karlsruhe

Gilson, Limburg-Offheim

Roth, Karlsruhe

Geuder, Heidelberg

\subsection{Zelllinien}

Human umbilical vein endothelial cells (HUVECs)

Humane Lymphendothelzellen

Die HUVECs wurden aus Nabelschnüren in unserer Arbeitsgruppe, die Lymphendothelzellen aus kindlichen Lymphangiomen von Frau Dr. Maria Papoutsi isoliert und mir zur weiteren Verwendung zur Verfügung gestellt.

\subsection{Blutproben}

Nach Zustimmung der Ethik-Kommission der Medizinischen Fakultät (Antragsnummer: 5/11/06, Titel: Isolierung und molekulare Charakterisierung zirkulierender Lymph/Endothelzellen; Universität Göttingen) wurden mononukleäre periphere Blutzellen aus „Buffy coats“ gesunder Blutspender (Transfusionsmedizin Universitätsklinikum Göttingen) und aus überschüssigem Blutmaterial der Kinderklinik (Pädiatrie I mit Schwerpunkt Hämatologie und Onkologie) isoliert bzw. Blutausstrichpräparate und Zytospins angefertigt.

\subsection{Tierisches Material}

C57B1/6 Mausembryonen

NMRI Mausembryonen

SV129/B16 Mausembryonen

SV129/B16 Mausembryonen (transgen)
Tierstall der Universität Göttingen

Tierstall der Universität Göttingen

Universität Lausanne, Schweiz

Universität Lausanne, Schweiz 


\subsection{Computerprogramme}

Adobe Photoshop 7.0

CellQuest ${ }^{\circledR}$ Software

EndNote 7.0

Image J

Leica FW 4000

Microsoft Office X 10.1.0

MJ Opticon Monitor Analysis Software 3.1

ND-1000 V3.1.0

Primer Express 2.0

Safari 1.3.2

Internet-Ressourcen:

- NCBI (National Center for Biotechnology Information):

http://www.ncbi.nlm.nih.gov/

- Primer 3: http://biotools.umassmed.edu/bioapps/primer3_www.cgi 


\section{Methoden}

\subsection{Immunhistologische Methoden}

Immunhistologische Untersuchungen wurden an den in 2.11 genannten Mausstämmen C57B1/6 und NMRI durchgeführt.

\subsubsection{Isolierung von Mausembryonen aus dem Uterus des Muttertieres}

Für die immunhistologischen Untersuchungen wurden Mausembryonen der Entwicklungstage 9,5 bis 13,5 aus dem Uterus des toten Muttertieres entnommen und zur weiteren Verwendung in kaltes PBS überführt. Dabei war darauf zu achten, dass das Amnion entfernt wurde.

\subsubsection{Fixierung, Einbettung und Schnittanfertigung der Mausembryonen}

\subsubsection{Fixierung mittels Paraformaldehyd- (PFA) Lösung für Kryopräparate}

Um das Gewebe der Embryonen in möglichst naturgetreuem Zustand zu erhalten und einem Gewebezerfall vorzubeugen, wurden die Embryonen in einer PFA-Lösung über Nacht fixiert. Es folgten 3 Waschschritte mit Kaliumphosphatpuffer (KPP). Die Embryonen wurden zunächst für 15 min in einer 5\%igen Saccharose-Lösung, anschließend für 30 bis 45 Minuten (je nach Größe) in einer 15\%igen Saccharose-Lösung inkubiert und in Tissue Tek eingebettet. Eine Einbettung des Gewebes in einem Medium ist notwendig, damit dünne Schnitte hergestellt werden können. Mit dem Kryotom wurden $20 \mu \mathrm{m}$ dicke Schnitte (transversal) hergestellt, auf Superfrost Objektträger aufgezogen und bis zur weiteren Behandlung bei $-20^{\circ} \mathrm{C}$ aufbewahrt.

\subsubsection{Fixierung mittels Ethanol-Eisessig-Lösung und Einbettung in Paraffin}

Diese Art der Fixierung und Einbettung wurde durchgeführt, weil hierbei eine sehr gute Morphologie des Gewebes erzielt wird und die Schnitte dünner als bei den Kryopräparaten hergestellt werden können. In der Ethanol- (EtOH) Eisessig-Lösung wurden die Mausembryonen über Nacht fixiert. Nach einer Inkubtionszeit von je 20 und 30 min in 
100\% EtOH, je 20 und 45 min in Rotihistol und 2,5 h in Paraffin in einem Wärmeschrank bei $58^{\circ} \mathrm{C}$ folgte die Einbettung in Paraffin. Mittels Mikrotom wurden Transversalschnitte von $8 \mu \mathrm{m}$ Dicke hergestellt, die Präparate auf Objektträger aufgezogen und bei $4^{\circ} \mathrm{C}$ bis zur weiteren Verwendung aufbewahrt.

\subsubsection{Unfixiertes Gewebe für Kryopräparate}

Die unter 3.1.2.1 und 3.1.2.2 beschriebenen Fixierungen können die Zugänglichkeit von Epitopen beeinträchtigen. Daher blieben Präparate, die für die jeweiligen Antikörpernachweise vorgesehen waren, unfixiert. Die Mausembryonen wurden zunächst für $15 \mathrm{~min}$ in eine 5\%ige, anschließend für 30 bis $45 \mathrm{~min}$ (je nach Größe) in eine 15\%ige Saccharose-Lösung gegeben. In Tissue Tek inkubierten die Embryonen 15 min, bis sie dann wiederum in Tissue Tek eingebettet wurden. Mit dem Kryotom hergestellte $20 \mu \mathrm{m}$ dicke Transversalschnitte wurden auf Superfrost Objektträger aufgezogen und bis zu weiteren Untersuchungen bei $-20^{\circ} \mathrm{C}$ gelagert.

\subsubsection{Hämatoxylin-Eosin- (HE) Färbung}

Die HE-Färbung ist eine Übersichtsfärbung, bei der das Hämatoxylin die Zellkerne und Zytoplasmaanteile, die reich an rauhem endoplasmatischen Retikulum sind, blau-violett färbt. Eosin färbt basische Zytoplasmaanteile und extrazelluläre Matrix rot (Welsch, 2006). Die Paraffinpräparate wurden 4 x je 3 min in Roti-Histol entparaffiniert und in folgender absteigenden EtOH-Reihe rehydriert: je $2 \min 100 \%$ ( 2 x), 96\%, 70\%, 50\%, 30\% EtOH und 3 min Aqua bidest. Nach 5 min Inkubation mit gefilterter Hämalaunlösung wurden die Schnitte vorsichtig 10 min mit fließendem Leitungswasser gespült. Nach 2 min Waschen mit Aqua bidest. erfolgte für 3 min eine Färbung mit einer gefilterten Eosinlösung. Auf kurzes Spülen mit Aqua bidest., 70\%, 80\%, 90\%, 96\% und 2 x 100\% EtOH folgten 4 x je 2 min Inkubation in Roti-Histol. Mit dem Eindeckmedium Entellan wurden die Präparate luftdicht verschlossen.

\subsubsection{Immunhistologische Färbungen}

Die Verdünnungen der verwendeten Antikörper sind in 2.4.1 und 2.4.2 aufgeführt und mit 0,1 M Kaliumphosphatpuffer angesetzt worden. 
Die Auswertungen der immunhistologischen Untersuchungen wurden mit dem Fluoreszenzmikroskop DM5000B und dem Axioplan 2 LSM 510 Laser-ScanningMikroskop vorgenommen.

3.1.4.1 Immunhistochemischer Nachweis von Lyve-1 an Paraffinpräparaten mittels Peroxidasereaktion

Lyve-1 ist ein Rezeptor für Hyaluronsäure und wird u.a. auf Lymphendothelzellen exprimiert (Banerji et al., 1999; Prevo et al., 2001). Ich habe $\alpha$-Lyve-1-Antikörper für den Nachweis von Lymphendothelzellen in Mausembryonen verwendet. Die Präparate wurden in einer Glasküvette 4 x je $3 \mathrm{~min}$ in Roti-Histol entparaffiniert. Anschließend wurden sie zweimal je drei Minuten in 100\% EtOH inkubiert. 30 min Einwirkzeit in einer Lösung aus $200 \mathrm{ml}$ Methanol und $600 \mu \mathrm{H}_{2} \mathrm{O}_{2}$ blockierte die endogene Peroxidasereaktion. Nach kurzem Waschen mit Aqua bidest folgten 5 min Permeabilisierung in PBS / Tween und zwei Waschschritte für jeweils 3 min in PBS auf einem Schüttler. Eine BSA-Inkubation für 20 min, 1 h Lyve-1-Inkubation und zwei Waschschritte für je 3 min mit PBS auf dem Schüttler schlossen sich an. Der mit Peroxidase gekoppelte Sekundärantikörper wurde für $1 \mathrm{~h}$ auf die Präparate gegeben. Unspezifisch gebundene Antikörper wurden durch zweifaches Waschen in PBS entfernt. Eine Lösung aus $175 \mathrm{ml}$ Tris-HCl-Puffer, $25 \mathrm{ml}$ Ammoniumnickelsulfat, $40 \mu \mathrm{H} \mathrm{H}_{2} \mathrm{O}_{2}$ und $150 \mu$ 1 DAB löste die Peroxidasereaktion aus. Mit Spülschritten in Aqua bidest. für 5 und 2 x 3 min wurde fortgefahren. Eine Gegenfärbung erfolgte mit Kernechtrot für 20 s. In einer Ethanolreihe (jeweils kurz in 70\%, 80\%, 90\%, 95\%, zweimal 100\% EtOH) wurden die Präparate gewaschen und entwässert, je 3 x 3 min mit Roti-Histol behandelt und anschließend mit Entellan luftdicht eingeschlossen.

\subsubsection{Immunfluoreszenzfärbungen an Kryopräparaten}

Mauspräparate aus 3.1.2.1 und 3.1.2.3 wurden für Immunfluoreszenzfärbungen verwendet, um spezifische Antikörper in Doppel- oder auch Dreifachfärbungen nachweisen zu können. Die Schnitte wurden auf den Objektträgern für eine Stunde an der Luft getrocknet. Eine einstündige Behandlung mit einer BSA-Lösung war für die Blockierung von unspezifischen Bindungsstellen erforderlich. Dieser Schritt und die nachfolgenden Antikörperinkubationen wurden in einer feuchten Kammer durchgeführt. Nach dem Entfernen der BSA-Lösung folgte für eine Stunde eine Inkubation mit einem, zwei oder 
drei Primärantikörpern. Um nicht gebundene Antikörper von den Präparaten zu entfernen, wurde zweimal mit KPP gewaschen. Während einer einstündigen Inkubationszeit band ein mit Fluoreszenzfarbstoff gekoppelter Sekundärantikörper (bei Mehrfachfärbungen wurden verschiedene Fluorochrome verwendet) an den jeweiligen Primärantikörper. Nicht gebundene Sekundärantikörper wurden durch viermaliges Waschen mit KPP entfernt. Die Immunfluoreszenzfärbungen wurden bei Bedarf mit einer 10 minütigen Kernfärbung (Dapi) komplettiert und anschließend wiederum 4 x mit KPP gespült. Der Einschluss erfolgte mit Fluoromount-G.

\subsubsection{Immunhistologischer Nachweis von Lyve-1 und Prox1 an Kryopräparaten}

Die in 3.1.4.2 beschriebene Immunfluoreszenzfärbung mit den Primärantikörpern Lyve-1 und Prox 1 bedurfte einiger Modifikationen, da beide Antikörper polyklonal sind. Nach der einstündigen Trocknung der unfixierten Präparate bei Raumtemperatur, erfolgte für $10 \mathrm{~min}$ eine Fixierung mit Aceton und eine Inkubation mit BSA für 1h. Die Präparate wurden mit dem Primärantikörper Prox 1 in einer feuchten Kammer über Nacht bei $4^{\circ} \mathrm{C}$ inkubiert. Auf zweifaches Waschen mit KPP folgte eine Inkubation mit einem Alexa 594-gekoppelten Sekundärantikörper für $1 \mathrm{~h}$ und erneutes zweifaches Waschen mit KPP. Nach Fixierung mit PFA-Lösung für 10 min erfolgte eine einstündige Lyve-1-Inkubation, zweimaliges Waschen mit KPP, eine einstündige Inkubation mit dem Alexa 488-gekoppelten Sekundärantikörper, vierfaches Waschen mit KPP und das Eindecken mit Fluoromount-G.

3.1.4.4 Immunhistologischer Nachweis von Lyve-1 und Ki-67 an Paraffinpräparaten nach Demaskierung (Antigen Retrieval)

Für einen Nachweis von proliferierenden Lymphendothelzellen habe ich die Antikörper Lyve-1 und Ki-67 verwendet. Ki-67 wird in allen proliferierenden Zellen exprimiert (Scholzen und Gerdes, 2000). Die Entparaffinierung wurde in vier Schritten von jeweils 3 min in Roti-Histol durchgeführt. Nach Behandlung mit Ethanol (jeweils 3 min 100\%, 96\%, $50 \%, 30 \%$ ) und Aqua bidest. wurden die Präparate $4 \times 5 \mathrm{~min}$ in Citratpuffer in einer Mikrowelle gekocht, um eine Kernfärbung durchführen zu können. Der Flüssigkeitsverlust wurde mit Aqua bidest. ausgeglichen. Dem Abkühlen für $30 \mathrm{~min}$ auf Eis folgten einige Wasch- und Inkubationsschritte: 2 x 5 min Aqua bidest., 5 min PBS, 5 min PBS / Tween, 2 x je 3 min PBS auf einem Schüttler. Die Blockierung mit BSA erfolgte für 20 Minuten und 
im Anschluss die Primärantikörperinkubation mit Lyve-1 und Ki-67 für $1 \mathrm{~h}$. Die Schnitte wurden zweimal mit KPP gewaschen, bevor die Sekundärantikörperinkubation (Alexagekoppelte Antikörper) für $1 \mathrm{~h}$ erfolgen konnte. Zum Waschen wurde 4 x KPP eingesetzt und die Präparate mit Fluoromount-G eingedeckt.

3.1.4.5 Immunhistologischer Nachweis von Lyve-1 und CD31 an transgenen PPAR $\gamma$ Mausembryonen

Für die Durchführung eines immunhistologischen Vergleiches von Mausembryonen mit unterschiedlichem PPAR $\gamma$-Genotyp, wurden die Embryonen der ET 11,5 - 13,5 nach 3.1.2.1, 3.1.2.2, 3.1.4.1 und 3.1.4.2 eingebettet, fixiert und immunhistologisch gefärbt.

\subsection{Etablierung einer Schnittkultur von Mausembryonen}

Die Etablierung der Schnittkultur wurde mit Mausembryonen der Stämme C57B1/6 (Inzucht-Stamm) und NMRI (Auszucht-Stamm) durchgeführt.

\subsubsection{Gewebekultur ohne Zusatz von VEGF-C}

Die Explantation der Mausembryonen (ET 10,5) aus dem Uterus des Muttertieres wurde wie in Punkt 3.1.1 beschrieben durchgeführt. Der Kopf der Embryonen wurde unterhalb des optischen Vesikels mit einer Schere entfernt. Es wurden Gewebeschnitte von kranial nach kaudal mit einer Federschere hergestellt, die eine Dicke von 200 - $300 \mu \mathrm{m}$ aufwiesen. Teilweise wurde die Herzregion (-schleife) separat als Gewebeteil in Kultur genommen. Die Abbildung 5B zeigt schematisch die später in Kultur genommenen Transversalschnitte der Mausembryonen. Die Gewebeschnitte wurden einzeln auf Gewebekulturmembranen in 24-Well-Platten platziert, die jeweils Dulbecco's modifiziertes Eagle's Medium (DMEM) mit 10\% FBS und 1\% Pen/Strep enthielten. Bei $37^{\circ} \mathrm{C}$ und $5 \% \mathrm{CO}_{2}$ wurden die Gewebeschnitte für 3 Tage in einem Zellkulturinkubator kultiviert. Die Gewebeschnitte wurden in $0,5 \mathrm{ml}$ Eppendorfcups mit 4\% PFA / TweenLösung überführt und für zwei Stunden fixiert und permeabilisiert. Vor einem Wechsel der Lösungen wurden jeweils die alten Inkubationsflüssigkeiten vorsichtig abpipettiert. Spülen mit KPP für 10 min entfernte Reste der Fixans. Es folgten eine BSA-Inkubation für vier bis 
fünf Stunden und eine Primärantikörperinkubation mit Lyve-1 (Verdünnung 1:300) und CD31 (Verdünnung 1:100) über Nacht. Gespült wurde anschließend wieder mit KPP für fünf Stunden. Die Schritte der Sekundärantikörperfärbung (Ziege anti-Ratte gekoppelt mit Alexa 488, Ziege anti-Kaninchen gekoppelt mit Alexa 594; Verdünnung jeweils 1:300) und eines nachfolgenden Waschschrittes mit KPP erfolgten ebenfalls jeweils über Nacht. Nach einstündigem Fixieren mit PFA-Lösung und kurzem Spülen mit KPP wurden die Präparate mit Fluoromount-G eingedeckt.
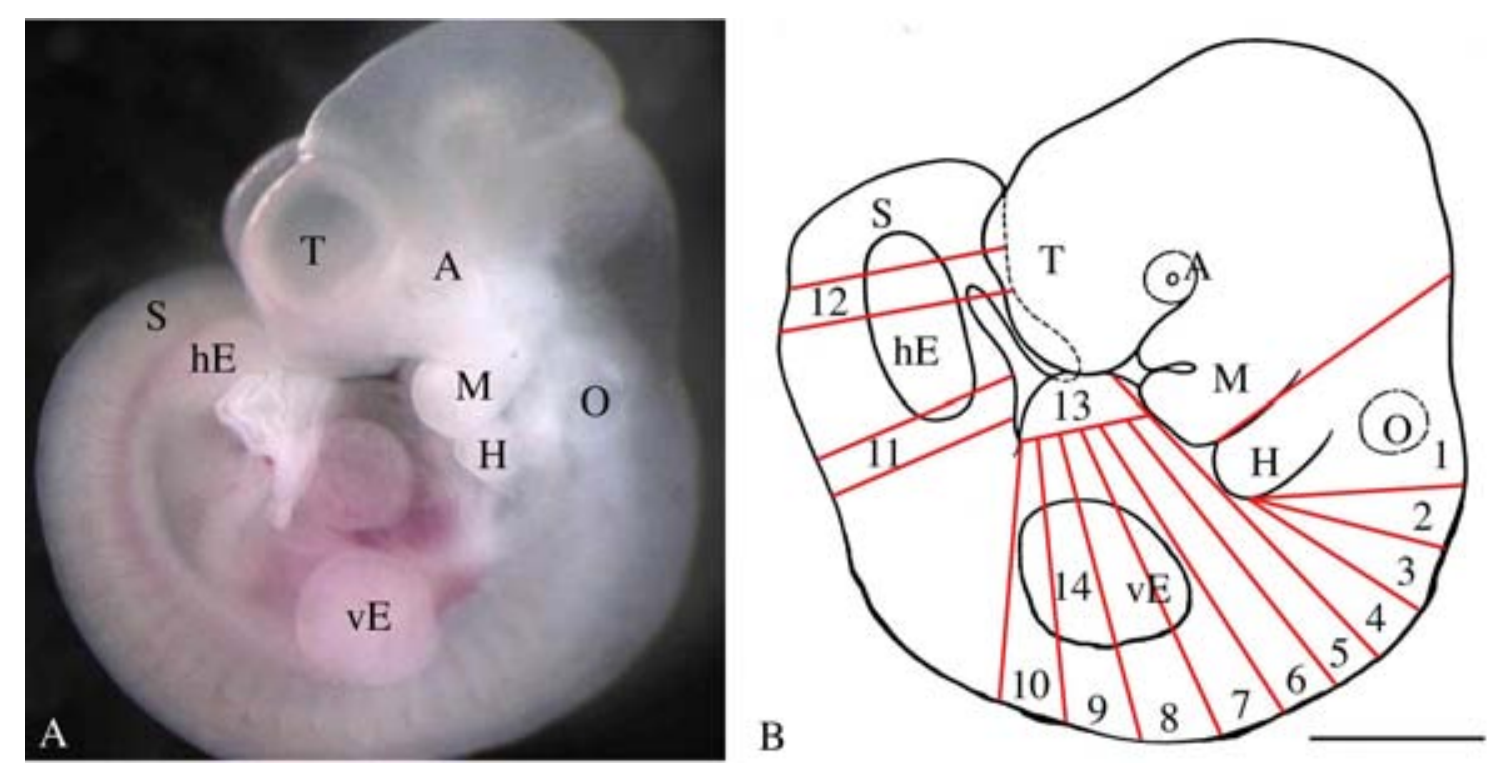

Abb. 5: Mausembryo des ET 10,5 (A) und schematische Darstellung (B). Die Transversalschnitte 1 - 13 wurden von kranial nach kaudal durchgeführt, wobei der Kopf und Teile der Schwanzanlage verworfen wurden. A, Augenanlage; H, Hyoidbogen; hE, hintere Extremitätenanlage; M, Mandibularbogen; O, Ohrvesikel; S, Schwanzanlage; T, Telencephalon; vE, vordere Extremitätenanlage. Balken in B) 1 mm. B) verändert nach Kaufman (2004).

Nach dem Eindecken der Präparate war eine Trocknungsdauer von ca. 15 Stunden bei Raumtemperatur im Dunkeln nötig, um eine Auswertung an einem Fluoreszenzmikroskop durchführen zu können.

\subsubsection{Gewebekultur mit Zugabe von Wachstumsfaktor VEGF-C}

Die Gewebekultur wurde wie in 3.2.1 beschrieben durchgeführt. Das Medium wurde vor Zugabe auf die Gewebekulturmembranen mit VEGF-C (300 ng/ml) supplementiert. Die 
sonstigen Kulturbedingungen sowie die anschließenden immunhistologischen Färbungen mit den Antikörpern Lyve-1 und CD31 entsprachen den Beschreibungen aus 3.2.1.

\subsubsection{Gewebekultur an PPAR $\boldsymbol{\gamma}$-knock-out Mausembryonen}

Die Gewebekultur wurde wie in 3.2.1 beschrieben an Mausembryonen des in 2.11 genannten Stammes SV129/B16 (genverändert) durchgeführt. Die hierfür verwendeten Embryonen waren 9,5 Tage alt. Aufgrund des früheren Entwicklungsstadiums konnten weniger Transversalschnitte angefertigt werden als bei Embryonen der ET 10,5 (Abb. 6). Die immunhistologischen Färbungen mit Lyve-1 und CD31 wurden wie in 3.2.1 beschrieben duchgeführt.

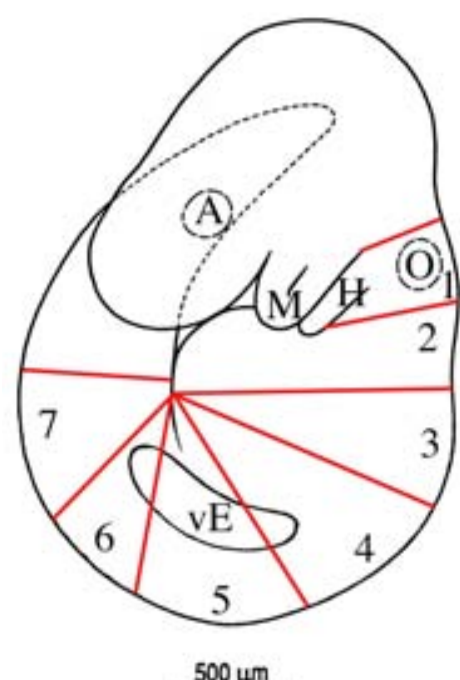

Abb. 6: Schematische Darstellung eines Mausembryos des ET 9,5. Die Transversalschnitte 1 - 7 wurden von kranial nach kaudal durchgeführt, wobei der Kopf und Teile der Schwanzanlage für die Genotypisierung verwendet wurden. A, Augenanlage; H, Hyoidbogen; M, Mandibularbogen; O, Ohrvesikel; vE, vordere Extremitätenanlage. Verändert nach Kaufman (2004).

\subsection{Zellbiologische Methoden}

\subsubsection{Anfertigung von Blutausstrichen und Immunfluoreszenzfärbungen}

Für die Blutausstriche wurden jeweils $3 \mu$ l Blut in eine Ecke eines Objektträgers gegeben und mit einem Deckgläschen in einem Winkel von ca. $45^{\circ}$ über den Objektträger geschoben. Die frischen Blutausstriche wurden für ca. $1 \mathrm{~h}$ an der Luft getrocknet und 
anschließend 10 min in Methanol fixiert. Die Primärantikörper-Inkubation erfolgte für $1 \mathrm{~h}$, bzw. mit $\alpha$-Prox1 über Nacht, mit den unter 2.4.1 angegebenen Verdünnungen. Nach zweimaligem Spülen mit KPP wurden die Sekundärantikörper für $1 \mathrm{~h}$ inkubiert. Viermaliges Waschen mit KPP, 5 min Inkubationszeit von Dapi, wieder vierfaches Spülen mit KPP und Eindeckeln mit Fluoromount-G schloss die Färbeprozedur der Blutausstriche ab. Doppelfärbungen wurden mit Antikörpern gegen Lyve-1 und CD31, Lyve-1 und CD45, Prox1 und CD31, Prox1 und CD45, Lyve-1 und Podoplanin sowie Lyve-1 und CD34 vorgenommen. CD34 ist ein Stammzellmarker und wird ebenfalls auf Blutendothelzellen exprimiert.

\subsubsection{Isolierung mononukleärer Zellen aus peripherem humanem Blut mittels Dichtegradientenzentrifugation}

Mononukleäre Zellen aus peripherem Blut können aufgrund ihrer Dichte über eine Dichtezentrifugation von anderen Bestandteilen des Blutes isoliert werden. Nach Zentrifugation des EDTA-Blutes bei $500 \mathrm{xg}$ für $25 \mathrm{~min}$ bei Raumtemperatur (ohne Bremse) wurde die Interphase abgenommen, mit PBS/EDTA 1:7 verdünnt und über Lymphoprep in Zentrifugenröhrchen geschichtet. Es folgte eine weitere Zentrifugation (500 x g für 25 min bei Raumtemperatur, ohne Bremse), bei der die Zellen nach ihrer

Dichte aufgetrennt wurden. Die entstandene Interphase mit den mononukleären Zellen und Thrombozyten wurde entnommen, zweimal mit PBS / EDTA gewaschen und bei $85 \mathrm{x} g$ für 10 min bei Raumtemperatur (mit Bremse) zentrifugiert. Für die Zellzahlbestimmung (siehe 3.3.3) wurde das Pellet in PBS resuspendiert.

\subsubsection{Bestimmung der Zellzahl}

Die Zellsuspension aus 3.3.2 wurde 1:10 mit Trypanblau verdünnt und in eine Neubauer Zählkammer gegeben. Mit dieser Methode kann neben der Zellzahlbestimmung auch die Vitalität der Zellen bestimmt werden. Nur tote Zellen nehmen den Farbstoff auf. Die ungefärbten Zellen der vier Kammerfelder wurden ausgezählt und die durchschnittliche Zellzahl bestimmt. Multiplikation mit dem Verdünnungs- und Kammerfaktor ergab die Zellkonzentration pro $\mathrm{ml}$. 


\subsubsection{Anfertigung von Zytospins und Immunfluoreszenzfärbungen}

Die in 3.3.2 isolierten PBMCs (periphere mononukleäre Blutzellen) wurden in PBS resuspendiert und $10 \mathrm{~min}$ in einer 3\% PFA-Lösung fixiert. Nach einem Zentrifugationsschritt für 10 min bei 85 x g und Raumtemperatur, sind die Zellen mit PBS so verdünnt worden, dass in $100 \mu \mathrm{l}$ Zellsuspension ca. 1 x $10^{4}$ bis $1 \times 10^{5}$ Zellen enthalten waren. $100 \mu \mathrm{l}$ Zellsuspension wurden in die Zytospinzentrifuge pipettiert und bei $800 \mathrm{rpm}$ für 5 min zentrifugiert. Auf jeden Objektträger wurden zwei Spins aufgetragen. Nach Trocknung der Zytospins folgte eine einstündige Inkubation des Primärantikörpers (Prox1 über Nacht), zweifaches Waschen mit KPP und eine Inkubation des Sekundärantikörpers für eine Stunde. Vier Waschschritte mit KPP, 10 min Inkubation mit Dapi und wieder vier Waschschritte folgten, um die Präparate zum Ende mit Fluoromount-G eindecken zu können. Die Antikörpernachweise wurden in Kombinationen wie unter 3.3.1 beschrieben durchgeführt.

\subsubsection{Isolierung von Lyve-1-positiven Zellen aus mononukleären Zellen mittels magnetischer Zellseparation (MACS)}

Für die Detektion von Lyve-1-positiven Zellen in Zellsuspensionen, wurden diese Zellen mit Hilfe magnetischer Teilchen von den anderen Zellen getrennt. Die Zellsuspension aus 3.3.2 wurde mit MACS-Puffer vorsichtig resuspendiert, mit Anti-Lyve-1 gemischt und 15 min auf Eis inkubiert. Nach einem Waschschritt mit PBS/EDTA-Lösung und 10 minütigem Zentrifugieren bei $4^{\circ} \mathrm{C}(300 \mathrm{xg})$ wurden die Zellen mit MACS-Puffer resuspendiert. Es erfolgte eine Zugabe von Anti-Kaninchen IgG MicroBeads, die spezifisch nur an Lyve-1-positive Zellen binden. Nach 15 min Inkubation auf Eis wurde die Suspension mit PBS / EDTA-Lösung gewaschen und 5 min zentrifugiert (200 x g bei Raumtemperatur). Das Pellet wurde mit MACS-Puffer resuspendiert und in zwei Schritten auf eine mit einem Filter versehene Säule gegeben, die in einem Magnetfeld platziert wurde. Anschließend wurde der Filter entfernt und zweimal vorsichtig mit MACS-Puffer gewaschen. Um die magnetgekoppelten Zellen zu separieren, wurde die Säule aus dem Magnetfeld entfernt und mit MACS-Puffer eluiert. Für eine präzisere Separation wurde, nachdem drei Waschvorgänge mit MACS-Puffer durchgeführt worden waren, eine zweite Elution vorgenommen. 


\subsubsection{Durchflusszytometrie (FACS)}

Die in 3.3.5 separierten Zellen wurden in drei Ansätzen mit je $5 \mu 1$ Anti-Lyve-1, Alexa 488-gekoppeltem Sekundärantikörper oder der IgG Isotypkontrolle für $10 \mathrm{~min}$ auf Eis inkubiert, mit FACS-Puffer gewaschen und anschließend für $10 \mathrm{~min}$ bei $200 \mathrm{x}$ g bei $4^{\circ} \mathrm{C}$ zentrifugiert. Die Zellpellets wurden in FACS-Puffer resuspendiert. Anschließend erfolgte für die Anti-Lyve-1-Färbung noch eine 15 minütige Inkubation auf Eis mit dem Alexa 488-gekoppelten Sekundärantikörper, ein Zentrifugationsschritt und ein Waschschritt. Die Zellsuspensionen wurden mit Propidiumjodid (1:200) versetzt, um tote Zellen von der Messung ausschließen zu können. Über eine nicht gefärbte Probe (Autofluoreszenz) erfolgte die Kalibrierung des Geräts. Die Probe mit einem irrelevanten Antikörper des selben Isotyps wie der spezifische Antikörper (Isotypkontrolle) und die Probe ohne den ersten Antikörper dienten der Bestimmung unspezifischer Färbung der Zellen. Die Messung der Zellen erfolgte mit einem FACScan Durchflusszytometer, die Auswertung mit der CellQuest Software.

\subsubsection{Kultivierung von Blutendothelzellen (HUVECs)}

Die Kultivierung der adhärent wachsenden HUVECs erfolgte in Zellkulturmedium in Petrischalen. In einem Inkubator wurden sie bei $37^{\circ} \mathrm{C}, 5 \% \mathrm{CO}_{2}$ und $95 \%$ Luftfeuchtigkeit unter sterilen Bedingungen bis $\mathrm{zu}$ einer Konfluenz von $80-100 \%$ vermehrt und anschließend im Verhältnis 1:3 gesplittet. Hierfür wurde das Medium abgesaugt, die Zellen mit PBS 1 x gewaschen und für kurze Zeit unter Beobachtung bei Raumtemperatur mit Trypsin-EDTA inkubiert. Nach erfolgter Ablösung wurde die Reaktion durch Zugabe von Zellkulturmedium gestoppt und die Zellsuspension 5 min bei 200 x g zentrifugiert. Nach Resuspension des Zellpellets in frischem Medium wurden die Zellen in neue Schalen überführt. Das Medium wurde alle 2 Tage gewechselt.

\subsubsection{Kultivierung von Lymphendothelzellen}

Die Kultivierung von LECs erfolgte weitestgehend nach den unter 3.3.7 beschriebenen Bedingungen. Dem Zellkulturmedium wurde zusätzlich VEGF-C (250 ng/ml) zugegeben. 


\subsubsection{Kryokonservierung und Rekultivierung von Zellen}

Für die Kryokonservierung wurden die Zellen für 5 min bei Raumtemperatur und 200 x g zentrifugiert. Das Medium wurde abgenommen, die Zellen in $1 \mathrm{ml}$ Einfriermedium (90\% FBS, 10\% DMSO) resuspendiert und in Kryoröhrchen überführt. Nach Gefrieren in einer Einfrierbox und einem Tag Lagerung bei $-80^{\circ} \mathrm{C}$ (schonendes Einfrieren, damit die Zellen nicht durch schnelle Eiskristallbildung zerstört werden), erfolgte die Langzeitlagerung der Zellen in flüssigem Stickstoff.

Zur Rekultivierung wurden die Zellen in einem Wasserbad bei $37^{\circ} \mathrm{C}$ aufgetaut, in $10 \mathrm{ml}$ Medium (RPMI-1640, 10\% FBS, 1\% Pen/Strep) aufgenommen und bei $200 \mathrm{x}$ g für 5 min zentrifugiert. Der Überstand wurde verworfen, die Zellen in $5 \mathrm{ml}$ Zellkulturmedium resuspensiert und in eine Petrischale überführt.

\subsection{Molekularbiologische Methoden}

\subsubsection{Isolierung und Quantifizierung von gesamt-RNA aus peripheren mononukleären Blutzellen (PBMCs)}

Für den Nachweis der Expression bestimmter Gene, ist die Isolierung von RNA aus den zu untersuchenden Zellen notwendig. Alle Schritte der RNA-Isolierung wurden mit Trizol bei Raumtemperatur durchgeführt. Die in 3.3.2 isolierten PBMCs (5-10 x 10 Zellen) wurden für 5 min mit Trizol inkubiert, anschließend mit Chloroform gemischt und wiederum etwa 5 min bei Raumtemperatur inkubiert. Dann schloss sich ein Zentrifugationsschritt an (10 min bei $16.000 \mathrm{xg}$ ), durch den eine Trennung der organischen und der wässrigen Phase, die die RNA enthält, erfolgt. Die obere wässrige Phase wurde abgenommen, in einem neuen Gefäß mit gleichem Volumen Isopropanol gemischt und für $10 \mathrm{~min}$ bei Raumtemperatur inkubiert. Es folgte ein Zentrifugationsschritt (10 min bei $16.000 \mathrm{x} \mathrm{g}$ ), um die RNA auszufällen. Das RNA-Pellet wurde mit 75\% Ethanol gewaschen (5 min) und dann erneut wie oben zentrifugiert und die Waschlösung anschließend verworfen. Im Heizblock wurde das RNA-Pellet für ca. $15 \mathrm{~min}$ bei $50^{\circ} \mathrm{C}$ getrocknet und anschließend in 20 - $50 \mu 1$ sterilem Aqua bidest. $\left(\mathrm{ddH}_{2} \mathrm{O}\right)$ gelöst. Die Konzentration und Reinheit der isolierten RNA wurde mit Hilfe eines Spektralphotometers bestimmt. Die Optische Dichte (OD) wurde bei 260 und $280 \mathrm{~nm}$ gemessen $\left(1 \mathrm{OD}_{260}=40 \mu \mathrm{g}\right.$ RNA/ml). Der Quotient $\mathrm{OD}_{260}$ und $\mathrm{OD}_{280}$ gibt Auskunft über eine mögliche Kontamination der Probe mit Proteinen 
(aromatische Aminosäuren absorbieren bei $280 \mathrm{~nm}$ ) und sollte zwischen 1,8 und 2,0 liegen (Sambrook et al., 1989).

\subsubsection{Isolierung von DNA aus embryonalem Mausgewebe}

Um die genetische Variation der PPAR $\gamma$-Mausembryonen bestimmen zu können, wurde das Gewebe des Kopfes und ein Teil des Schwanzes für die DNA-Extraktion benutzt. Das Gewebe wurde mit Lysispuffer und Proteinase K $(20 \mathrm{mg} / \mathrm{ml})$ gemischt und bei $55^{\circ} \mathrm{C}$ für 45 h oder über Nacht gelöst. Nach Zugabe von Phenol und vorsichtigem Mixen mittels eines Rotationsrades für 15 min (in diesem Protokoll immer für das Mischen benutzt) erfolgte eine Zentrifugation für 5 min bei 16.000 x g und Raumtemperatur. Die obere Phase wurde in ein neues Gefäß überführt, mit mit Chloroform / Isoamylalkohol versetzt und erneut 10 min vermischt. Nach einem Zentrifugationsschritt für $5 \mathrm{~min}$ bei $16.000 \mathrm{x} \mathrm{g}$ bei Raumtemperatur wurde wiederum die obere Phase mit Natriumacetat und kaltem Ethanol gemischt und anschließend zentrifugiert (10 min bei $15.700 \mathrm{x} \mathrm{g}$ und $4^{\circ} \mathrm{C}$ ), um die DNA zu fällen. Es schlossen sich ein Waschschritt mit kaltem EtOH, ein Zentrifugationsschritt (10 min bei $16.000 \mathrm{x} \mathrm{g}$ und $4^{\circ} \mathrm{C}$ ) und eine Trocknung des DNA-Pellets im Thermomixer bei $55^{\circ} \mathrm{C}$ an. Das Pellet wurde anschließend in sterilem Aqua bidest. aufgenommen und für $1 \mathrm{~h}$ bei $65^{\circ} \mathrm{C}$ gelöst. Für die PCR-Reaktion wurde die gewonnene DNA 1:200 mit sterilem Aqua bidest. verdünnt.

\subsubsection{Polymerase-Ketten-Reaktion (PCR)}

Die PCR ist eine Methode, mittels derer eine in vitro Amplifikation von spezifischen DNA-Fragmenten möglich ist. Sie wurde in dieser Arbeit eingesetzt, um Genvarianten der PPAR $\gamma$-Mäuse bestimmen zu können (isolierte DNA aus 3.4.2). Für die Aktivierung der hitzestabilen DNA-Polymerase (und Denaturierung der doppelsträngigen DNA) wurden die Reaktionsansätze im Thermocycler zunächst bei einer Temperatur von $95^{\circ} \mathrm{C}$ inkubiert. Es folgten drei Schritte, die sich in 35 Zyklen wiederholten. Im ersten Schritt wurde die zu amplifizierende doppelsträngige DNA bei hoher Temperatur $\left(94^{\circ} \mathrm{C}\right)$ denaturiert, so dass zwei Einzelstränge vorlagen. Der folgende Schritt machte es den Oligonukleotiden (Primern) möglich, bei einer Temperatur von $62^{\circ} \mathrm{C}$ spezifisch an die einzelsträngige DNA zu hybridisieren (Anlagerung). Bei $72^{\circ} \mathrm{C}$ begann die thermostabile DNA-Polymerase, die 
Primer am DNA-Einzelstrang entlang in 5' - 3'-Richtung zu verlängern (Synthese). Bei einer zyklischen Wiederholung dieser drei Reaktionsschritte werden die DNA-Amplifikate exponentiell vermehrt. Die PCR-Reaktionen für jedes Allel wurden in einem Volumen von $25 \mu 1$ angesetzt und enthielten folgende Komponenten:

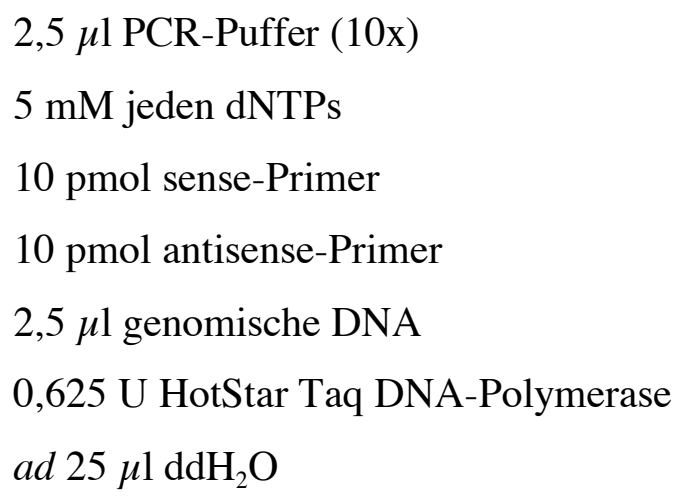

In einem Thermocycler wurden die Reaktionsansätze nach folgendem Programm durchgeführt:

$\left.\begin{array}{ll}95^{\circ} \mathrm{C}-15 \mathrm{~min} & \begin{array}{l}\text { (Aktivierung der HotStar Taq DNA-Polymerase, } \\ \text { Denaturierung) }\end{array} \\ 94^{\circ} \mathrm{C}-1 \mathrm{~min} & \begin{array}{l}\text { (Denaturierung) } \\ 62^{\circ} \mathrm{C}-1 \mathrm{~min}\end{array} \\ 72^{\circ} \mathrm{C}-1 \mathrm{~min} & \text { (Primer-Anlagerung) } \\ 72^{\circ} \mathrm{C}-10 \mathrm{~min} & \text { (abschließende Verlängerung) }\end{array}\right\} \quad 35$ Zyklen

Die PCR-Produkte wurden anschließend mittels Gelelektrophorese analysiert.

\subsubsection{Agarose-Gelelektrophorese}

Die in 3.4.3 generierten DNA-Fragmente wurden 6:1 mit einem DNA-Probenpuffer in einem 1\%igen Agarosegel (mit $10 \mu 1$ Ethidiumbromidlösung) aufgetragen und 45 min bei 120 Volt in $1 \times$ TAE-Elektrophoresepuffer aufgetrennt. Dabei interkaliert das Ethidiumbromid (Fluoreszenzfarbstoff) zwischen die Basenpaare der DNA. Dieser Komplex wird bei Anregung durch UV-Licht (Wellenlänge von $254 \mathrm{~nm}$ ) sichtbar. Parallel 
wurde ein DNA-Größenstandard aufgetrennt, um die Größe der PCR-Fragmente zu identifizieren.

\title{
3.4.5 Reverse Transkription- (RT) PCR
}

Die RT-PCR ist eine Methode, bei der Protein kodierende RNA-Sequenzen (mRNA) in einzelsträngige cDNA umgeschrieben wird (Reverse Transkription). Die anschließende PCR (siehe 3.4.3) amplifiziert die spezifischen cDNA-Fragmente. Die Umschreibung der mRNA ist notwendig, weil die für die PCR verwendete Taq-Polymerase nur DNA, nicht aber RNA als Vorlage akzeptiert. Der Reaktionsansatz für die Reverse Transkription setzte sich wie folgt zusammen (20 $\mu$ l Gesamtvolumen):

\author{
$2 \mu 1$ RT-Puffer (10x) \\ $5 \mathrm{mM}$ jeden dNTPs \\ $10 \mu \mathrm{M}$ Oligo-Hexamer Primer \\ 8 U RNase Inhibitor \\ 4 U Reverse Transkriptase \\ bis $\mathrm{zu} 2 \mu \mathrm{g}$ RNA \\ ad $20 \mu \mathrm{ldd} \mathrm{H}_{2} \mathrm{O}$
}

In einem Thermocycler wurde die Reverse Transkription für 60 min bei $37^{\circ} \mathrm{C}$ durchgeführt und die Ansätze anschließend für 5 min bei $93^{\circ} \mathrm{C}$ deaktiviert. Die cDNA konnte direkt für die nachfolgende PCR verwendet werden. Der PCR-Ansatz (50 $\mu 1$ Gesamtvolumen) enthielt folgende Komponenten:

$$
\begin{aligned}
& 5 \mu 1 \text { PCR-Puffer (10x) } \\
& 5 \mathrm{mM} \text { jeden dNTPs } \\
& 4 \mathrm{U} \text { DNA-Polymerase } \\
& 10 \text { pmol sense-Primer } \\
& 10 \text { pmol antisense-Primer } \\
& \text { bis zu } 5 \mu 1 \mathrm{cDNA} \\
& \text { ad } 50 \mu 1 \mathrm{dd}_{2} \mathrm{O}
\end{aligned}
$$


Die PCR wurde mit folgendem Programm durchgeführt $(\mathrm{x}=$ je nach Primer: Lyve-1 = $60^{\circ} \mathrm{C}, \mathrm{GAPDH}=60^{\circ} \mathrm{C}$; Prox $1=57^{\circ} \mathrm{C}$; Podoplanin $\left.=56^{\circ} \mathrm{C}\right)$ :

$\left.\begin{array}{lll}95^{\circ} \mathrm{C}-5 \mathrm{~min} & \text { (initiale Denaturierung) } \\ 95^{\circ} \mathrm{C}-30 \mathrm{~s} & \text { (Denaturierung) } \\ \mathrm{x}^{\circ} \mathrm{C}-30 \mathrm{~s} & \text { (Primer-Anlagerung) } \\ 72^{\circ} \mathrm{C}-30 \mathrm{~s} & \text { (Synthese) } \\ 72^{\circ} \mathrm{C}-10 \mathrm{~min} & \text { (abschließende Verlängerung) }\end{array}\right\} \quad 40$ Zyklen

Die Analyse der DNA-Produkte erfolgte mittels Gelelektrophorese gemäß 3.4.4.

\subsubsection{Reverse Transkription-PCR mittels Qiagen OneStep RT-PCR Kit}

Mit Hilfe dieses Kits können die Umschreibung der RNA in cDNA und die anschließende PCR in einem Reaktionsgefäß durchgeführt werden. Diese Methode eignet sich besonders, wenn nur geringe RNA-Mengen vorhanden sind und ist daher für die molekulargenetischen Untersuchungen von kindlichen Blutzellen besser geeignet. Der Gesamtansatz betrug $50 \mu 1$ und beinhaltete folgende Komponenten:

$10 \mu 1$ RT-PCR-Puffer (5x)

$10 \mathrm{mM}$ jeden dNTPs

$2 \mu 1$ RT-PCR Enzym Mix

10 pmol sense-Primer

10 pmol antisense-Primer

8 U RNase Inhibitor

$1 \mathrm{pg}$ bis $2 \mu \mathrm{g}$ RNA

ad $50 \mu 1 \mathrm{ddH}_{2} \mathrm{O}$

Folgende Programmschritte im Thermocycler schlossen sich an ( $\mathrm{x}=$ je nach Primer: Lyve$1=60^{\circ} \mathrm{C}, \mathrm{GAPDH}=60^{\circ} \mathrm{C} ;$ Prox $1=57^{\circ} \mathrm{C} ;$ Podoplanin $\left.=56^{\circ} \mathrm{C}\right)$ : 


$\left.\begin{array}{ll}50^{\circ} \mathrm{C}-30 \mathrm{~min} & \text { (reverse Transkription) } \\ 95^{\circ} \mathrm{C}-15 \mathrm{~min} & \text { (Aktivierung der Polymerase, Denaturierung) } \\ 94^{\circ} \mathrm{C}-45 \mathrm{~s} & \text { (Denaturierung) } \\ \mathrm{x}^{\circ} \mathrm{C}-45 \mathrm{~s} & \text { (Primer-Anlagerung) } \\ 72^{\circ} \mathrm{C}-1 \mathrm{~min} & \text { (Synthese) } \\ 72^{\circ} \mathrm{C}-10 \mathrm{~min} & \text { (abschließende Verlängerung) }\end{array}\right\} \quad$ Zyklen

Die Analyse der DNA-Produkte erfolgte mittels Gelelektrophorese gemäß 3.4.4.

\subsubsection{Real-Time-PCR}

Die Real-Time-PCR ermöglicht es, Nukleinsäuren zu vervielfältigen (PCR, siehe auch 3.4.3) und gleichzeitig die Produktzunahme während der Reaktion quantitativ zu analysieren. Um die PPAR $\alpha-, \beta / \delta$ - und $\gamma$-mRNA-Expression von HUVECs und LECs (aus kindlichen Lymphangiomen) vergleichen zu können, wurde jeweils RNA aus den Zellen isoliert (siehe 3.4.1) und in cDNA umgeschrieben (siehe 3.4.5). Die PCR-Ansätze (25 $\mu 1$ Gesamtvolumen) wurden in eine 96-Well-Platte nach folgendem Schema pipettiert:

$$
\begin{aligned}
& \text { 12,5 } \mu 1 \text { SYBR Green JumpStart Taq ReadyMix } \\
& 0,2 \mu 1 \text { Reference Dye } \\
& 0,1 \mu 1 \text { Primer Mix (sense und antisense jeweils } 0,2 \mu \text { M Endkonzentration) } \\
& 5 \mu 1 \mathrm{cDNA} \\
& 7,2 \mu 1 \mathrm{ddH}_{2} \mathrm{O}
\end{aligned}
$$

Die Real-time-PCR und die Messungen der Proben erfolgten im DNA Engine Opticon 2 nach den unten aufgeführten Reaktionsbedingungen.

$\left.\begin{array}{ll}95^{\circ} \mathrm{C}-10 \mathrm{~min} & \text { (Initiale Denaturierung) } \\ 95^{\circ} \mathrm{C}-15 \mathrm{~s} & \text { (Denaturierung) } \\ 60^{\circ} \mathrm{C}-30 \mathrm{~s} & \text { (Primer-Anlagerung, Synthese) } \\ \begin{array}{l}\text { Messung der Fluoreszenz (Produktzunahme) } \\ 60-95 \mathrm{C}^{\circ}\end{array} & \text { (Schmelzkurve) }\end{array}\right\}$ 40 Zyklen


Während des Syntheseschrittes der PCR lagert sich der Fluoreszenzfarbstoff SYBR Green in die doppelsträngige DNA ein. Da sich mit jedem Zyklus die Menge der synthetisierten DNA verdoppelt, interkaliert mehr SYBR Green und die Fluoreszenzintensität steigt an. Vor jedem Denaturierungsschritt der PCR wird die Fluoreszenzintesität gemessen. Neben dem zu untersuchenden Gen wird ein Referenzgen (nicht-reguliertes Gen) eingesetzt, um einen Bezugspunkt zu haben, der später die Normalisierung der Signale (auf eine einheitliche Ausgangsmenge an Probenmaterial) erlaubt. Der Beginn der exponentiellen Phase ist der Zyklus, in dem die Fluoreszenz erstmals deutlich die Hintergrundfluoreszenz übersteigt. Dieses ist ein Schwellenwert, der sogenannte $\mathrm{C}_{\mathrm{T}}$-Wert (Threshold Cycle = „Schwellenwert-Zyklus“). Bei der relativen Quantifizierung wird der $\mathrm{C}_{\mathrm{T}}$-Wert des Referenzgens (hier $\beta$-Aktin) von dem $\mathrm{C}_{\mathrm{T}}$-Wert des zu untersuchenden Gens subtrahiert. Das Ergebnis ist der sogenannte $\Delta \mathrm{C}_{\mathrm{T}^{-}}\left(\right.$delta $\left.\mathrm{C}_{\mathrm{T}}\right)$ Wert. Hierdurch werden Proben miteinander vergleichbar, obwohl die Quantität ihres Ausgangsmaterials unterschiedlich sein kann. Von dem $\Delta \mathrm{C}_{\mathrm{T}}$-Wert wird wiederum der $\Delta \mathrm{C}_{\mathrm{T}}$-Wert einer Kontrolle bzw. Bezugsprobe (hier HUVECs) subtrahiert $\left(\Delta \Delta \mathrm{C}_{\mathrm{T}}\right.$-Wert). Nach der Formel $2^{-\Delta \Delta C \mathrm{~T}}$ wird dann der relative Expressionsunterschied berechnet. Um zu kontrollieren, ob die Amplifikation in den einzelnen Ansätzen spezifisch ist, wurde am Ende der PCR eine Schmelzkurve erstellt. Die Temperatur steigt dabei langsam von $60 \mathrm{C}^{\circ}$ auf $95 \mathrm{C}^{\circ}$ an und das PCR-Produkt denaturiert bei einer spezifischen Temperatur, die von seiner Größe und Basenzusammensetzung abhängt. Das SYBR Green wird freigesetzt und die Fluoreszenzintensität nimmt ab. Die erhaltenen Werte wurden anschließend mit der Software MJ Opticon Monitor Analysis 3.1 analysiert. 


\section{Ergebnisse}

\subsection{Lymphangiogenese im Jugularbereich von Mausembryonen}

In der Jugularregion werden die ersten Anlagen des Lymphgefäßsystems, die jugulären Lymphsäcke (JLS), an ET 11,5 morphologisch sichtbar. Dieser Bereich wird im Folgenden näher untersucht. Eine Übersicht gut erhaltener morphologischer Strukturen eines Gewebes lässt sich mittels der HE-Färbung an Paraffinpräparaten erreichen. Ich habe Mausembryonen der ET 10,5 bis 13,5 des Mausstammes NMRI für die Analysen herangezogen. Die Abbildung 7 zeigt Transversalschnitte der Mausembryonen. Die Zellkerne wurden mit Hämatoxylin dunkel violett gefärbt, die rote Gegenfärbung mit Eosin markiert das Zytoplasma. An ET 10,5 konnten keine Zellen eindeutig als lymphatisches Endothel identifiziert werden. Im Bereich des Pharynx liegen dorso-lateral die dorsale Aorta und die Kardinalvenen, ebenso wie die Arterien der Viszeralbögen (lateral bzw. ventral). An ET 11,5 werden die paarigen jugulären Lymphsäcke entlang der Jugularvenen bzw. anterioren Kardinalvenen sichtbar und haben sich einen Tag später in ihrem Umfang erweitert. ET 13,5 lässt Ausdehnungen der JLS dorsal in Richtung Rückenmuskulatur, lateral in Richtung Haut und medial in Richtung Mediastinum erkennen. Die JLS erstrecken sich kaudal bis zur Thymusregion (Abb. 7E,F).
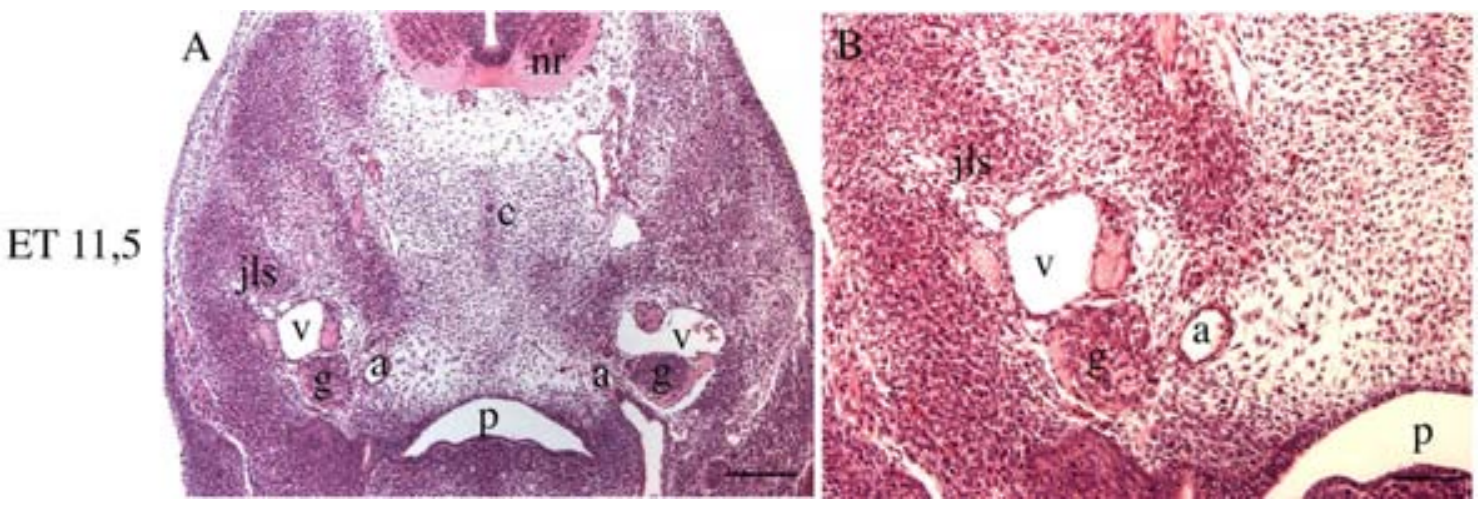

Abb. 7 A,B) Legende siehe nächste Seite. 

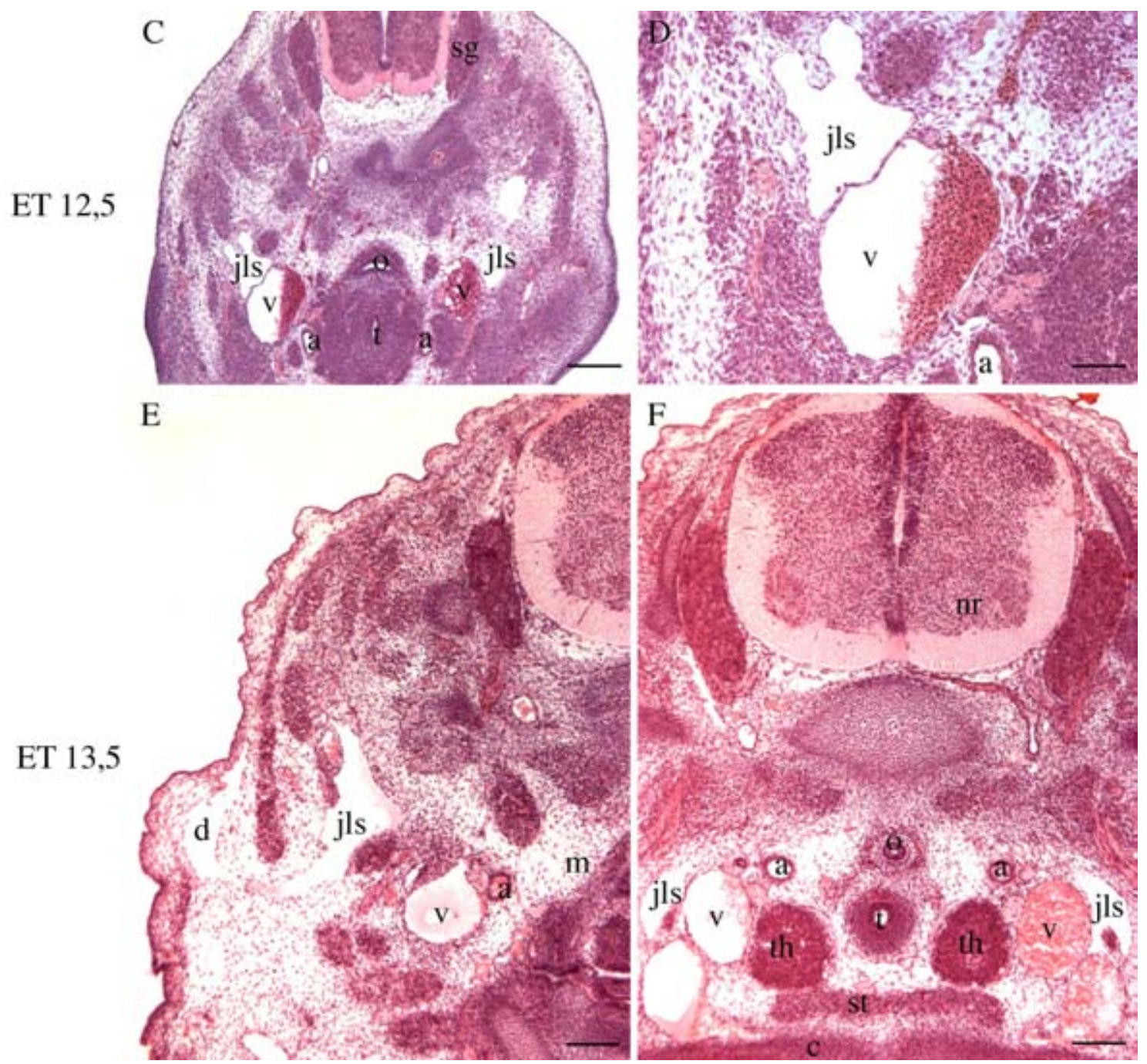

Abb. 7: HE-Färbung von Paraffinschnitten von Mausembryonen der ET 11,5 (A,B), 12,5 (C,D) und 13,5 (E,F). A) Dorso-lateral des Pharynx (p) sind die dorsale Aorta (a), die anteriore Kardianalvene (v), das Ganglion inferius ( $\mathrm{g}$ ) des Nervus vagus und die sich entwickelnden jugulären Lymphsäcke (jls) lokalisiert. nr, Neuralrohr; c, Corda dorsalis. B) Ausschnittvergrößerung aus A. C,D) An ET 12,5 sind die JLS in ihrer Lage, Größe und anhand ihres deutlich von der Vene separierten Lumens präziser zu bestimmen. Sie liegen dorso-lateral der Kardinalvene (v), die mit Blut gefüllt ist. t, Trachea; o, Oesophagus; sg, Spinalganglion. D) Ausschnittvergrößerung aus C. E) Neben der Volumenzunahme der JLS kann man an ET 13,5 auch Ausdehnungen in Richtung Dermisanlage (d) beobachten. a, dorsale Aorta. F) Die JLS verlaufen kaudal entlang der Kardinalvenen bis zur Anlage der Clavicula (c) und den Anlagen der Thymusläppchen (th). nr, Neuralrohr; st, Sternocleidomastoideus-Muskel. Balken in A,F) $200 \mu \mathrm{m}$, B) $100 \mu \mathrm{m}$, C) $500 \mu \mathrm{m}, \mathrm{D}$,E) $250 \mu \mathrm{m}$. E,F) verändert nach Buttler et al. (2006).

Die nachfolgenden Ergebnisse stellen überwiegend den Jugularbereich dar. 


\subsubsection{Expression des Lymphendothelmarkers Lyve-1}

An ET 10,5, also vor Ausbildung der JLS, konnte ich mit anti-Lyve-1 Antikörpern Hinweise für die Entwicklung von LECs finden. Erste Lyve-1-Signale waren in Segmenten der Kardinalvenen, der Dottersackvene, im Mitteldarmplexus und später auch in den jugulären Lymphsäcken zu beobachten (Abb. 8A-H). Für eine deskriptive Darstellung der Entwicklung des Lymphgefäßsystems in der Maus eignet sich eine spezifische Anfärbung des Lymphendothels mit dem Antikörper Lyve-1 besonders gut. Der Sekundärantikörper war mit dem Enzym Peroxidase konjugiert und löste unter Zugabe des Chromogens DAB eine Farbreaktion aus. Alle Lyve-1-positiven Zellen wurden durch Präzipitation des Endproduktes (Schwarzfärbung) sichtbar. Die mittels der HE-Färbung erzielten Ergebnisse lassen zwar die jugulären Lymphsäcke aufgrund ihrer Lage und ihres Lumens als lymphatisches Endothel erkennen, die sich entwickelnden JLS, kleinere Lymphgefäße oder Einzelzellen mit lymphendothelialem Charakter sind jedoch durch diese Anfärbung nicht eindeutig zu identifizieren. Aufgrund der guten Morphologie der Paraffinpräparate lassen sich die Lyve-1-positiven Strukturen im Detail darstellen. Ich habe die Entwicklungsstadien der ET 10,5 bis 13,5 von NMRI-Mausembryonen untersucht (Abb. 8). In der frühen Entwicklungsphase des ET 10,5 zeigten sich Lyve-1-positive Zellen in Segmenten der Kardinalvenen, der Lebersinusoide, der Dottersackvene und des vaskulären Mitteldarmplexus. Zusätzlich konnte ich aber auch einige wenige verstreute Einzelzellen im Mesenchym detektieren (Abb. 8A,B). Bereits einen Tag später (ET 11,5) markierte der Antikörper die sich entwickelnden jugulären Lymphsäcke (Abb. 8C). Daneben waren spezielle Bereiche der Kardinalvenen Lyve-1-positiv. Jetzt zeigte sich auch eine zunehmende Zahl von Einzelzellen im Dermatom, in den Anlagen der Hirnhäute und im Mediastinum (Abb. 8C,D). Mausembryonen der ET 12,5 und 13,5 wiesen eine deutliche Zunahme Lyve-1-positiver Einzelzellen in den genannten Bereichen auf: besonders in der Anlage der Kutis, in den primitiven Hirn- und Rückenmarkshäuten (Meningen) und im lockeren Bindegewebe des Pharynx (Abb. 8E,F). Sehr auffällig waren die Ausdehnungen der Lymphsäcke in dorsaler, ventraler, medialer und lateraler Richtung (Abb. 8G,H). Ab dem ET 12,5 ließen sich Lymphgefäße in der Haut nachweisen. Auch in Organen wie Lunge, Herz und Darm konnten Lymphgefäße mit Hilfe des Antikörpers detektiert werden. Im Gegensatz zu einer Lyve-1-Expression in spezifischen Segmenten der Kardinalvenen an ET 12,5, blieb der Antkörpernachweis an ET 13,5 in den Venen negativ. 


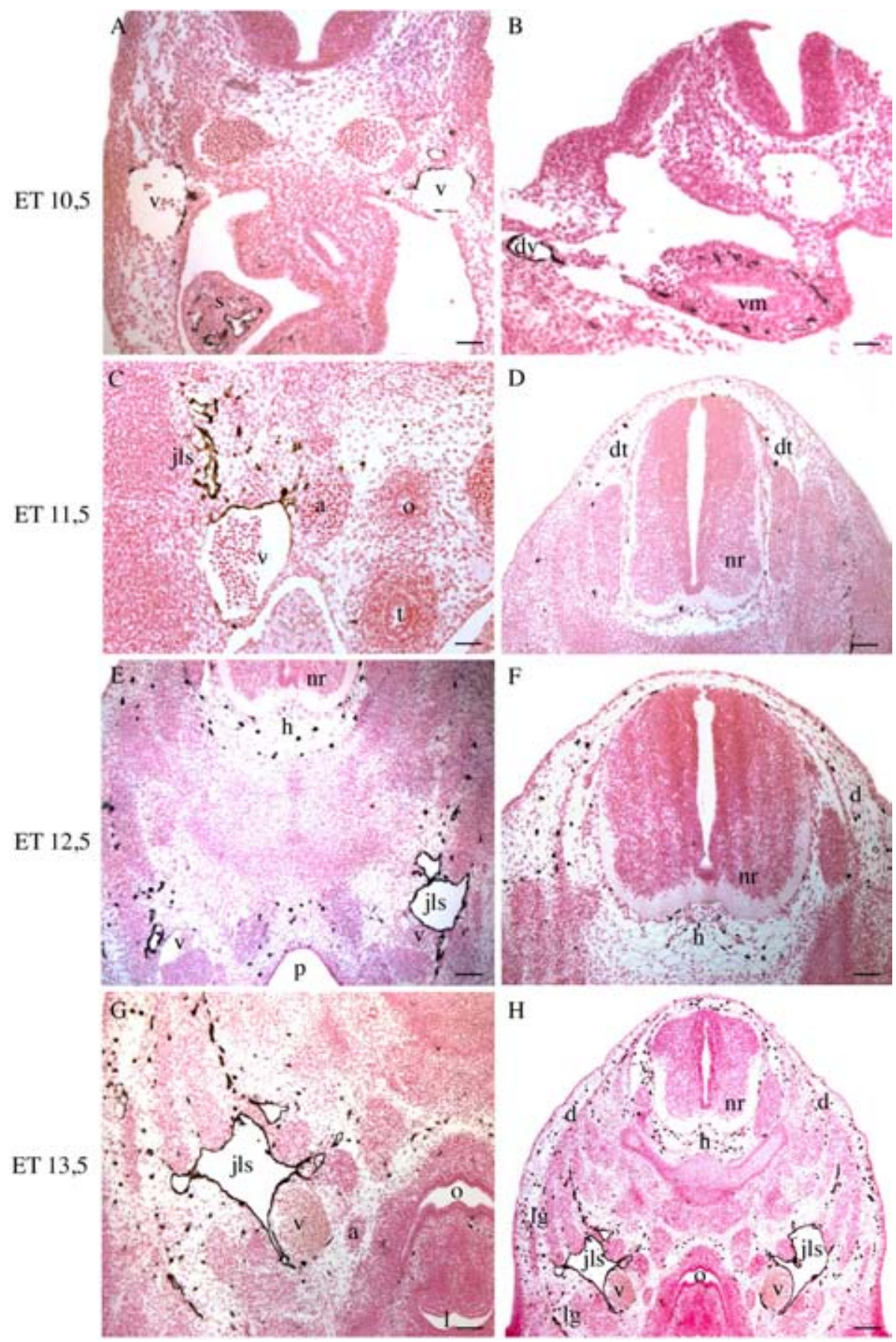

Abb. 8: Anti-Lyve-1-Färbung von Paraffinschnitten von Mausembryonen der ET 10,5 - 13,5.

A,B) ET 10,5 Embryonen exprimieren Lyve-1 in spezifischen Segmenten der Kardinalvenen (v), Lebersinusoiden (s), Dottersackvene (dv) und dem vaskulären Mitteldarmplexus (vm). C,D) An ET 11,5 markiert Lyve-1 ebenfalls Abschnitte der Kardinalvenen sowie die sich entwickelnden JLS (jls). o, Oesophagus; t, Trachea. Positive Einzelzellen können in der Jugularregion im Dermatom (dt) lateral des Neuralrohrs (nr) nachgewiesen werden (D). E,F) Die Anzahl dieser Einzelzellen im lockeren Bindegewebe nimmt mit dem Alter des Embryos kontinuierlich zu. Zusätzlich wird Lyve1 in Zellen der Hirnhautanlagen (h), der Dermisanlage (d) und im Mediastinum exprimiert. G,H) Die JLS in unmittelbarer Nähe der Kardinalvenen zeigen an ET 13,5 Ausweitungen nach dorsal, medial, ventral und lateral. 1, Larynx; lg, Lymphgefäße; o, Oesophagus. Balken in A,B,D-G) 100 $\mu \mathrm{m}$, C) $50 \mu \mathrm{m}$, H) $200 \mu \mathrm{m}$. Verändert nach Buttler et al. (2006). 


\subsubsection{Koexpression der Lymphendothelmarker Lyve-1 und LA102}

Erst vor kurzem wurde ein neuer Lymphendothelmarker (LA102) beschrieben (Ezaki et al., 2006). In meiner Arbeit wurde dieser Marker erstmalig bei der murinen Embryonalentwicklung untersucht. Bei erwachsenen Mäusen detektiert LA102 Leukozyten und Lymphgefäße, ausgenommen hiervon sind der Ductus thoracicus und der Randsinus von Lymphknoten (Ezaki et al., 2006). Es zeigte sich, dass LA102 bei Mausembryonen der ET 12,5 und 13,5 in den jugulären Lymphsäcken, in Lymphgefäßen der Haut, des Mediastinums, der Lunge und in anderen Organen zusammen mit Lyve-1 exprimiert wird (Abb. 9). Nur wenige Lyve-1-positive Lymphgefäße wiesen keine LA102-Expression auf. Einzelzellen im Dermatom, dem Mediastinum und im umliegenden Gewebe der jugulären Lymphsäcke wurden ebenfalls doppelt markiert.
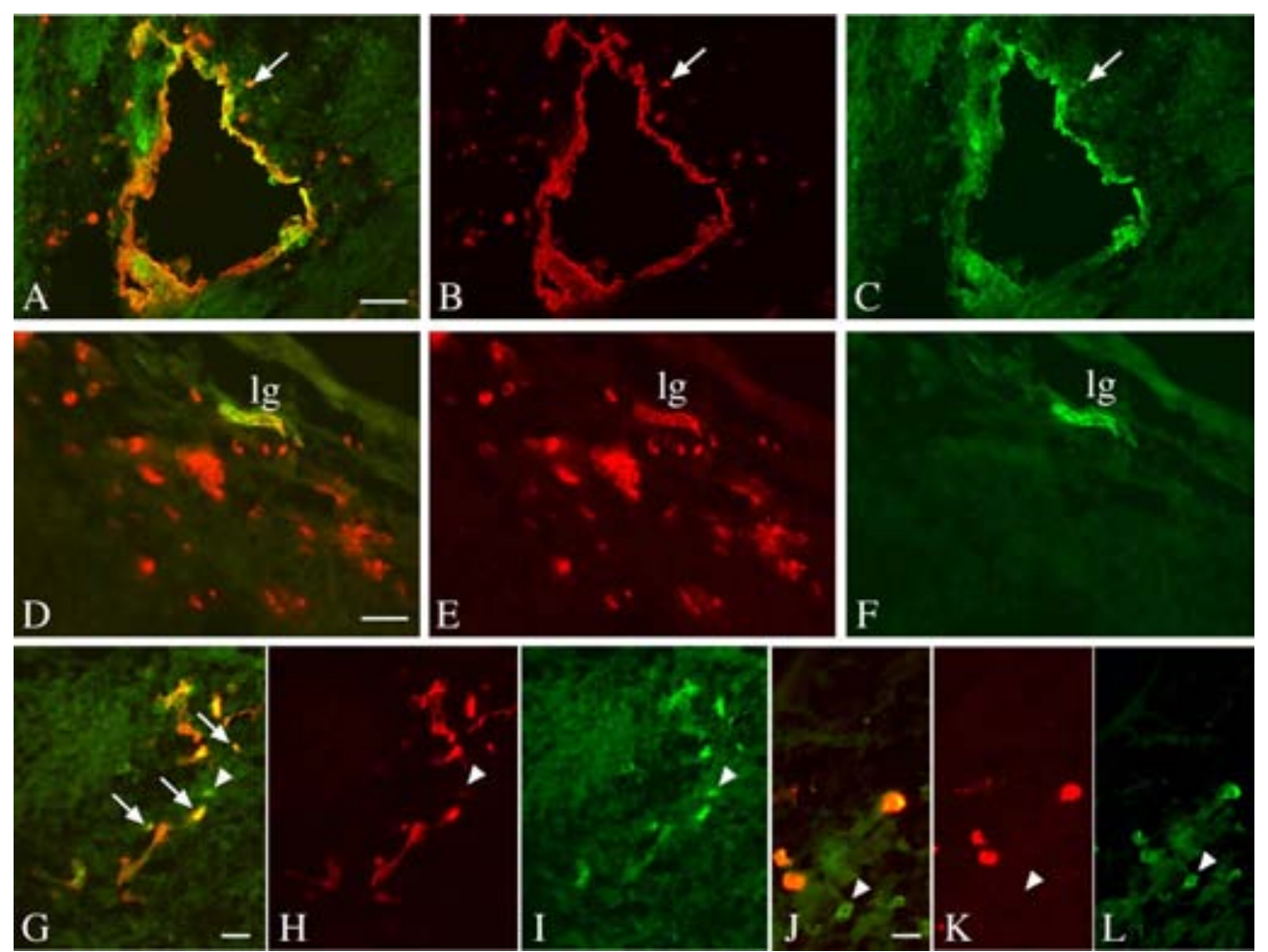

Abb. 9: Anti-Lyve-1 / LA102-Doppelfärbung an Kryoschnitten von Mausembryonen der ET 13,5 (A-F) und 12,5 (G-I). A-C) Der Juguläre Lymphsack exprimiert Lyve-1 (rot) und in spezifischen Segmenten LA102 (grün). Eine Einzelzelle in der Nähe des JLS ist doppelt-positiv (Pfeil). D-F) Ein Lymphgefäß (lg) in der Hautanlage zeigt Koexpression beider Marker, während Einzelzellen nur Lyve-1 exprimieren. G-I) Ein sich entwickelndes Lymphgefäß zeigt Kolokalisation von Lyve-1 und LA102 ebenso wie Einzelzellen in dem umgebenden Gewebe (Pfeile). Eine Zelle exprimiert nur LA102 (Pfeilkopf). J-L) Einzelzellen koexprimieren beide Lymphendothelmarker. Eine Zelle ist nur LA102-positiv (Pfeilkopf). Balken in A,D) $50 \mu \mathrm{m}, \mathrm{G}, \mathrm{J}$ ) $20 \mu \mathrm{m}$. A,D,J) verändert nach Buttler et al. (2008). 


\subsubsection{Differenzierung zwischen Blut- und Lymphgefäßendothel}

Mesenchymale Einzelzellen, spezifische Abschnitte der Kardinalvenen sowie die jugulären Lymphsäcke exprimieren die Lymphendothelmarker Lyve-1 und LA102. Für eine klare Differenzierung zwischen Blut- und Lymphendothelzellen ist eine Doppelfärbung mit einem für die jeweilige Endothelart (Lyve-1 für Lymphendothel, CD31 / PECAM-1 für Blut- und Lymphendothel) spezifischen Antikörper notwendig. Wie in 4.1.1 beschrieben, exprimierten Endothelzellen von Embryonen der ET 11,5 Lyve-1 in spezifischen Bereichen der Kardinalvenen sowie in den sich entwickelnden jugulären Lymphsäcken. Zudem koexprimierten diese Lymphendothelzellen auch den Pan-Endothelmarker CD31. Blutgefäße waren dagegen nur CD31-positiv (Abb. 10). Einzelzellen in der Dermis lateral des Neuralrohrs zeigten in diesem frühen Embryonalstadium nur Lyve-1-Positivität (Abb. 10A). Ein ähnliches Expressionsmuster war an ET 12,5 zu sehen. Nun war aber auch zu beobachten, dass Lyve-1-positive Einzelzellen in der Kutisanlage von medial nach lateral einen zunehmenden CD31-Expressionsgradienten aufwiesen (Abb. 10B,C). Nur wenige Lyve-1-positive Einzelzellen der Dermis unmittelbar neben dem Neuralrohr exprimierten CD31. Weiter lateral, in Richtung auf den JLS, wurden die Zellen länglich und exprimierten verstärkt CD31. Dies deutet auf eine zunehmende endotheliale Charakteristik der Lyve-1-positiven Einzelzellen hin, je näher sie an jugulären Lymphsäcken gelegen sind. Einen ähnlichen Expressionsgradienten wiesen Einzelzellen vom Mediastinum in Richtung der JLS auf (Abb. 10B,D).

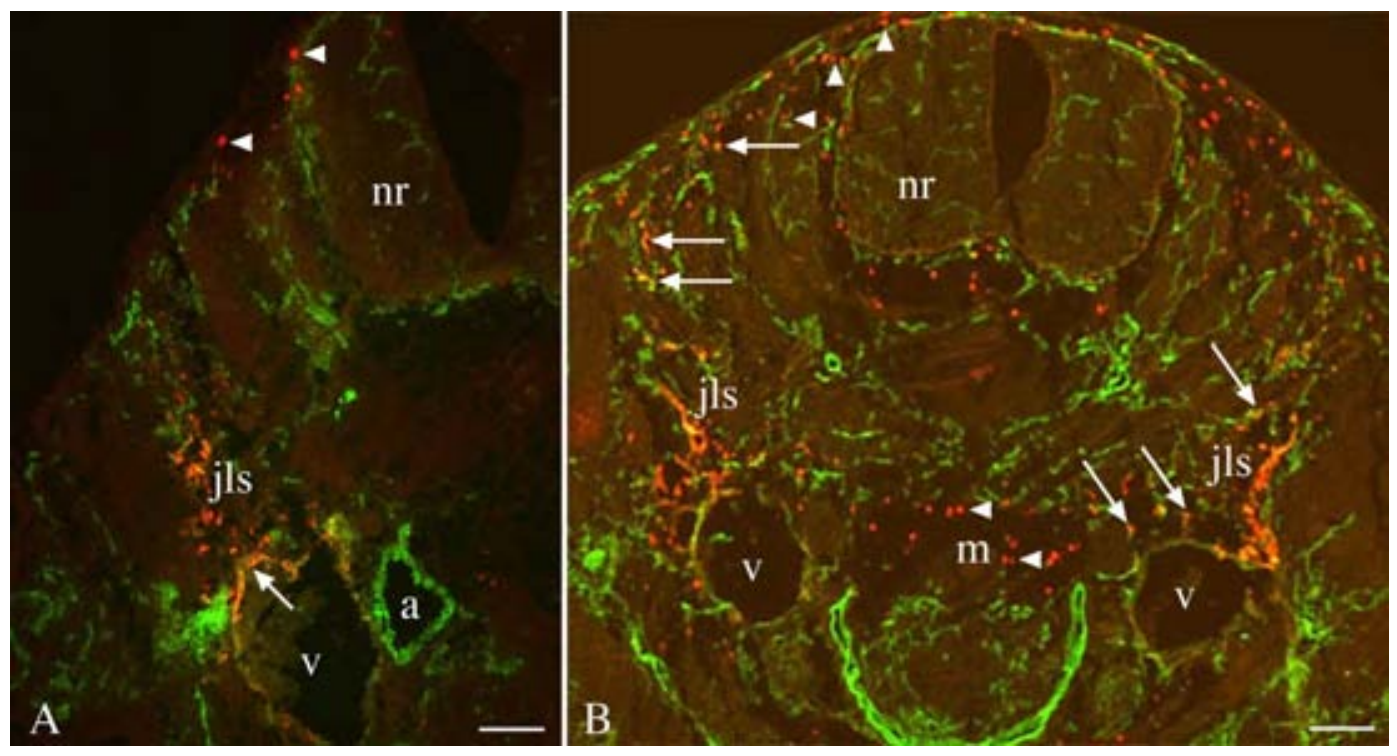

Abb. 10 A,B) Legende siehe nächste Seite. 

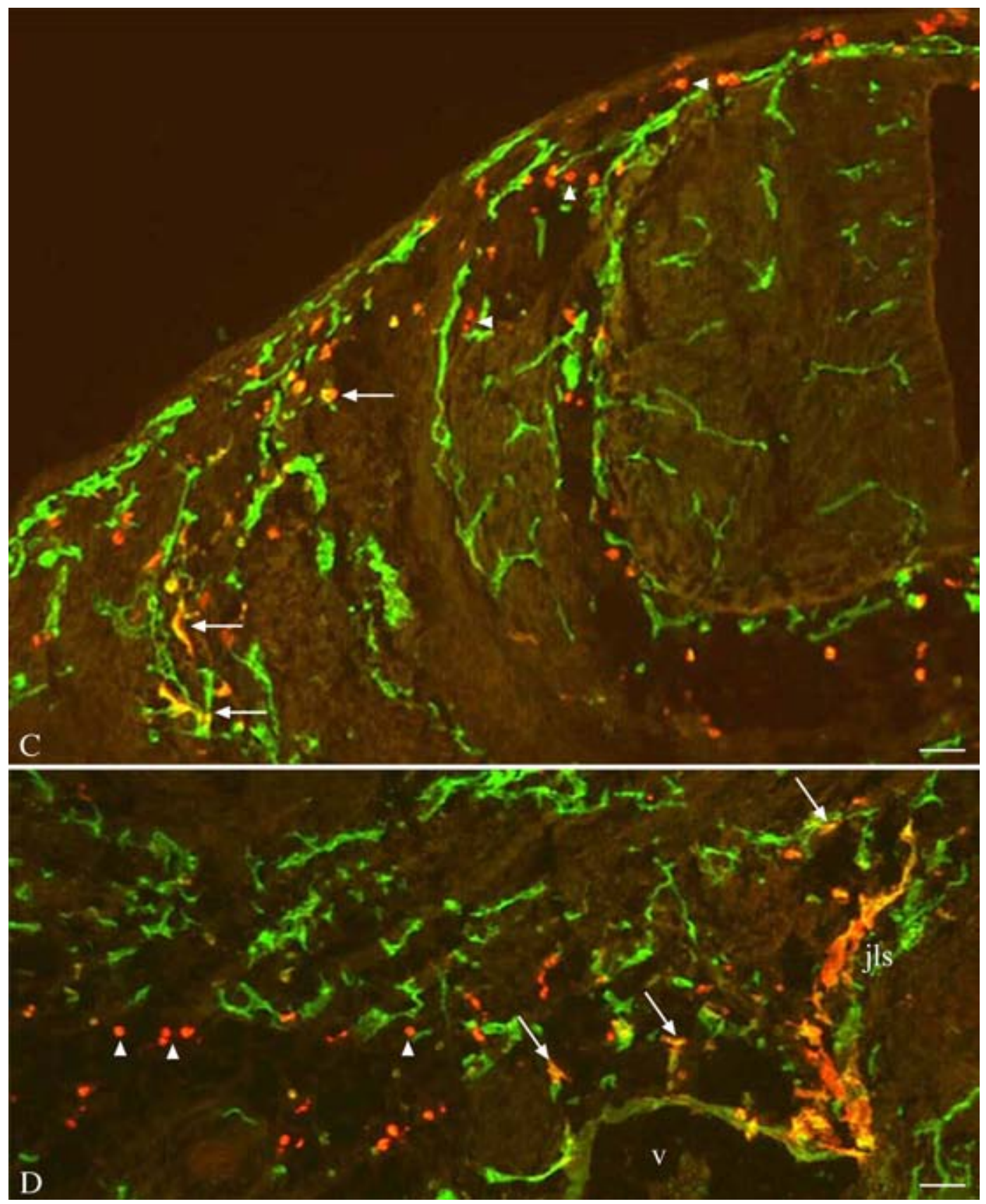

Abb. 10: Anti-Lyve-1 / CD31-Doppelfärbung an Kryoschnitten von Mausembryonen der ET 11,5 und 12,5. A) An ET 11,5 sind Lyve-1-positive (rot) Einzelzellen (Pfeilköpfe) lateral des Neuralrohrs (nr) nachzuweisen. Die Jugularvene (v) exprimiert den Pan-Endothelmarker CD31 (grün) sowie partiell auch Lyve-1 (Pfeil). Eine Koexpression beider Marker weisen ebenfalls die sich entwickelnden Lymphsäcke (jls) auf. Die Arterie (a) und andere Blutgefäße dagegen exprimieren nur CD31. B) An ET 12,5 zeigen Lyve-1-positive runde und ovale Einzelzellen (Pfeilköpfe) dorsal und lateral des Neuralrohrs (nr) nur sehr geringe CD31 Expression, während in Richtung auf die jugulären Lymphsäcke (jls) die Einzelzellen vermehrt CD31 exprimieren (Pfeile). Diese Zellen weisen eine längliche Form auf (Vergrößerung in C). Auch im Mediastinum (m) sind rundliche Lyve-1-positive Zellen vorhanden (Pfeilköpfe), die praktisch kein CD31 exprimieren, während weiter lateral die Zellen gelb, also CD31-positiv werden (Pfeile) (Vergrößerung in D). v, Kardinalvene. Balken in A,B) $200 \mu \mathrm{m}, \mathrm{C}, \mathrm{D}) 400 \mu \mathrm{m}$. A,B,C) verändert nach Buttler et al. (2006). 


\subsubsection{Lyve-1-positive Einzelzellen koexprimieren den Leukozytenmarker CD45}

Um Lyve-1-positive Einzelzellen von Leukozyten unterscheiden zu können, habe ich Doppelfärbungen mit Anti-Lyve-1 und dem allgemeinen Leukozytenmarker CD45 durchgeführt. Dieser Antikörper markiert alle Zellen der hämatopoetischen Reihe, ausgenommen Erythrozyten. Hierbei zeigte sich, dass Einzelzellen der Dermisanlage und des übrigen Mesenchyms neben Lyve-1 häufig auch CD45 exprimierten. Daneben bestanden Zellpopulationen, die nur einen der zwei Marker exprimierten. Die Anzahl dieser Zellpopulationen stieg mit dem Alter des Embryos an. Die Form der doppelt positiven Zellen variierte. Es waren runde, ovale sowie ramifizierte Einzelzellen, auch in unmittelbarer Umgebung von Lymphgefäßen und Lymphsäcken, vorhanden. Die Expressionsintensität von CD45 variierte bei doppelt positiven Zellen.
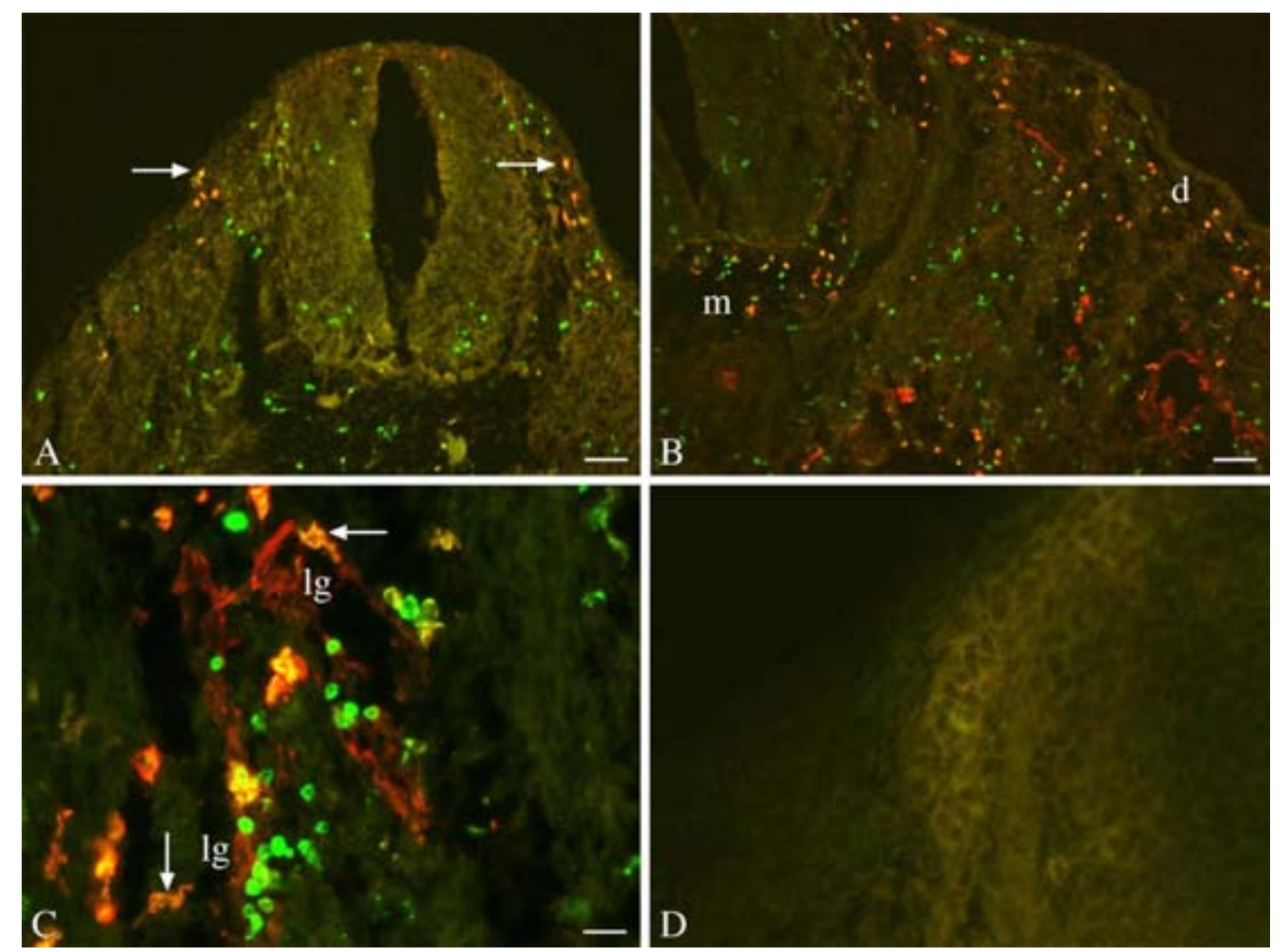

Abb. 11: Anti-Lyve-1 (rot)/CD45- (grün) Doppelfärbung an Kryoschnitten von Mausembryonen der ET 10,5 (A), 12,5 (B, D-F) und 13,5 (C). A) Wenige Zellen (Pfeile) lateral des Neuralrohrs koexprimieren Lyve-1 und CD45 (gelb). B) Die Anzahl dieser Zellen nimmt mit dem Alter des Embryos auch in anderen Regionen wie den Meningen (m) und der Dermisanlage (d) zu. C) Im Mesenchym verändern koexprimierende Zellen (Pfeil) in der Nähe von Lymphgefäßen (lg) ihre Form. D) Für die Negativkontrollen wurden nur die Sekundärantikörper verwendet (exemplarische Darstellung). Balken in A) $50 \mu \mathrm{m}$, B) $100 \mu \mathrm{m}$, C) $25 \mu \mathrm{m}$. A,B) verändert nach Buttler et al. (2006). 
Die Intensität der CD45 Expression schien dabei in den ramifizierten Zellen abzunehmen (Abb. 11C, Pfeile). Das Neuralrohr war frei von Lyve-1-positiven Zellen. Es enthielt aber CD45-positive Zellen, bei denen es sich um Vorläufer der Mikroglia handeln dürfte. Im Zentralnervensystem entwickeln sich keine Lymphgefäße.

\subsubsection{Expression des Lymphendothelmarkers Prox1}

Ein hoch spezifischer Marker für das Lymphendothel ist der Transkriptionsfaktor Prox1. Er wird bereits in frühen Embryonalstadien bei der Lymphgefäßentwicklung exprimiert (Wigle und Oliver, 1999) und ist auch in pathologischen Geweben ein stabiler Marker, um zwischen Lymph- und Blutendothelzellen zu differenzieren (Wilting et al., 2002).

\subsubsection{Koexpression der Lymphendothelmarker Lyve-1 und Prox1}

Lymphendothelzellen sind in den meisten Arbeiten bisher mit nur jeweils einem Lymphendothelmarker nachgewiesen worden. Um eine sichere Aussage über den lymphendothelialen Charakter von Zellen, insbesondere Einzelzellen, machen zu können, ist die Anwendung von zwei sehr spezifischen Markern für das Lymphendothel von Vorteil. Der Nachweis einer Koexpression von Prox1 und Lyve-1 ist durch die in 3.1.4.3 etablierte Methode erst möglich geworden, da beide Antikörper polyklonal in Kaninchen hergestellt wurden. In dieser Arbeit habe ich Lymphendothelzellen nachweisen können, die Prox1 und Lyve-1 koexprimierten. In Endothelzellen der Lymphsäcke von Mausembryonen sind Prox1 und Lyve-1 kolokalisiert. Gleiches ist in Endothelzellen von Lymphgefäßen zu beobachten (Abb. 12). Zusätzlich konnte ich Einzelzellen im Mesenchym detektieren, die ebenfalls eine Koexpression von Lyve-1 und Prox1 zeigten. 

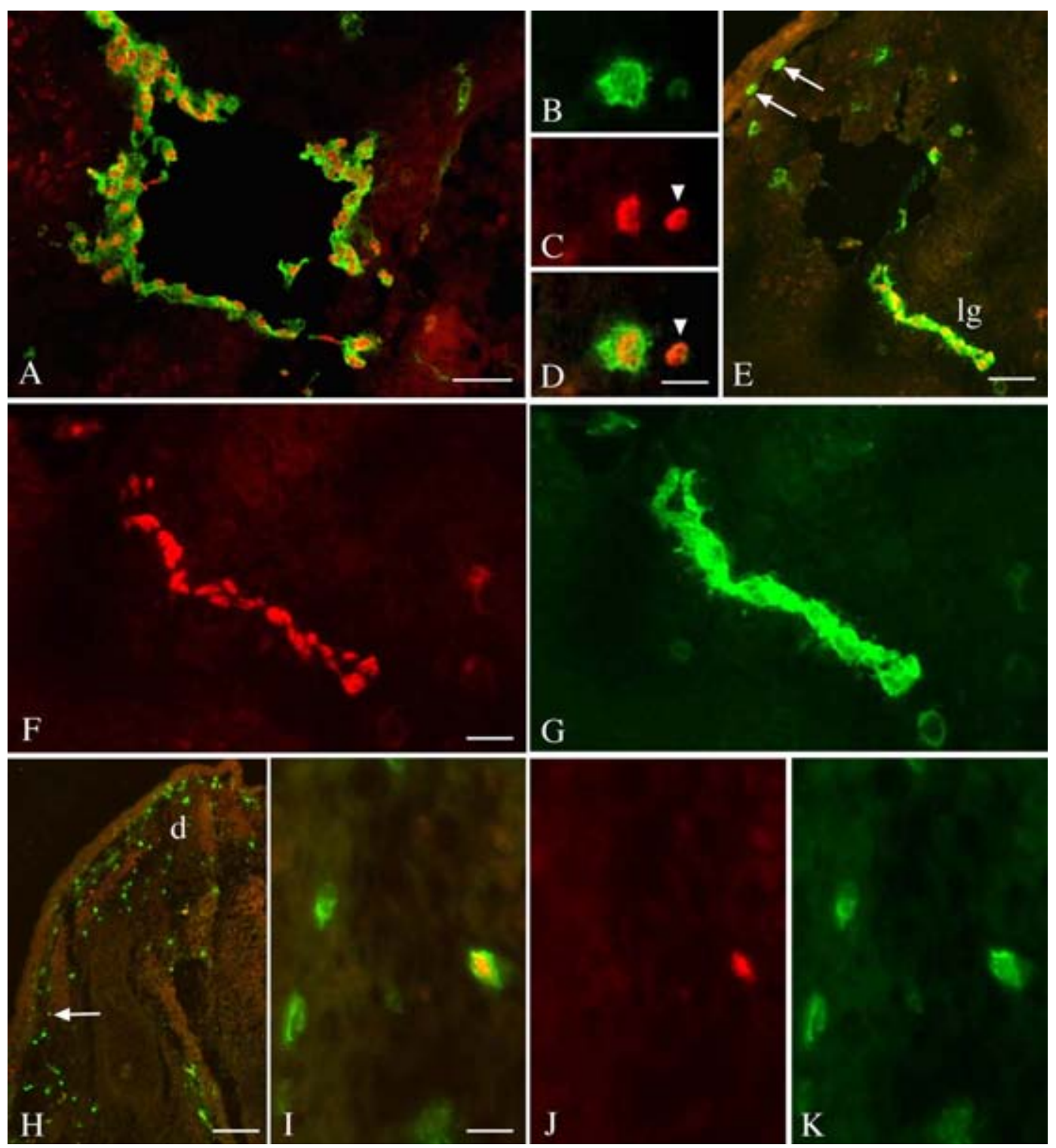

Abb. 12: Anti-Lyve-1 / Prox1-Doppelfärbung an Kryoschnitten von Mausembryonen an ET 13,5. A) Lymphsack eines Mausembryos zeigt Lyve-1 Expression (grün) in der Zellmembran und Prox 1 (rot) im Zellkern. B-D) Eine Einzelzelle im Mesenchym der Haut exprimiert Lyve-1 (B) und Prox1 (C), während eine andere Zelle nur Prox1-Expression zeigt (Pfeilköpfe). E) Ein Lymphgefäß (lg) exprimiert ebenfalls beide Marker. Einige Einzelzellen der Haut sind nur Lyve-1-positiv (Pfeile). F,G) Ausschnittvergrößerung aus E. F) Prox1 und G) Lyve-1 in einem Lymphgefäß. H) Übersicht eines Querschnitts mit Dermis (d). Eine doppelt-positive Einzelzelle in der Haut (Pfeil) ist in I-K vergrößert. J) Prox1 (rot) ist im Zellkern lokalisiert, K) Lyve-1 (grün) in der Zellmembran. Balken in A) $50 \mu \mathrm{m}$, B) $10 \mu \mathrm{m}$, E) $40 \mu \mathrm{m}$, F) $30 \mu \mathrm{m}, \mathrm{H}) 200 \mu \mathrm{m}$, I) $15 \mu \mathrm{m}$. A) verändert nach Buttler et al. (2008); B-D) verändert nach Buttler et al. (2006).

\subsubsection{Koexpression der Lymphendothelmarker Prox1 und LA102}

Weiterhin habe ich die Kolokalisation der zwei Lymphendothelmarker Prox1 und LA102 in LECs der jugulären Lymphsäcke, Lymphgefäße und mesenchymalen Zellen untersucht. 
Die jugulären Lymphsäcke von Mausembryonen der ET 11,5 bis 13,5 zeigten, wie auch sprossende Endothelzellen aus den Lymphsäcken, eine Koexpression der beiden Marker (Abb. 13). Die Intensität der LA102-Expression variiert in einigen Bereichen. Wenige Prox1-positive LECs wiesen kein LA102 auf. Der Nachweis beider Marker in Lymphgefäßen verschiedener Entwicklungsstadien konnte ebenso erbracht werden. Im Mesenchym der Haut traten doppelt positive Einzelzellen an ET 12,5 und 13,5 auf.

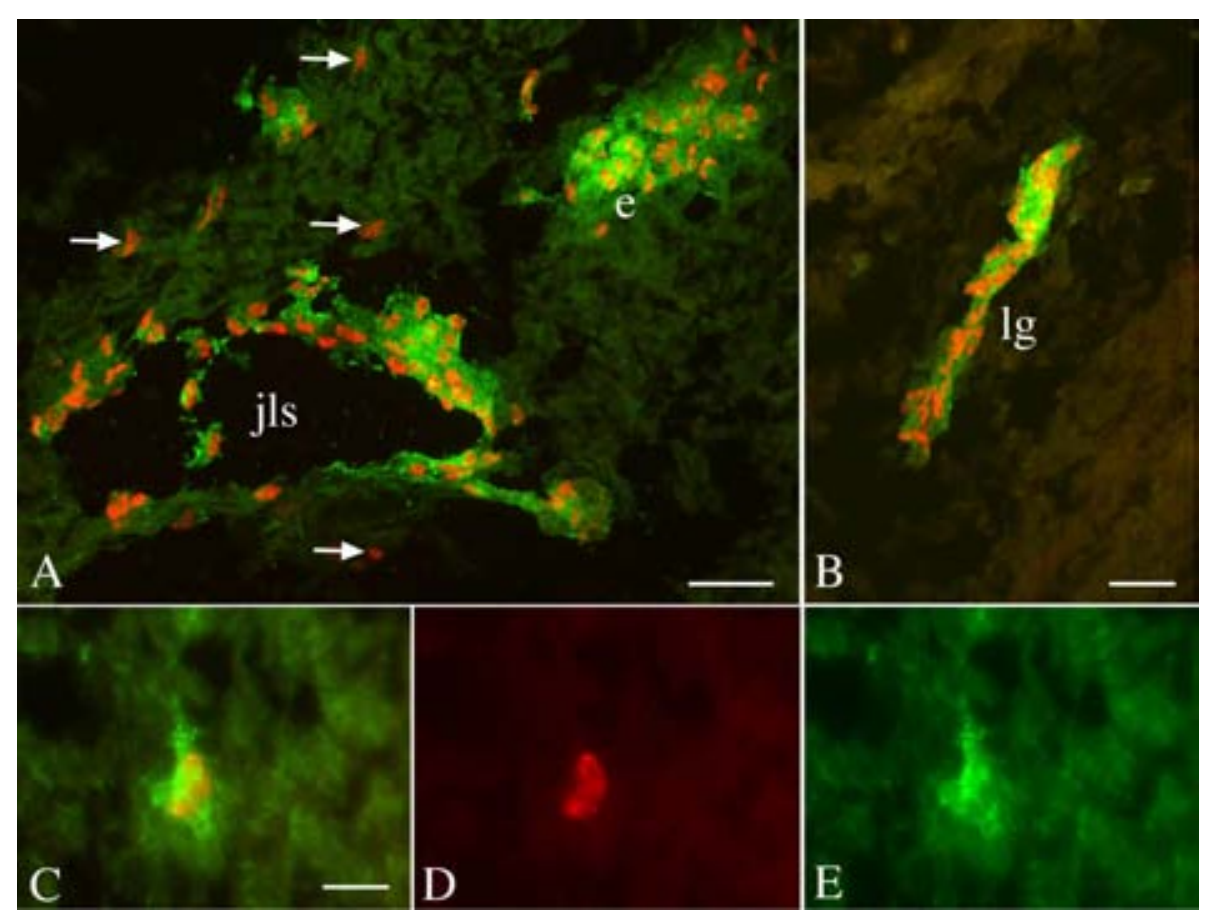

Abb.13: Anti-Prox1 / LA102-Doppelfärbung an Kryoschnitten von Mausembryonen der ET 12,5 (A,B) und 13,5 (C-E). A) Die jugulären Lymphsäcke (jls) und sprossende Endothelzellen (e) exprimieren Prox1 (rot) im Zellkern und LA102 (grün) in der Zellmembran. Die Expressionsintensität von LA102 ist bei einigen Zellen schwächer. Die Venen-nahen LECs sind LA102-negativ (Pfeile). B) Eine Koexpression von beiden Markern konnte ebenfalls in Lymphgefäßen (lg) detektiert werden. C-E) Eine Einzelzelle in der Dermis exprimiert Prox1 (rot) im Zellkern und LA102 (grün) in der Zellmembran. Balken in A) $50 \mu \mathrm{m}$, B) $30 \mu \mathrm{m}$, C) $10 \mu \mathrm{m}$. A) verändert nach Buttler et al. (2008).

\subsubsection{Differenzierung zwischen Blut- und Lymphgefäßendothel}

Hinweise zur Unterscheidung zwischen Blut- und Lymphgefäßendothel liefern Doppelfärbungen der Endothelmarker Prox1 (Lymphendothel) und CD31 (Lymph- und Blutendothel). Während eine Koexpression beider Marker Lymphendothel markiert, liegt bei einer Einfachfärbung mit CD31 Blutendothel vor. Prox1 war zusammen mit CD31 im Endothel der jugulären Lymphsäcke, in bestimmten Abschnitten der Kardinalvenen und in 


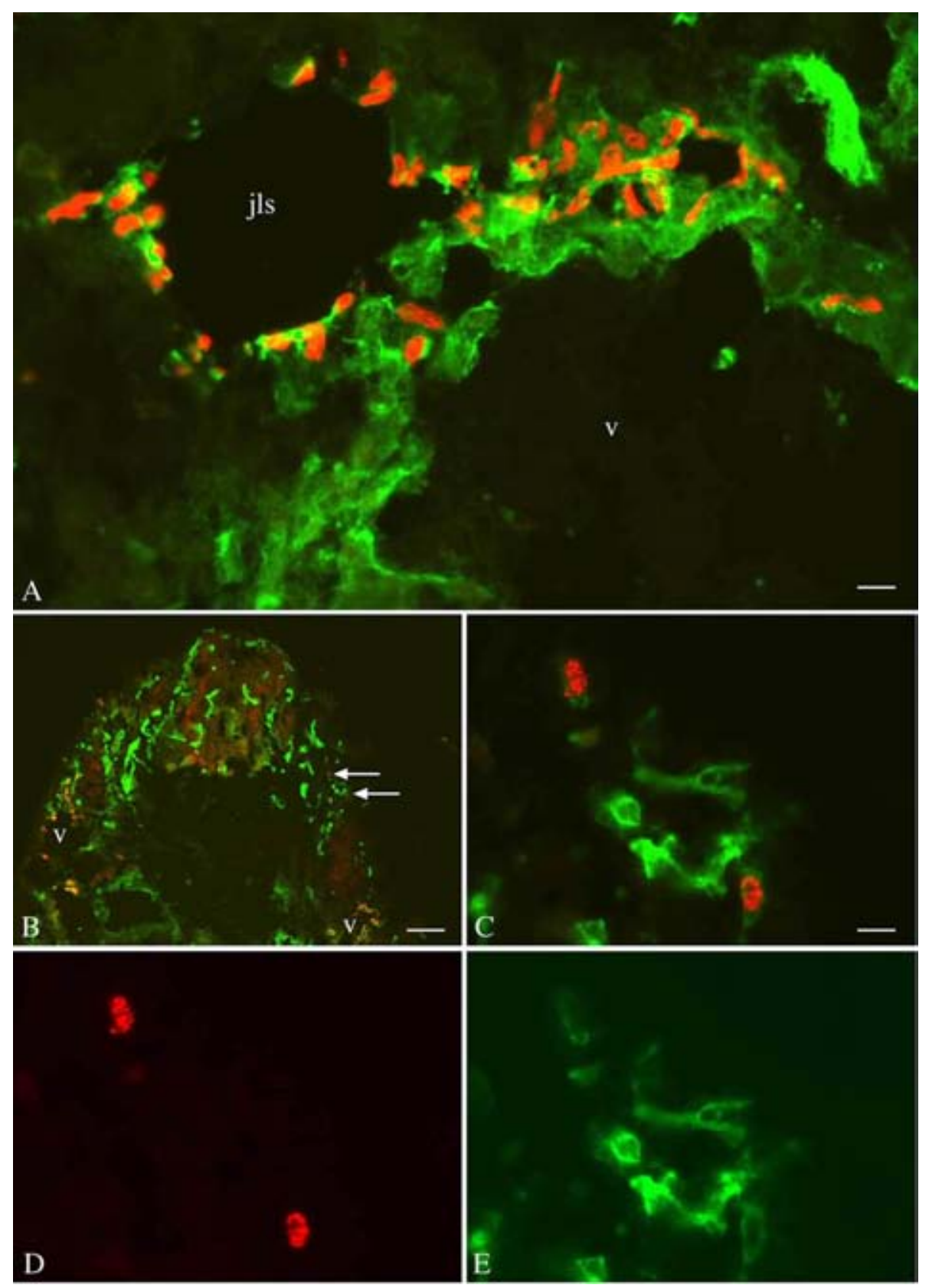

Abb. 14: Anti-Prox1 / CD31-Doppelfärbung an Kryoschnitten von Mausembryonen der ET 12,5 (A) und 10,5 (B-E). A) Der juguläre Lymphsack (jls) sowie Zellen der Kardinalvene (v) sind Prox 1- (rot) und CD31- (grün) positiv. B) Einzelzellen (Pfeile) lateral des Neuralrohrs weisen eine Expression beider Marker auf. Sie liegen in großem Abstand zu den ebenfalls Prox1/CD31positiven Kardinalvenen (v). Die JLS sind in diesem Entwicklungsstadium noch nicht vorhanden. C-E) Vergrößerungen der mit Pfeilen markierten Zellen aus B mit Prox1 (rot) im Zellkern und CD31 (grün) in der Zellmembran. Blutgefäße exprimieren CD31, den Lymphendothelmarker Prox1 aber nicht. Balken in A,C) $10 \mu \mathrm{m}, \mathrm{B}) 150 \mu \mathrm{m}$. B,C) verändert nach Buttler et al. (2008).

Lymphgefäßen der Haut, des Mediastinums und weiteren Organen wie der Lunge, des Herzens und in verschiedenen Darmbereichen exprimiert (Abb. 14). Doppelt positive Einzelzellen im Mesenchym der Dermatome konnte ich bereits in sehr frühen 
Embryonalstadien nachweisen (Abb. 14B-E), noch bevor sich die jugulären Lymphsäcke entwickelt hatten. Diese Einzelzellen lagen in großem Abstand zum späteren Lymphsackbereich. Die Expressionsintensität von CD31 war bei Lymphendothel deutlich geringer als bei Blutendothel.

\subsubsection{Prox1-positive Einzelzellen koexprimieren den Leukozytenmarker CD45}

Lymphendothelzellen lassen sich von Leukozyten differenzieren, da sie den allgemeinen Leukozytenmarker CD45 nicht exprimieren. In 4.1.1.3 habe ich gezeigt, dass mesenchymale Einzelzellen den Lymphendothelmarker Lyve-1 und den allgemeinen Leukozytenmarker CD45 in vielen Fällen koexprimierten. Doppelfärbungen mit Prox1 und CD45 wurden durchgeführt, um diese Art von Zellen zu verifizieren. Eine kleine Population CD45-positiver Zellen mit gleichzeitiger Prox1-Expression konnte ich bei Mausembryonen in dieser Arbeit nachweisen. Diese Zellen traten als Einzelzellen in der Dermisanlage auf (Abb. 15). Die Intensität der CD45-Expression war bei Prox1-positiven Zellen geringer als bei Leukozyten, die nur CD45 exprimierten. 


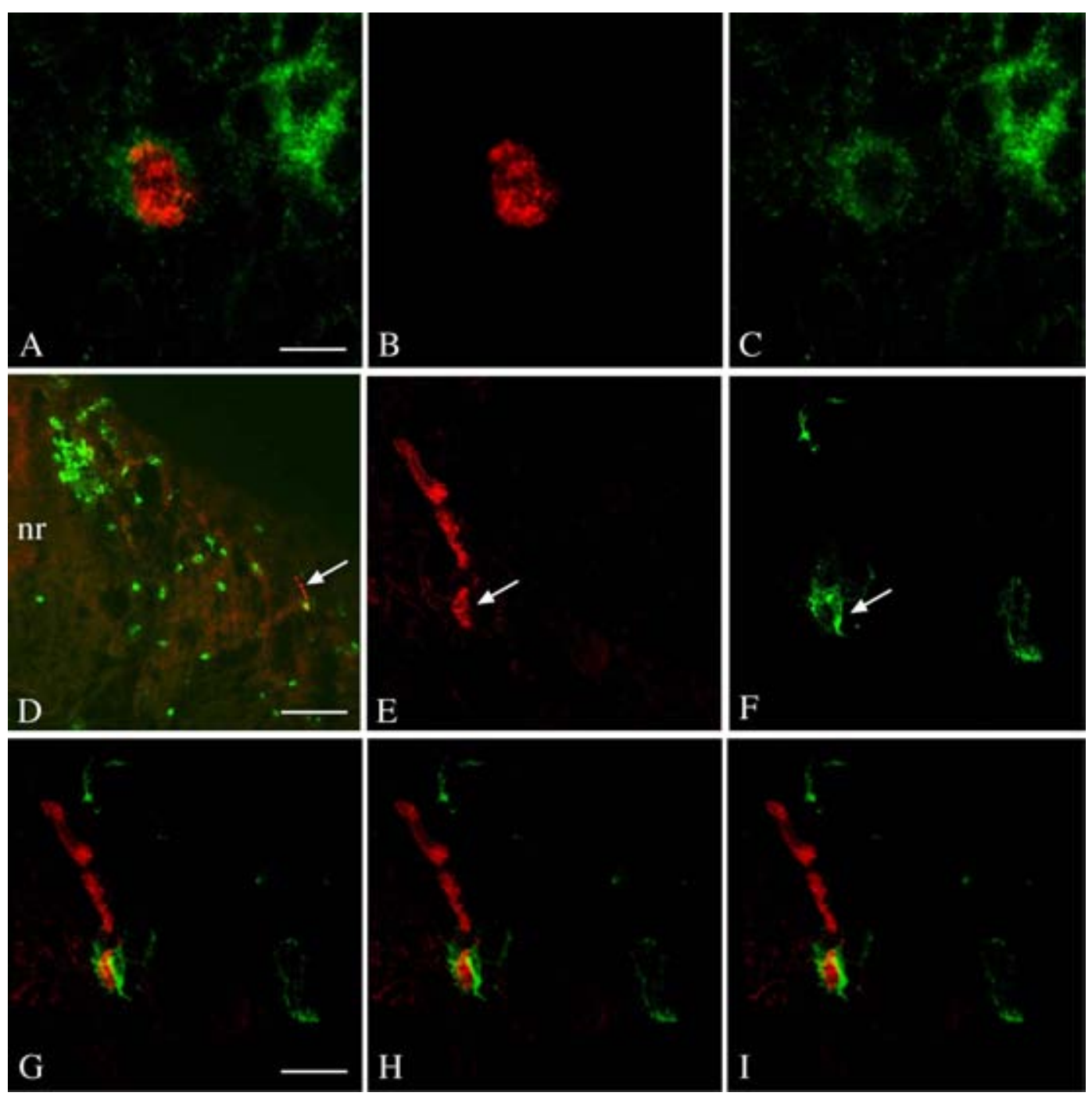

Abb. 15: Anti-Prox1 / CD45-Doppelfärbung an Kryoschnitten von Mausembryonen an ET 11,5. Diese Bilder wurden mit Hilfe eines konfokalen Laser-Scanning-Mikroskops erstellt. A-C) Eine doppelt-positive Einzelzelle mit Prox1 (rot) im Zellkern und CD45 (grün) in der Zellmembran. D) Übersicht aus dem Bereich des Neuralrohrs (nr) und des paraxialen Mesoderms zeigt ein Lymphgefäß (Pfeil). E-I) Vergrößerung aus D. Das Lymphgefäß mit mehreren Prox1(rot) positiven Zellen enthält eine Lymphendothelzelle (Pfeil), die CD45 (grün) koexprimiert. G-I) Verschiedene Rotationswinkel der Lymphendothelzellen. Balken in A) $10 \mu \mathrm{m}$, D) $100 \mu \mathrm{m}, \mathrm{G})$ $15 \mu \mathrm{m}$. A) verändert nach Buttler et al. (2006).

\subsubsection{Koexpression lymphendothelialer Marker mit dem Makrophagenmarker CD11b}

Auf einigen Zellen konnte ich, wie in 4.1.1.3 und 4.1.2.4 beschrieben, Koexpression des Leukozytenmarkers CD45 mit LEC-Markern beobachten. Um eine genauere Klassifizierung dieser CD45-positiven Zellpopulation vornehmen zu können, habe ich Doppelfärbungen mit dem Makrophagenmarker CD11b und jeweils einem der zwei 

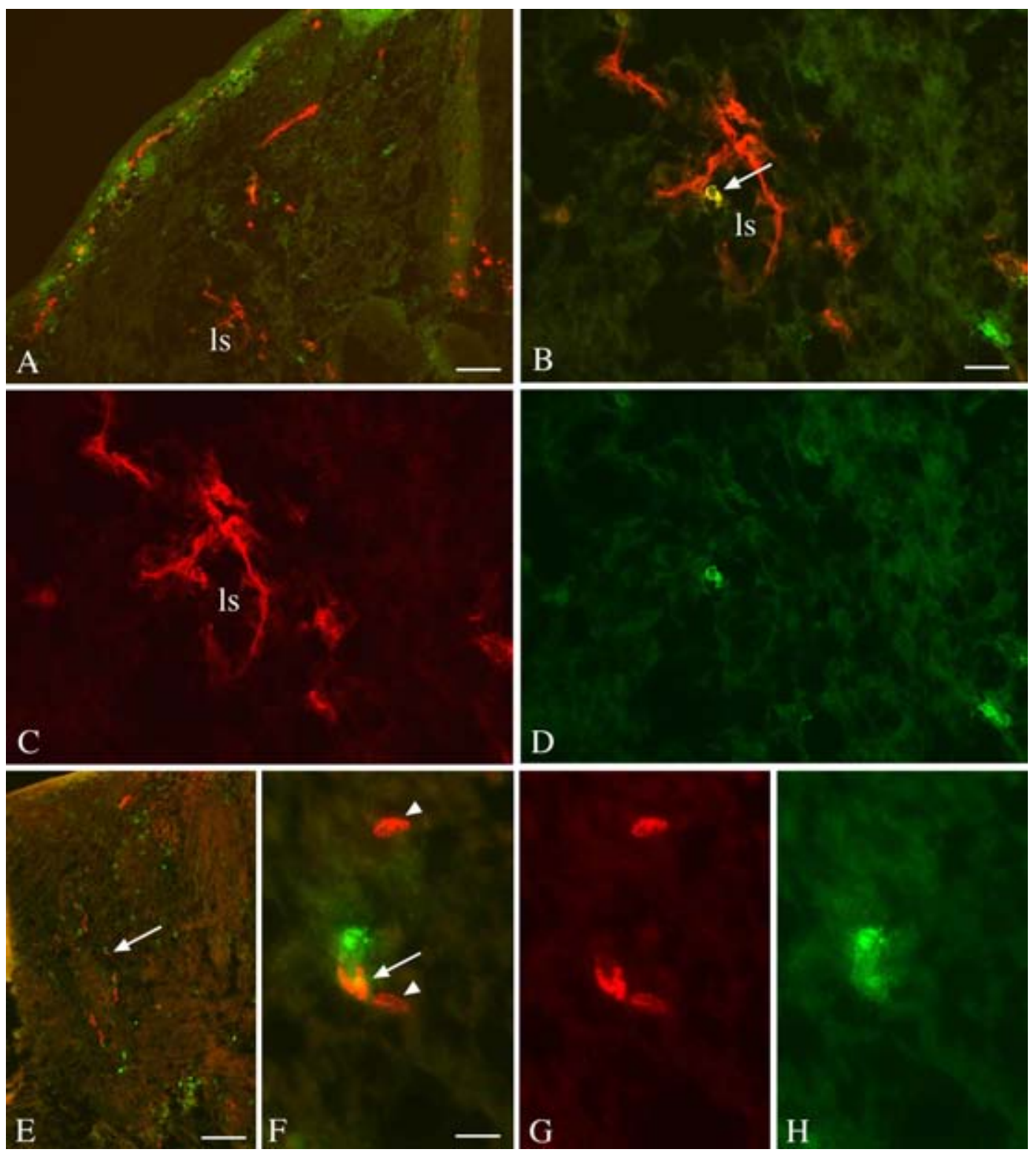

Abb. 16: Anti-CD11b / Prox1 bzw. Lyve-1-Doppelfärbungen an Kryoschnitten von Mausembryonen der ET 13,5 (A-D) und 12,5 (E-H). A) Übersicht mit paraxialem Mesoderm lateral des Neuralrohrs, gefärbt mit CD11b (grün) und Lyve-1 (rot). 1s, Lymphsack. B) Vergrößerung aus A mit dem Lyve-1-positiven Lymphsack (1s) und einer doppelt positiven Zelle (Pfeil). C) Lyve-1-Antikörperfärbung aus B. D) CD11b-Antikörperfärbung aus B. E) Übersicht aus einem ähnlichen Abschnitt wie A, gefärbt mit den Antikörpern gegen CD11b (grün) und Prox1 (rot). F) Ausschnittvergrößerung aus E mit zwei doppelt-positiven Zellen (Pfeil) und zwei Prox1positiven Zellen (Pfeilköpfe). G) Prox 1-Antikörperfärbung H) CD11b-Antikörperfärbung. Balken in A) $150 \mu \mathrm{m}$, B) $50 \mu \mathrm{m}$, E) $200 \mu \mathrm{m}$, F) $10 \mu \mathrm{m}$. B,F) verändert nach Buttler et al. (2008).

Lymphendothelmarker Lyve-1 und Prox1 durchgeführt. CD11b markiert neben Makrophagen auch Granulozyten, Dendritische Zellen, Natürliche Killerzellen und BLymphozyten. Ich konnte beobachten, dass doppelt positive Zellen (sowohl CD11b / Lyve1 als auch CD11b/Prox1) im Mesenchym der Dermisanlage und im Mediastinum 
vorhanden waren (Abb. 16). Außerdem konnte ich vereinzelte doppelt-positive Zellen in unmittelbarer Umgebung der Lymphsäcke detektieren. Der Makrophagenmarker CD11b war isgesamt nur auf wenigen Zellen mit dem Lymphendothelmarker Lyve-1 kolokalisiert, noch seltener konnte ich Zellen nachweisen, die CD11b und Prox1 koexprimierten.

\subsubsection{Koexpression lymphendothelialer Marker mit dem Makrophagenmarker F4/80}

Ein zweiter, häufig verwendeter Markrophagenmarker für Mausgewebe ist F4/80. In vielen Organen wie Leber, Milz, Thymus, Haut und Lymphknoten markiert F4/80 Makrophagen, während er in Granulozyten, Lymphozyten und Thrombozyten nicht nachgewiesen werden konnte. Ich habe Anti-F4/80 zusammen mit Prox1 und Lyve-1 in einer Dreifachfärbung angewandt, um Lymphendothelzellen mit Makrophageneigenschaften deutlich von nichtlymphendothelialen Makrophagen abgrenzen zu können. Ich konnte dreifach-positive Zellen in unmittelbarer Nachbarschaft der jugulären Lymphsäcke sowie in der Körperwand lateral der Perikardhöhle nachweisen. Einige wenige Lymphendothelzellen in Lymphgefäßen exprimierten ebenfalls alle drei Marker. Beispiele hierfür zeigt die Abbildung 17. Zwar ist der Makrophagenmarker F4/80 sehr selten in embryonalem Mausgewebe mit den Lymphendothelmarkern Prox1 und Lyve-1 koexprimiert, die Existenz dieser Zellen zeigt aber die Heterogenität des Lymphendothels. 

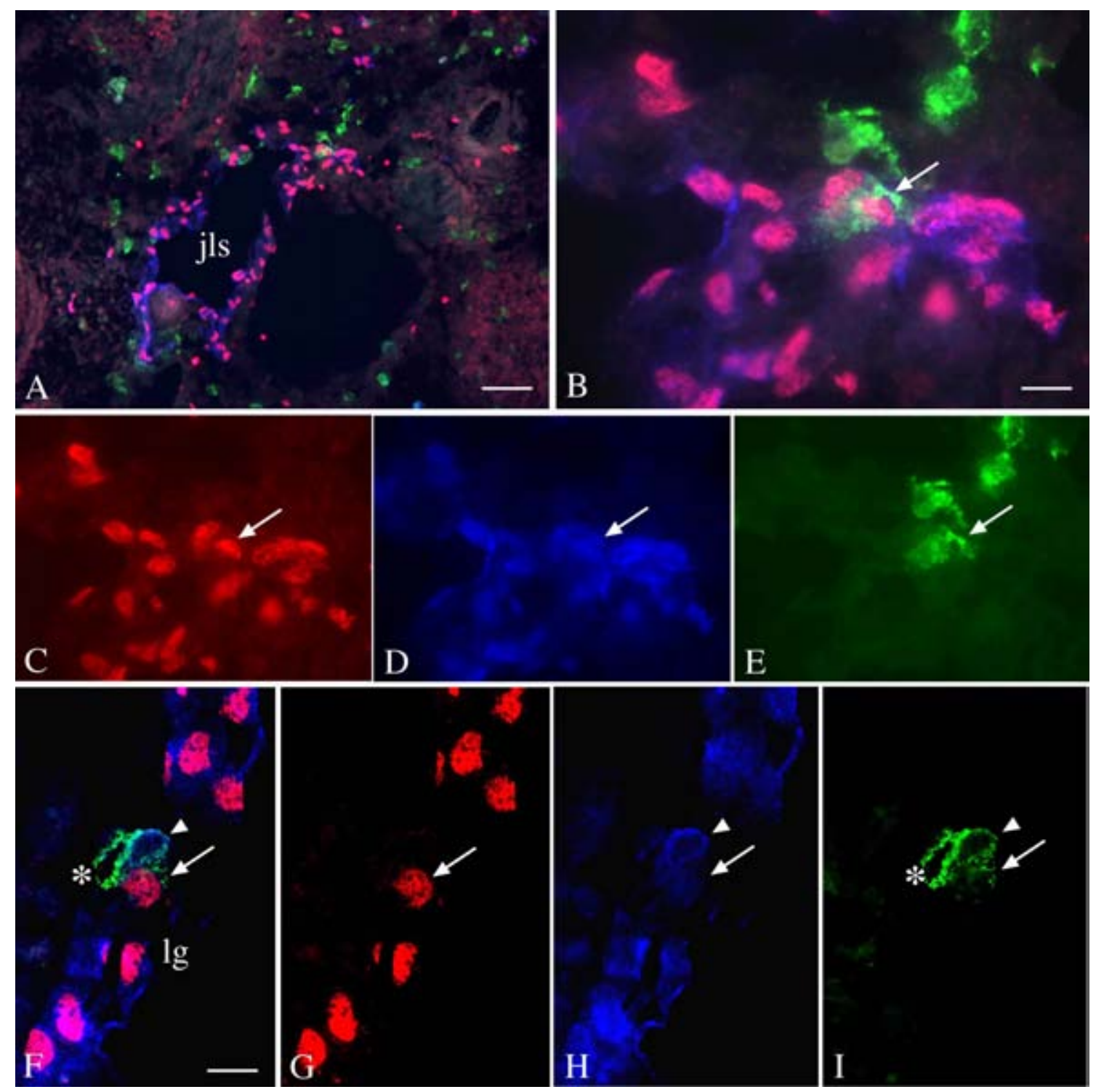

Abb. 17: Anti-F4/80 / Prox1 / Lyve-1-Dreifachfärbung an Kryoschnitten von Mausembryonen an ET 13,5. A) Jugulärer Lymphsack (jls) in der Übersicht. Die Lymphendothelmarker Prox1 (rot) und Lyve-1 (blau) sind in jeder Endothelzelle des Lymphsacks koexprimiert. B-E) Ausschnittvergrößerung aus A. B) Dreifach positive Lymphendothelzelle (Pfeil) mit C) Prox1 im Kern (rot), D) Lyve-1 (blau) in der Zellmembran und E) F4/80 (grün) ebenfalls in der Zellmembran. F-I) Lymphgefäß (lg) mit Prox1-positiven Zellkernen (G) und Lyve1-positiver Zellmembran (H). Eine Lymphendothelzelle koexprimiert F4/80 (Pfeil). Eine andere Zelle zeigt F4/80- und Lyve-1-Expression (Pfeilkopf), während eine weitere Zelle nur F4/80 exprimiert (*). Balken in A) $50 \mu \mathrm{m}, \mathrm{B}, \mathrm{F}) 10 \mu \mathrm{m}$. A-F) verändert nach Buttler et al. (2008).

\subsubsection{Untersuchungen mit dem Proliferationsmarker Ki-67}

Während der Entwicklung von Mäusen findet in allen Organanlagen Zellproliferation statt. Mit Hilfe des Proliferationsmarkers Ki-67 können alle Zellen dargestellt werden, die sich in den Phasen $\mathrm{G}_{1}, \mathrm{~S}, \mathrm{G}_{2}$ und $\mathrm{M}$ des Zellzyklusses befinden. Um eine gute Morphologie der 
Mausembryonen in der Jugularregion und eine Übersicht über alle Regionen zu erhalten, habe ich den Antikörper Ki-67 an Paraffinschnitten angewendet. Eine Vielzahl der Zellen befanden sich in der Zellteilung, so dass im gesamten Gewebe Ki-67-Expression nachgewiesen werden konnte. Strukturen wie das Neuralrohr, die dorsale Aorta, die Kardinalvenen und die jugulären Lymphsäcke konnten aufgrund ihrer Morphologie identifiziert werden. In den Gefäßen, speziell den Lymphsäcken, konnte ich Ki-67-positive Endothelzellen nachweisen. Der Sekundärantikörper war mit dem Enzym Peroxidase gekoppelt und löste mit dem Substrat DAB eine Farbreaktion aus. Somit wurde eine spezifische Markierung des Proliferationsmarkers Ki-67 sichtbar (Abb. 18).
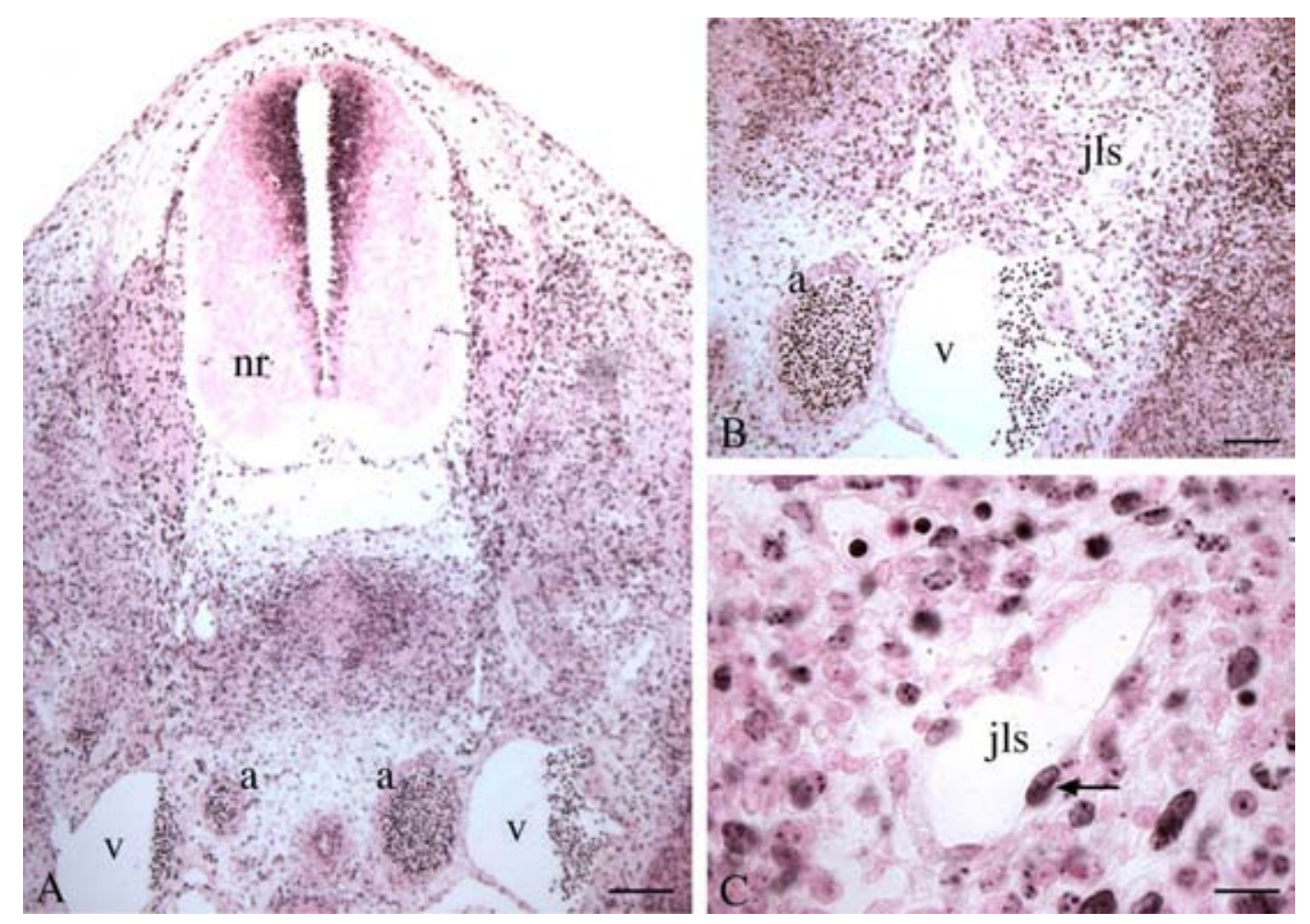

Abb. 18: Anti-Ki-67-Färbung (braun-schwarz) an Paraffinschnitten von Mausembryonen an ET 12,5. A) Übersicht eines dorsalen Abschnitts mit Neuralrohr (nr), Dorsalaorta (a) und Kardinalvenen (v). In allen Bereichen des Embryos sind proliferierende Zellen vorhanden. B) Ausschnittvergrößerung aus A mit der Dorsalaorta, Kardinalvene und dem sich entwickelnden jugulären Lymphsack (jls). C) Ausschnittvergrößerung des jugulären Lymphsacks aus B mit einer Ki-67- positiven Lymphendothelzelle (Pfeil). Balken in A) $200 \mu \mathrm{m}$, B) $100 \mu \mathrm{m}$, C) $30 \mu \mathrm{m}$.

Unspezifische Peroxidaseaktivität war aber auch in den Erythrozyten und einigen Leukozyten zu beobachten, die durch Zugabe von Wasserstoffperoxid weitgehend gehemmt wurde. 


\subsubsection{Proliferation Prox1- und Lyve-1-positiver Zellen}

Proliferierende Lymphendothelzellen der jugulären Lymphsäcke konnten in 4.1.5 aufgrund der guten Morphologie der Paraffinpräparate nachgewiesen werden. Um Lymphendothelzellen, die sich in der Proliferationsphase befinden, genau bestimmen zu können, ist eine Doppelfärbung mit einem Lymphendothelmarker, hier Lyve-1 oder Prox1, und Ki-67 notwendig. In Entwicklungsstadien der ET 11,5 bis 13,5 konnten proliferierende Ki-67- positive LECs in allen Bereichen des Mausembryos nachgewiesen werden, in denen Lymphangiogenese stattfand. Die lymphangiogenen Segmente der Kardinalvenen und die sich entwickelnden jugulären Lymphsäcke zeigten eine Koexpression der Marker (Abb. 19). In der Dermisanlage konnte ich mit Hilfe einer Prox1 / Ki-67-Doppelfärbung zeigen, dass die Endothelzellen von Lymphgefäßen ebenfalls zu einem hohen Prozentsatz proliferieren. Zusätzlich konnte ich Einzelzellen in der Dermisanlage und im Mediastinum beobachten, die sowohl Lyve-1 und Ki-67 als auch Prox1 und Ki-67 koexprimierten.

\subsubsection{Quantitative Analyse proliferierender Lymphendothelzellen}

Für eine vergleichende quantitative Auswertung der proliferierenden Lymphendothelzellen aus den verschiedenen Bereichen des Embryos habe ich die Ki-67-positiven LECs im Verhältnis zu der Gesamtzahl der LECs ausgezählt. Hieraus wurde für jeden ausgezählten Bereich (Lymphsack, Aussprossung aus Lymphsack, Hautanlage) der prozentuale Anteil der proliferierenden LECs ermittelt. Von den Lymphsack-LECs an ET 13,5 proliferierten durchschnittlich 26,8\%, während 22,5\% der aus den Lymphsäcken sprossenden LECs den Marker Ki-67 exprimierten. Die Lyve-1-positiven Einzelzellen der Dermisanlage wiesen an ET 13,5 eine Proliferationsrate von 33,4\% auf. An ET 12,5 lag diese mit 55,1\% signifikant höher. In 30\% der Fälle konnten Ki-67-positive LECs an ET 12,5 nachgewiesen werden, die aus den Lymphsäcken sprossen. Die durchschnittliche Proliferationsrate von Lymphsackendothelzellen lag bei 22,3\%. Eine Übersicht über absolute und relative Zahlen proliferierender LECs zeigen Tabelle 3 und Abbildung 20. 

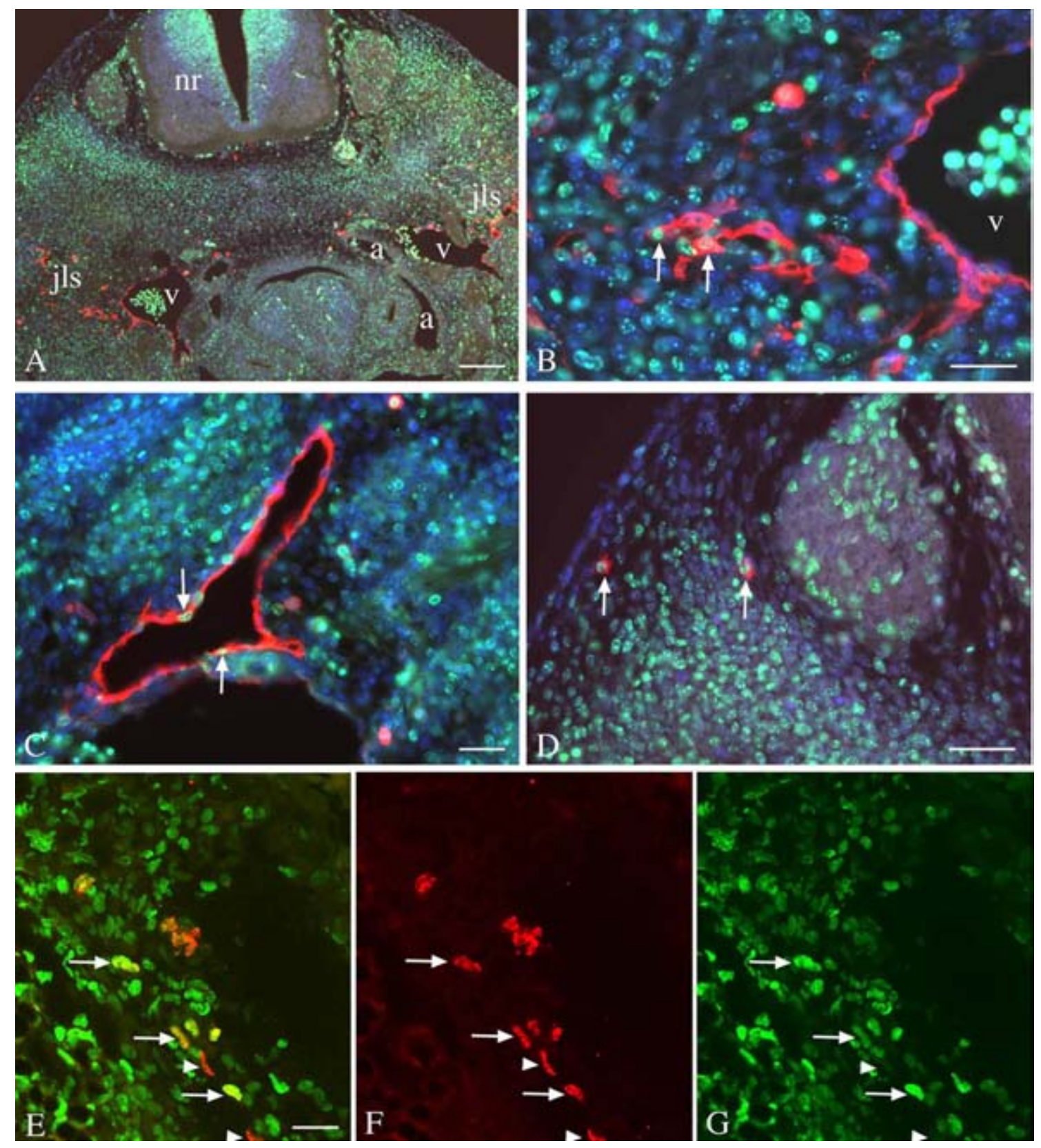

Abb. 19: Anti-Ki-67 (grün) / Lyve-1- (rot) Doppelfärbung an Paraffinschnitten (A-D) und Ki67 (grün) / Prox1- (rot) Doppelfärbung an Kryoschnitten (E-G) von Mausembryonen der ET 11,5 (A-C), 12,5 (D) und 13,5 (E-G). Die Präparate A-D wurden mit Dapi (blau) gegengefärbt. A) Übersicht der dorsalen Region mit Neuralrohr (nr), Kardinalvenen (v), Aortenbogen (a) und sich entwickelnden jugulären Lymphsäcken (jls). B) Bei höherer Vergrößerung ist ein Abschnitt der Kardinalvene, der keine Ki-67-positiven Zellen enthält, und der sich entwickelnde JLS mit proliferierenden Lymphendothelzellen (Pfeile) zu sehen. Ebenso exprimieren einige LECs der Lymphsäcke (C) und Einzelzellen in der Hautanlage (D) Ki-67. E) Ki-67-Expression in Prox1positiven Zellen eines Lymphgefäßes in der Hautanlage (Pfeile), andere Lymphendothelzellen weisen den Proliferationsmarker Ki-67 nicht auf (Pfeilkopf). F) Anti-Prox1 und G) Anti-Ki-67Färbung. Balken in A) $200 \mu \mathrm{m}, \mathrm{B}, \mathrm{E}) 30 \mu \mathrm{m}$, C) $25 \mu \mathrm{m}$, D) $50 \mu \mathrm{m}$. B-D) verändert nach Buttler et al. (2008). 
Tabelle 3: Absolute und relative Anzahl von Ki-67-positiven LECs in Mausembryonen der ET 12,5 und 13,5

\begin{tabular}{|c|c|c|c|c|c|}
\hline Bereich & ET & $\begin{array}{c}\text { Gesamt- } \\
\text { anzahl LECs }\end{array}$ & $\begin{array}{c}\text { Ki-67-positive } \\
\text { LECs }\end{array}$ & $\%$ & $\begin{array}{c}\text { Mittelwert } \\
\%\end{array}$ \\
\hline \multirow[t]{15}{*}{ Lymphsack } & \multirow[t]{5}{*}{13,5} & 67 & 20 & 29,8 & \\
\hline & & 118 & 33 & 27,9 & \\
\hline & & 114 & 36 & 31,6 & \\
\hline & & 73 & 22 & 30,1 & \\
\hline & & 34 & 5 & 14,7 & 26,8 \\
\hline & \multirow[t]{10}{*}{12,5} & 8 & 1 & 12,5 & \\
\hline & & 17 & 2 & 11,8 & \\
\hline & & 32 & 6 & 18,8 & \\
\hline & & 15 & 3 & 20,0 & \\
\hline & & 22 & 4 & 18,2 & \\
\hline & & 21 & 7 & 33,3 & \\
\hline & & 39 & 6 & 15,4 & \\
\hline & & 15 & 6 & 40,0 & \\
\hline & & 23 & 3 & 13,0 & \\
\hline & & 5 & 2 & 40,0 & 22,3 \\
\hline \multirow[t]{5}{*}{ Sprossende LECs } & \multirow[t]{2}{*}{13,5} & 15 & 5 & 33,3 & \\
\hline & & 60 & 7 & 11,7 & 22,5 \\
\hline & \multirow[t]{3}{*}{12,5} & 15 & 6 & 40,0 & \\
\hline & & 10 & 3 & 30,0 & \\
\hline & & 20 & 4 & 20,0 & 30 \\
\hline \multirow[t]{7}{*}{ Dermisanlage } & \multirow[t]{3}{*}{13,5} & 8 & 3 & 37,5 & \\
\hline & & 13 & 4 & 30,8 & \\
\hline & & 19 & 6 & 31,8 & 33,4 \\
\hline & \multirow[t]{4}{*}{12,5} & 6 & 4 & 66,7 & \\
\hline & & 5 & 3 & 60,0 & \\
\hline & & 13 & 6 & 46,1 & \\
\hline & & 19 & 9 & 47,4 & 55,1 \\
\hline
\end{tabular}




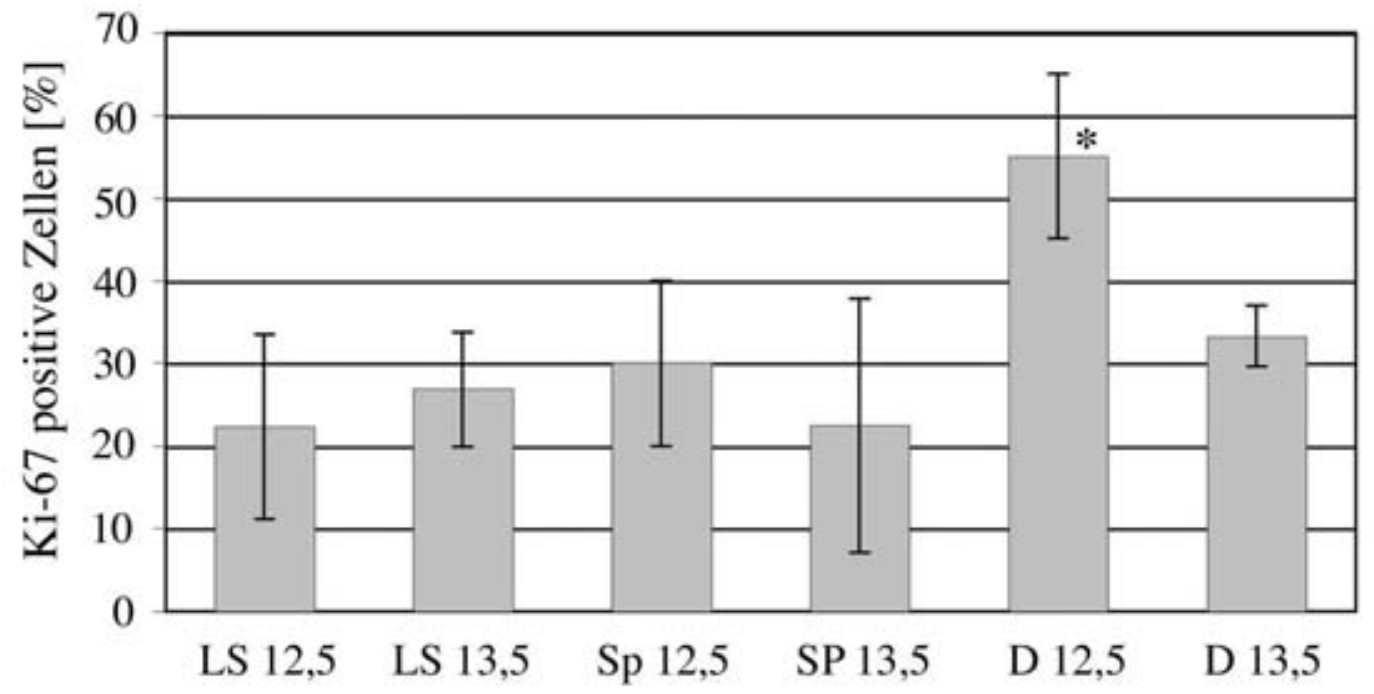

Abb. 20: Proliferationsraten von LECs in Mausembryonen der ET 12,5 und 13,5. Die relativen Proliferationsraten der Einzelzellen der Dermisanlage und der LECs der Lymphsäcke und deren Sprossen liegen im Bereich von 22,3\% bis 55,1\%, wobei der letztere Wert (Einzelzellen der Dermisanlage*) signifikant höher liegt. Die Standardabweichungen sind dargestellt. LS, Lymphsack; Sp, sprossende LECs; D, Einzelzellen der Dermisanlage. Verändert nach Buttler et al. (2008).

In dem Balkendiagramm (Abb. 20) sind die relativen Proliferationsraten der untersuchten lymphangiogenen Regionen dargestellt. Die Ergebnisse zeigen, dass alle Abschnitte des untersuchten Lymphgefäßsystems in annähernd gleichem Maße proliferieren. Einen signifikant höheren Proliferationswert mit 55\% besitzen die Lyve-1-positiven Einzelzellen der Dermisanlage. Die Gesamtzahl der Einzelzellen in diesem Bereich lag aber deutlich unter denen aus dem Lymphsackbereich.

\subsection{Untersuchung der lymphangiogenen Potenz an Schnittkulturen von Mausembryonen}

Schnittkulturen von Mausembryonen wurden wie unter Punkt 3.2.1 beschrieben durchgeführt. Es sollte untersucht werden, ob sich Lymphgefäße in embryonalen Geweben isoliert von der Jugularregion entwickeln. Mausembryonen vom ET 10,5 eigneten sich für diese Kultur am besten, da in diesem Entwicklungsstadium noch keine Lymphsäcke bzw. Lymphgefäße vorhanden sind. Um die Lymphendothelzellen nachzuweisen und Blut- von Lymphendothel unterscheiden zu können, habe ich nach einer Inkubationszeit von drei 
Tagen (entspricht ET 13,5) eine Doppelfärbung der Schnitte mit dem Pan-Endothelmarker CD31 und dem Lymphendothelmarker Lyve-1 durchgeführt. Es zeigte sich, dass in allen Präparaten eine Entwicklung von Blutgefäßen in Form von CD31-positiven Netzen stattgefunden hatte. Der Nachweis Lyve-1/CD31-doppelt-positiver Lymphgefäße beschränkte sich auf bestimmte Bereiche des Mausembryos.
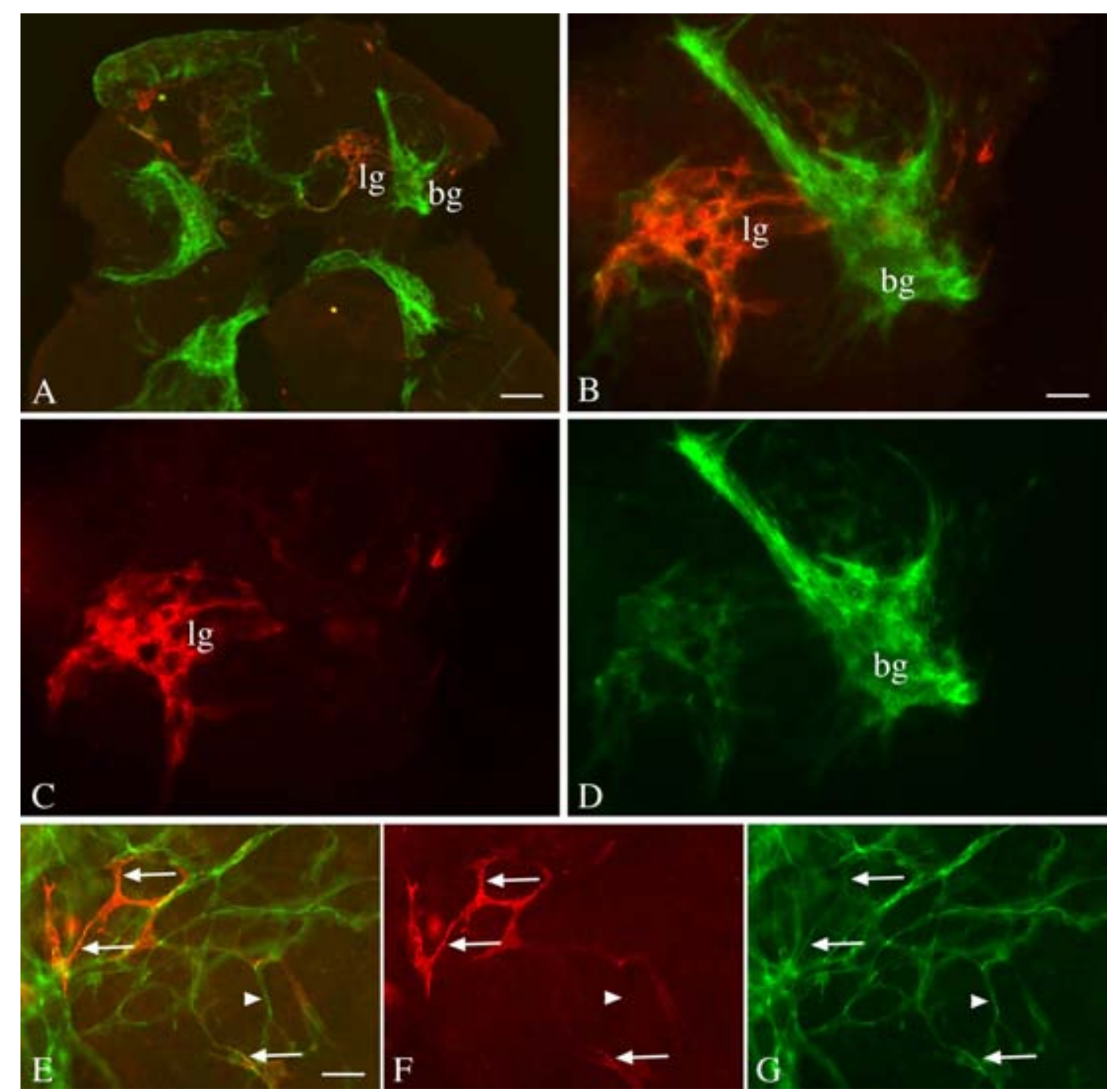

Abb. 21: Anti-CD31 (grün) / Lyve-1- (rot) Färbung an Schnittkulturen von Mausembryonen. A) Gewebeschnitt Nr. 7 mit Blutgefäßen (grün) und Lymphgefäßen (rot) im Bereich der jugulären Lymphsäcke. B-D) Vergrößerung aus A. Die Lyve-1-positiven Lymphgefäße (lg) exprimieren ebenfalls den Blutendothelmarker CD31, allerdings sehr viel schwächer als die ebenfalls CD31positiven Blutgefäße (bg). E-G) Gewebeschnitt Nr. 9 mit Lyve-1-positiven Lymphgefäßen (Pfeile), die eine schwache CD31-Expression aufweisen. Blutgefäße exprimieren CD31 stärker als die Lymphgefäße, sind aber Lyve-1-negativ (Pfeilkopf). Eine netzartige Struktur der Gefäße ist hier gut zu erkennen. Balken in A) $400 \mu \mathrm{m}$, B) $100 \mu \mathrm{m}$, E) $75 \mu \mathrm{m}$. 
Während die Schnitte kaudal des Hyoidbogens bis einschließlich der Höhe der oberen Extremität (Nr. 4 - 10; siehe auch Abb. 5) Lymphgefäßentwicklung zeigten (Abb. 21), wiesen die Gewebeschnitte kranial des Mandibularbogens (Nr.1-3 aus Abb.5), der oberen Extremität, der Herzschleife und der Schwanzregion (Nr. 11,12) keinerlei Anzeichen für Lymphangiogenese auf. Lyve-1-positive Einzelzellen konnte ich aber auch in diesen Bereichen detektieren.

\subsubsection{Untersuchungen der lymphangiogenen Potenz an Schnittkulturen unter Zugabe des Wachstumsfaktors VEGF-C}

Lymphgefäßentwicklung zeigte sich an Schnittkulturen, wie in 4.2 beschrieben, in vielen Regionen des Mausembryos. Bereiche kranial des Mandibularbogens, die oberen Extremitäten sowie Teile der Schwanzknospe blieben jedoch frei von Lymphgefäßen. Der Wachstumsfaktor VEGF-C kann die Lymphangiogenese in differenzierten Geweben und im Tumorstroma initiieren (Oh et al., 1997; Pepper et al., 2003). Um die Bedingungen der Schnittkulturen zu optimieren, habe ich in diesem Versuchsansatz zusätzlich VEGF-C in das Medium gegeben (siehe auch 3.2.2). Neben den in 4.2 genannten Regionen, in denen Lyve-1- und CD31-positive Lymphgefäße nachgewiesen werden konnten, haben sich unter diesen Bedingungen auch in den vorher negativen Gewebeabschnitten Lymphgefäße entwickelt. Diese Bereiche umfassten die Schnitte Nr. 2 und 3 kaudal des Hyoidbogens (Abb. 22A-C) und den Schnitt Nr. 11 im Schwanzbereich (Abb. 22D-F).

Die Versuche zeigen, dass vor allem nach Zugabe von VEGF-C, nahezu alle kraniokaudalen Abschnitte des Embryos die Potenz besitzen, LECs zu produzieren. Die Methode eignet sich auch, um die lymphangiogene Potenz von solchen Mausembryonen (z.B. bestimmten Knock-out-Mäusen) zu untersuchen, die unmittelbar nach ET 10,5 in utero absterben und resorbiert werden. Die Ergebnisse zu Untersuchungen von Knock-outMäusen sind unter 4.5.2 dargestellt. 

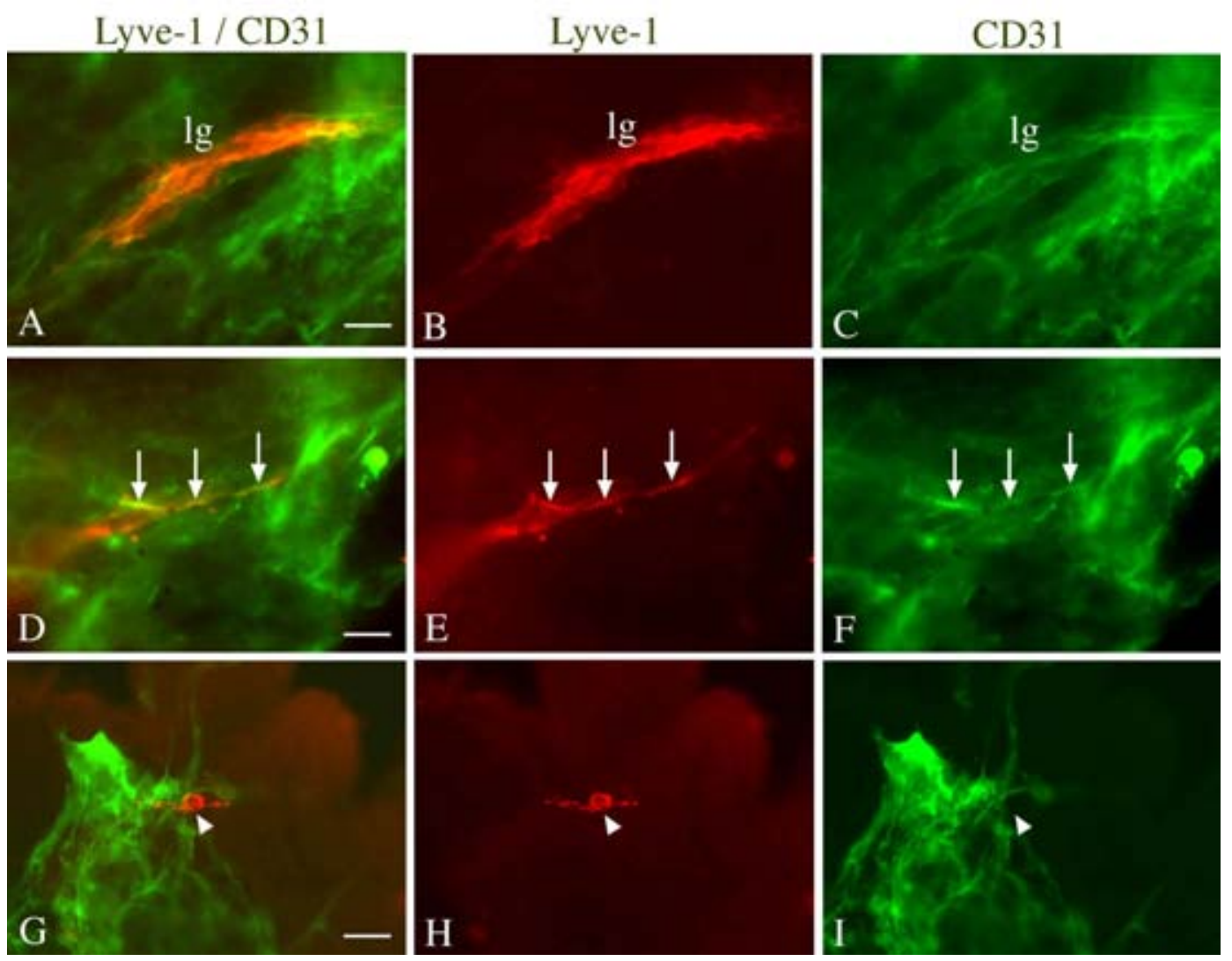

Abb. 22: Anti-CD31 (grün) / Lyve-1- (rot) Färbung an Schnittkulturen von Mausembryonen nach Zugabe von VEGF-C (A-F) und ohne VEGF-C (G-I). A-C) Das Lymphgefäß (lg) aus Schnitt Nr. 3 weist Lyve-1- und CD31-Koexpression auf. Auch in der Schnittkultur Nr. 11 (D-F) aus dem Schwanzbereich entwickelte sich ein Lymphgefäß, das beide Endothelmarker exprimiert (Pfeile), während der Schnitt Nr. 11 ohne VEGF-C (G-I) lymphgefäßfrei blieb. Nur eine Lyve-1positive Einzelzelle konnte hier nachgewiesen werden (Pfeilkopf). Balken in A,D) $20 \mu \mathrm{m}, \mathrm{G}) 50$ $\mu \mathrm{m}$.

\subsection{Untersuchungen mononukleärer Zellen aus peripherem Blut von Erwachsenen und Kindern}

Zirkulierende endotheliale Vorläuferzellen im peripheren Blut von Erwachsenen wurden vor einigen Jahren beschrieben (Salven et al., 2003; Religa et al., 2005), jedoch gibt es keine Hinweise auf zirkulierende lymphendotheliale Vorläuferzellen. Meine Untersuchungen an Mausembryonen haben gezeigt, dass es mesenchymale Zellen mit lymphendothelialen Charakteristika gibt. Da solche Zellen mobil sind und möglicherweise auch ins Blut gelangen können, habe ich peripheres kindliches Blut untersucht. Die Wahrscheinlichkeit, Vorläuferzellen zu finden, dürfte bei Kindern höher sein als bei Erwachsenen. Hierfür habe ich periphere mononukleäre Blutzellen (PBMCs) aus Vollblut 
von Kindern und aus Buffy Coats von erwachsenen Blutspendern isoliert und lymphendotheliale Marker analysiert. Buffy Coats habe ich für die Etablierung der Techniken benutzt, da größere Mengen zur Verfügung standen als von kindlichem Blut.

\subsubsection{Reinheitsbestimmung und Quantifizierung der isolierten RNA aus PBMCs}

Um RNA-Expression von Lyve-1, Prox1 und Podoplanin in zirkulierenden PBMCs untersuchen zu können, habe ich RNA aus PBMCs isoliert (siehe 3.4.1). Für die weiteren Analysen war es notwendig, zunächst Verunreinigungen auszuschließen. Nach Extraktion der RNA aus humanem Blut wurden die Proben in einem Agarosegel aufgetrennt, um Verunreinigungen oder Degradation der gewonnenen RNA zu erkennen. Bei sauberer Isolierung sind die $18 \mathrm{~S}-(1,9 \mathrm{~kb})$ und 28S- $(5,1 \mathrm{~kb})$ Banden der ribosomalen RNA klar voneinander getrennt (Abb. 23). Eine genauere Reinheitsbestimmung mit Hilfe des Spektralphotometers wurde mittels einer Quotientenbildung der $\mathrm{OD}_{260}$ und $\mathrm{OD}_{280}$ durchgeführt. Die Werte lagen zwischen 1,6 und 2,0, so dass keine Kontamination durch Proteine vermutet werden musste. Proben, bei denen die Werte unterhalb dieses Bereichs lagen, wurden für eine weitere Verwendung ausgeschlossen. Die Quantifizierung der extrahierten RNA wurde ebenfalls mit Hilfe des Spektralphotometers durchgeführt. Die Konzentrationen lagen zwischen 5 und 1184 ng/ $\mu 1$. Bei dem kindlichen Material waren die Konzentrationen aufgrund der geringen Blutmenge oftmals im unteren Bereich.

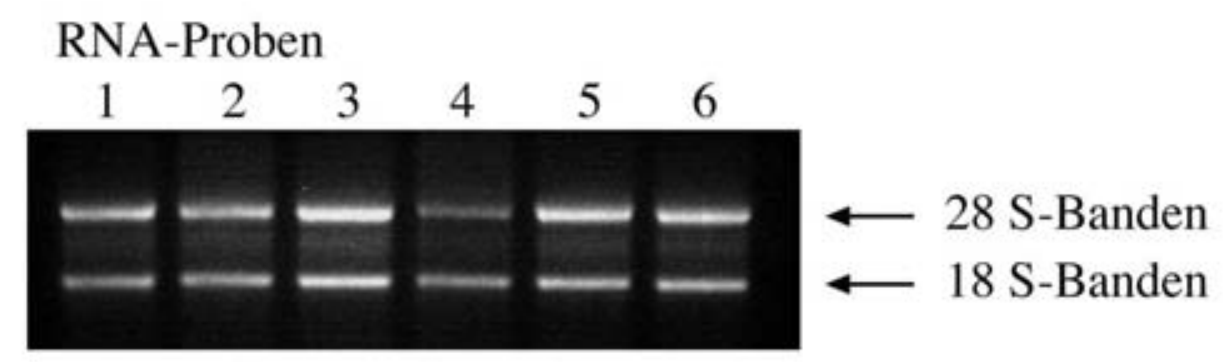

Abb. 23: Auftrennung der extrahierten RNA in einem Agarosegel. Die 18S- und 28S-Banden sind deutlich getrennt. 


\subsubsection{Expressionsnachweis von Lyve-1, Prox1 und Podoplanin auf mRNA-Ebene}

Die isolierte RNA aus PBMCs wurde in einer RT-PCR (siehe 3.4.5 und 3.4.6) eingesetzt, um Transkripte von Lyve-1, Prox1 und Podoplanin nachzuweisen. Diese PCR-Produkte wurden auf einem Agarosegel aufgetrennt und besaßen folgende Größen:

$\begin{array}{ll}\text { Lyve-1 } & 273 \mathrm{bp} \\ \text { Prox1 } & 360 \mathrm{bp} \\ \text { Podoplanin } & 299 \mathrm{bp} \\ \text { GAPDH (Positivkontrolle) } & 600 \mathrm{bp} .\end{array}$

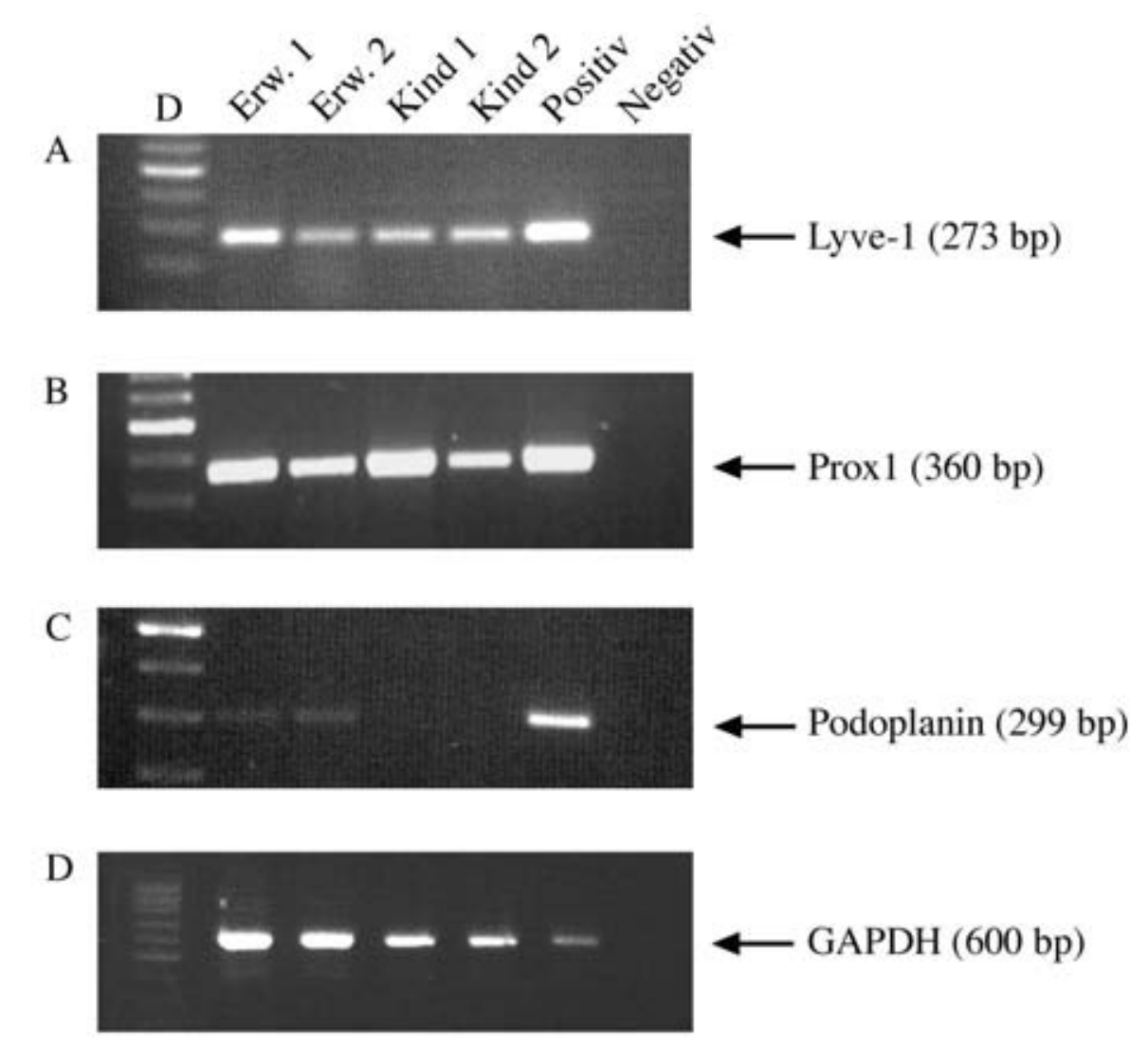

Abb. 24: Nachweis von Lyve-1-, Prox1- und Podoplanin-mRNA mittels RT-PCR. A) Lyve-1Expression ist bei den Proben von Erwachsenen und Kindern positiv. B) Prox1-Produkte wurden sowohl aus PBMCs von Erwachsenen als auch Kindern generiert, während C) eine PodoplaninExpression nur sehr schwach bei den Erwachsenen nachgewiesen werden konnte. D) Als Kontrolle wurde die RT-PCR unter Verwendung von GAPDH-Primern und RNA aus PBMCs von Erwachsenen und Kindern durchgeführt. Für Nachweise der Prox1-, Lyve-1- und Podoplaninspezifischen Fragmente wurde RNA aus Gallengangskarzinomgewebe eingesetzt. NegativKontrollen wurden ohne RNA durchgeführt. D, DNA-Größenstandard. 
Lyve-1 war ein Gen, das in nahezu allen untersuchten Proben der Kinder und der Erwachsenen eine Expression zeigte (Abb 24A). Prox1-Expression konnte ich in den meisten (89\%) Proben der Kinder und Erwachsenen nachweisen (Abb. 24B), während Podoplanin in keiner der kindlichen Proben, wohl aber schwach bei den Erwachsenen exprimiert wurde (Abb. 24C). Andeutungsweise traten sehr schwache Banden bei einigen kindlichen Probanden auf, die ich aber in Wiederholungsversuchen nicht bestätigen konnte. Die Untersuchungen zeigen, dass die LEC-Marker Lyve-1 und Prox1 in PBMCs von Erwachsenen und Kindern nachweisbar sind.

\subsubsection{Lyve-1-positive PBMCs von Erwachsenen}

Für einen Nachweis Lyve-1-positiver Zellen auf Proteinebene habe ich isolierte PBMCs von Erwachsenen mittels magnetischer Zellseparation in Lyve-1-positive und negative Zellpopulationen getrennt und anschließend analysiert (siehe 3.3.5 und 3.3.6).

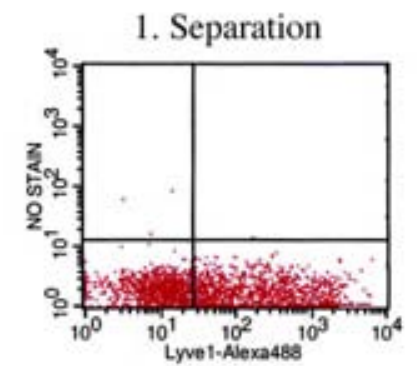

A

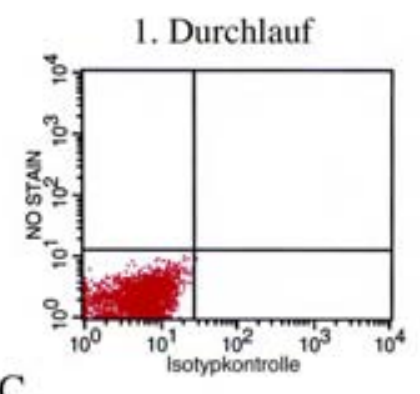

$\mathrm{C}$

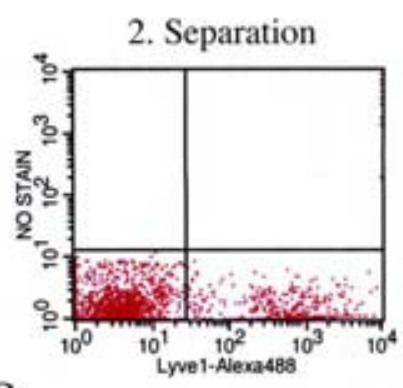

B

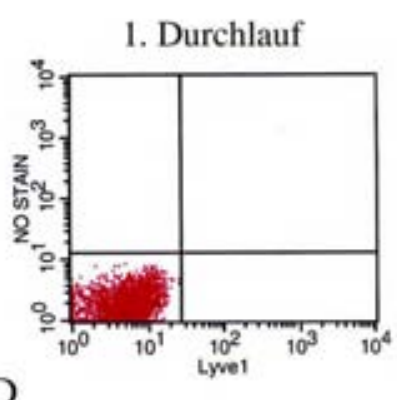

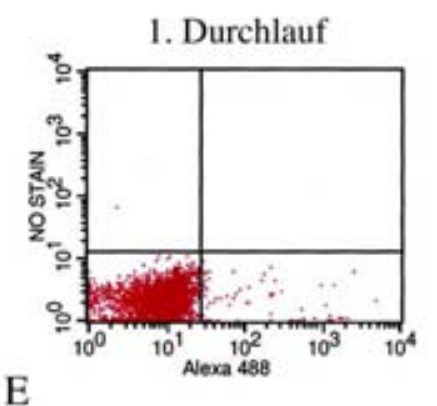

E

Abb. 25: FACS-Analysen von separierten PBMCs, gefärbt mit dem Primärantikörper Lyve-1 und einem Alexa 488-konjugierten Sekundärantikörper. A) Die 1. MACS-Separation enthält Lyve-1-negative Zellen (Quadrant unten links) und Lyve-1-positive Zellen (Quadrant unten rechts). B) Die 2. Zellseparation enthält ebenfalls Lyve-1-positive und -negative Zellen, wobei es deutlich weniger positive Zellen im Vergleich zur 1. Separation gibt. C-E) Negativkontrollen mit C) Isotypkontroll-Antikörper, D) Anti-Lyve-1, E) Alexa 488-konjugiertem Sekundärantikörper. 
Die erste Zellseparation enthielt deutlich mehr Lyve-1-positive Zellen als die zweite Separation (Abb. 25A,B). Die Kontrollen mit nur primärem oder sekundärem Antikörper ergaben keine markierten Zellpopulationen (Abb. 25C-E). Der sekundäre Alexa 488konjugierte Antikörper detektierte einige wenige Zellen, die mit dem antigenbindenden Fab-Fragment eine Bindung eingegangen sein könnten und deshalb ein unspezifisches Signal erzeugten.

\subsubsection{Untersuchungen von kindlichen PBMCs mit Lyve-1, Prox1 und CD31 Antikörpern}

Im Blut von Erwachsenen konnte ich Lyve-1-positive Zellen detektierten (4.3.3). Um zirkulierende lymphendotheliale Vorläuferzellen im Blut von Kindern zu untersuchen, habe ich Blutausstriche und Zytospins mit den Lymphendothelmarkern Anti-Lyve-1, AntiProx1 und dem Pan-Endothelmarker Anti-CD31 gefärbt.

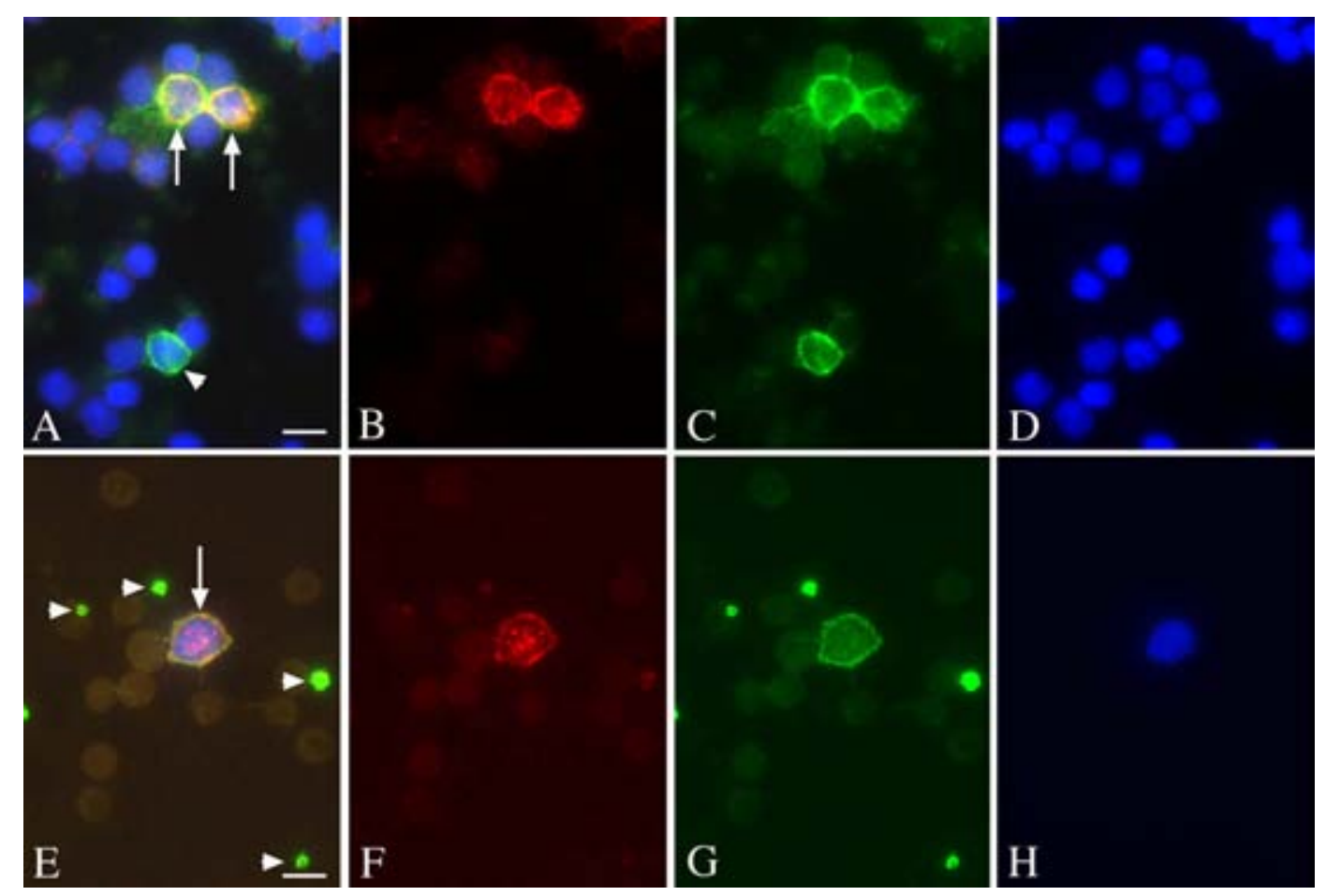

Abb. 26: Anti-Lyve-1 bzw. Prox1 / CD31-Doppelfärbungen von Blutausstrichen und Zytospins. A-D) Zytospin gefärbt mit Anti-Lyve-1 (rot) und CD31 (grün). Zwei Zellen exprimieren Lyve-1 und CD31 (Pfeile), während eine andere Zelle nur CD31-positiv ist (Pfeilkopf). E-H) Blutausstrich gefärbt mit Anti-Prox1 (rot) und CD31 (grün). Eine Zelle exprimiert beide Marker (Pfeil). Sie ist von vier Thrombozyten mit CD31-Markierung umgeben (Pfeilköpfe). Die Dapi-Gegenfärbung (blau) markiert alle Zellkerne. Balken in A,E) $10 \mu \mathrm{m}$. 
Es zeigte sich, dass Zellen, die positiv für Lyve-1 waren, auch den allgemeinen Endothelmarker CD31 exprimierten (Abb. 26A-D). Eine Gegenfärbung mit Dapi markierte alle Zellkerne der Blutzellen. Andere Zellpopulationen mit nur einem der Marker oder auch ohne Expressionsprofil der angewandten Antikörper waren ebenfalls im Blut vorhanden. Doppelfärbungen mit Prox1 und CD31 zeigten ebenfalls Zellen, die beide Marker exprimierten (Abb. 26E-H). Die Anzahl von Leukozyten im Blut von Säuglingen und Kleinkindern beträgt ca. 12.000 pro $\mu 1$ Blut, Erwachsene besitzen dagegen nur etwa 7.000 (Mittelwerte). Abweichungen sind je nach Tageszeit und Funktionszustand des Organismus möglich (Weiss und Jelkmann, 1997). Granulozyten wurden bei der Isolierung der PBMCs herauszentrifugiert, so dass nur noch ca. 40\% der Leukozyten (Monozyten und Lymphozyten) in der Zellsuspension enthalten waren. Die von mir untersuchten Blutproben der Kinder enthielten zwischen 400 und 5000 (Mittelwert 1.400) PBMCs pro $\mu 1$ Blut. Durchschnittlich war eine von zwölf PBMCs Lyve-1 / CD31-doppelt positiv ( $\underline{\underline{\Lambda}}$ 117 Zellen / $\mu 1$ ), während nur etwa jede 40. Zelle Prox1 und CD31 koexprimierte ( $\wedge 35$ Zellen $/ \mu 1$ ). Die Zellen besaßen einen runden, ca. $10 \mu \mathrm{m}$ großen Zellkern und einen dünnen Zytoplasmasaum, so dass sie histologisch der Gruppe der mittelgroßen Lymphozyten zuzuordnen sind.

\subsubsection{Untersuchungen von kindlichen PBMCs mit Lyve-1, Prox1 und CD45 Antikörpern}

Für die weitere Charakterisierung der PBMCs aus Kinderblut habe ich die Lymphendothelmarker Lyve-1 und Prox1 mit dem allgemeinen Leukozytenmarker CD45 auf Blutausstrichen und Zytospins angewendet. Einige Zellen koeprimierten Lyve-1 und CD45 (Abb. 27A-D). Ebenso konnte ich Zellen mit Prox1- und CD45-Expression nachweisen (Abb. 27E-H). Die quantitative Auswertung zeigte, dass etwa eine von acht PBMCs beide Marker koexprimierte ( $\underline{\underline{\Lambda}} 175$ Zellen / $\mu$ l). Es traten aber auch Zellen auf, die nur einen der beiden Lymphendothelmarker, aber kein CD45 exprimierten. Außerdem war die Prox1-Expression bei einigen Zellen nicht wie erwartet im Zellkern, sondern im Zytoplasma lokalisiert. 


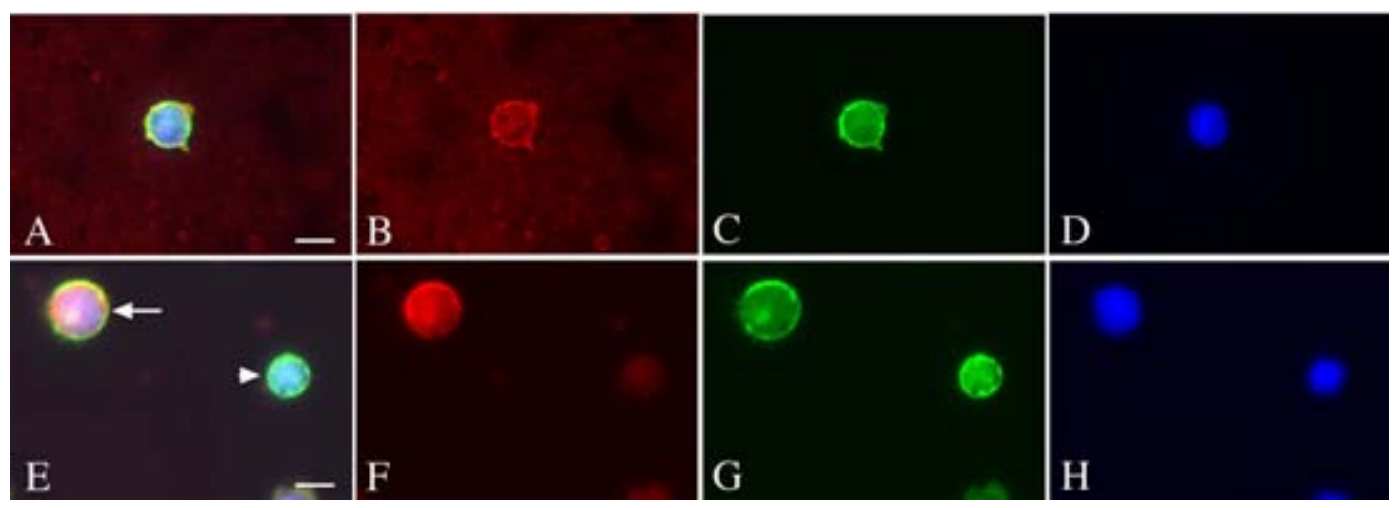

Abb. 27: Anti-Lyve-1 bzw. Prox1 / CD45-Doppelfärbungen von Blutausstrichen und Zytospins. A-D) Blutausstrich gefärbt mit Lyve-1 (rot) und CD45 (grün). Eine Zelle exprimiert Lyve-1 und CD45. E-H) Zytospin gefärbt mit Anti-Prox1 (rot) und CD45 (grün). Eine Zelle koexprimiert beide Marker (Pfeil), während eine zweite Zelle nur positiv für den Leukozytenmarker CD45 ist (Pfeilkopf). Die Gegenfärbung mit Dapi (blau) markiert alle Zellkerne. Balken in A,E) $10 \mu \mathrm{m}$.

\subsubsection{Untersuchungen von kindlichen PBMCs mit Lyve-1 und Podoplanin Antikörpern}

Weitere Untersuchungen der PBMCs von Kindern habe ich mit Lyve-1 und einem weiteren Lymphendothelmarker, Podoplanin, durchgeführt. Podoplanin wird im Lymphendothel, aber auch in einigen Epithelzellen (siehe 1.4.4) exprimiert. Die immunhistologischen Färbungen von Blutpräparaten mit Anti-Lyve-1 und Podoplanin resultierte in der Detektion einiger weniger mononukleärer Zellen mit einer Koexpression beider Marker (Abb. 28). Auszählungen von PBMCs der Zytospins und einer anschließenden Hochrechnung haben gezeigt, dass nur ca. eine von eintausend Zellen Lyve-1 und Podoplanin koexprimierte ( $\underline{\underline{\Lambda}}$ 1,4 Zellen / $\mu$ l). Auf RNA-Ebene konnte ich keine Podoplaninexpression in PBMCs aus Kinderblut nachweisen (siehe 4.3.2). 

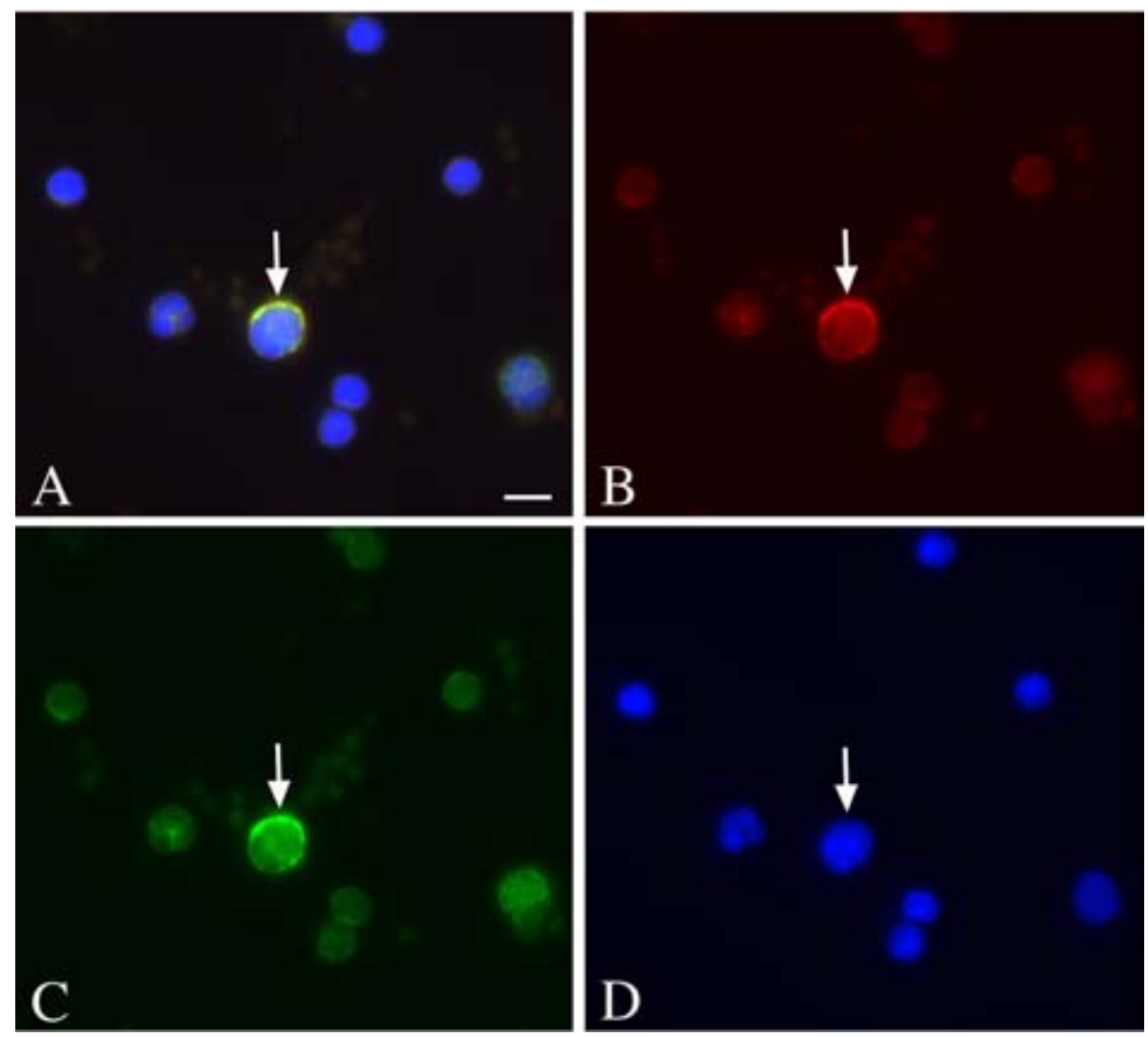

Abb. 28: Anti-Lyve-1 / Podoplanin-Doppelfärbung von Zytospins. A-D) Eine Zelle ist Lyve-1(rot) und Podoplanin- (grün) positiv (Pfeil). Die Dapi-Gegenfärbung (blau) markiert alle Zellkerne. Balken in A) $10 \mu \mathrm{m}$.

\subsubsection{Untersuchungen von kindlichen PBMCs mit Lyve-1 und CD34 Antikörpern}

CD34 ist ein Marker für hämatopoetische Vorläufer- (Stamm-) zellen, detektiert aber ebenfalls Endothelzellen der Blutgefäße. Eine Doppelfärbung der Blutpräparate habe ich mit Lyve-1 oder Prox1 und CD34 durchgeführt. Die hier untersuchten peripheren Blutzellen von Kindern exprimierten Lyve-1 bzw. Prox1 nicht zusammen mit CD34. Es wurden fast ausschließlich Blutzellen gefunden, die entweder Lyve-1, Prox1 oder CD34positiv waren. Lediglich in einem einzigen Fall konnte ich eine Koexpression von CD34 mit dem Lymphendothelmarker Lyve-1 beobachten (Abb. 29). 


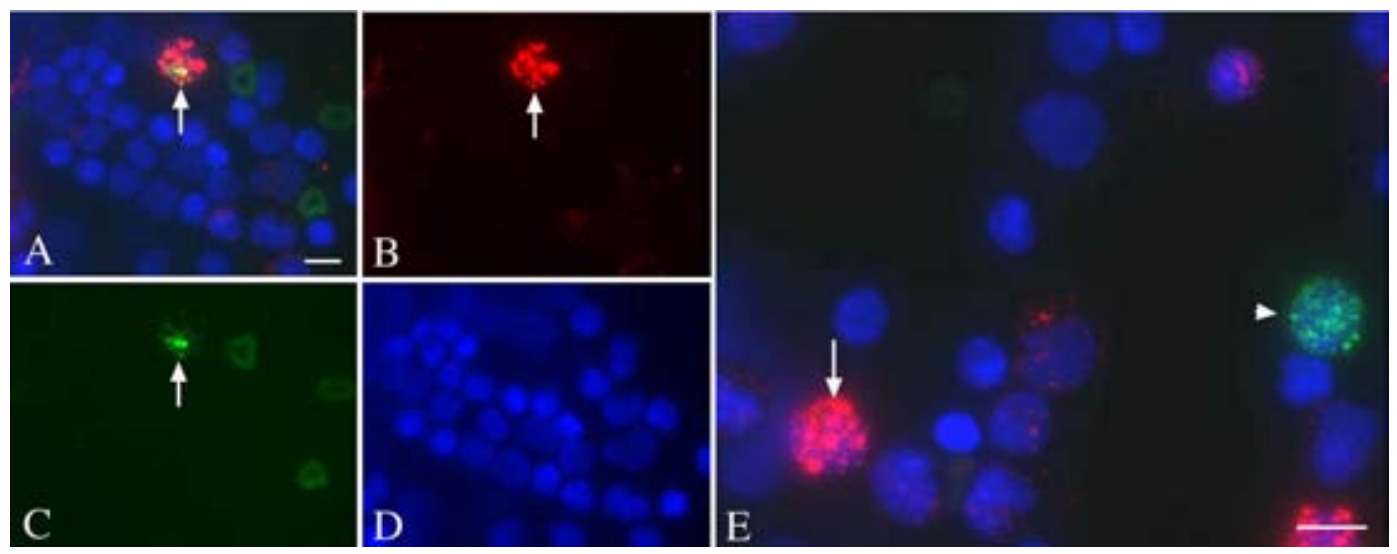

Abb. 29: Anti-Lyve-1 bzw. Prox1 / CD34-Doppelfärbungen von Zytospins. A-D) Die Abbildung zeigt die einzige Zelle, die Lyve-1 (rot) und CD34 (grün) koexprimierte (Pfeil). E) Zellen exprimieren entweder Prox1 (rot) (Pfeil) oder CD34 (grün) (Pfeilkopf). Die Gegenfärbung mit Dapi (blau) markiert alle Zellkerne. Balken in A,E) $10 \mu \mathrm{m}$.

Meine Untersuchungen mononukleärer Zellen aus peripherem Blut von Kindern haben gezeigt, dass die Lymphendothelmarker Lyve-1, Prox1 und Podoplanin sowie der PanEndothel- als auch der Pan-Leukozytenmarker CD45 von zirkulierenden Zellen koexprimiert werden. Einige humane PBMCs weisen also ähnliche Expressionsmuster wie die mesenchymalen Einzelzellen von Mäusen auf. Da die Zellen kein CD34 exprimieren, scheinen sie in ihrer Differenzierung bereits fortgeschritten zu sein.

\subsection{Suche nach neuen Lymphangiogenese-Genen}

Bisher sind nur wenige Moleküle bekannt, die einen maßgeblichen Einfluß auf die Lymphangiogenese ausüben. Für die Identifizierung neuer relevanter Gene werden häufig Genchip-Analysen eingesetzt, die auch in unserer Arbeitsgruppe mit Blut- und Lymphendothelzellen (LECs) durchgeführt wurden. Die Isolierung der LECs erfolgte durch meine Kollegin Frau Dr. Maria Papoutsi. Die Microarray-Anlaysen wurden am Zentralen Transkriptomlabor der Universitätsmedizin Göttingen durchgeführt. Ich habe die Zellen für die folgenden Untersuchungen verwendet.

\subsubsection{Vergleich humaner Lymphendothelzellen mit venösen Blutendothelzellen}

Die Abbildung 30 zeigt humane venöse Nabelschnur-Endothelzellen (HUVECs) und LECs in vitro. Die Zellen bilden einen Monolayer mit Kopfsteinplaster-artiger 
Morphologie. Doppelfärbungen mit dem Pan-Endothelmarker CD31 und dem Lymphendothelmarker Prox1 zeigten, dass beide Zelllinien CD31 exprimieren (Abb. 30B,D), wobei die Expression in LECs deutlich geringer ausfiel. Nur die LECs waren Prox1-positiv (Abb. 30D). Durch die Prox1-Expression konnte ich bei meinen folgenden Untersuchungen gewährleisten, dass es sich um eine reine Lymphendothelzellkultur handelte.

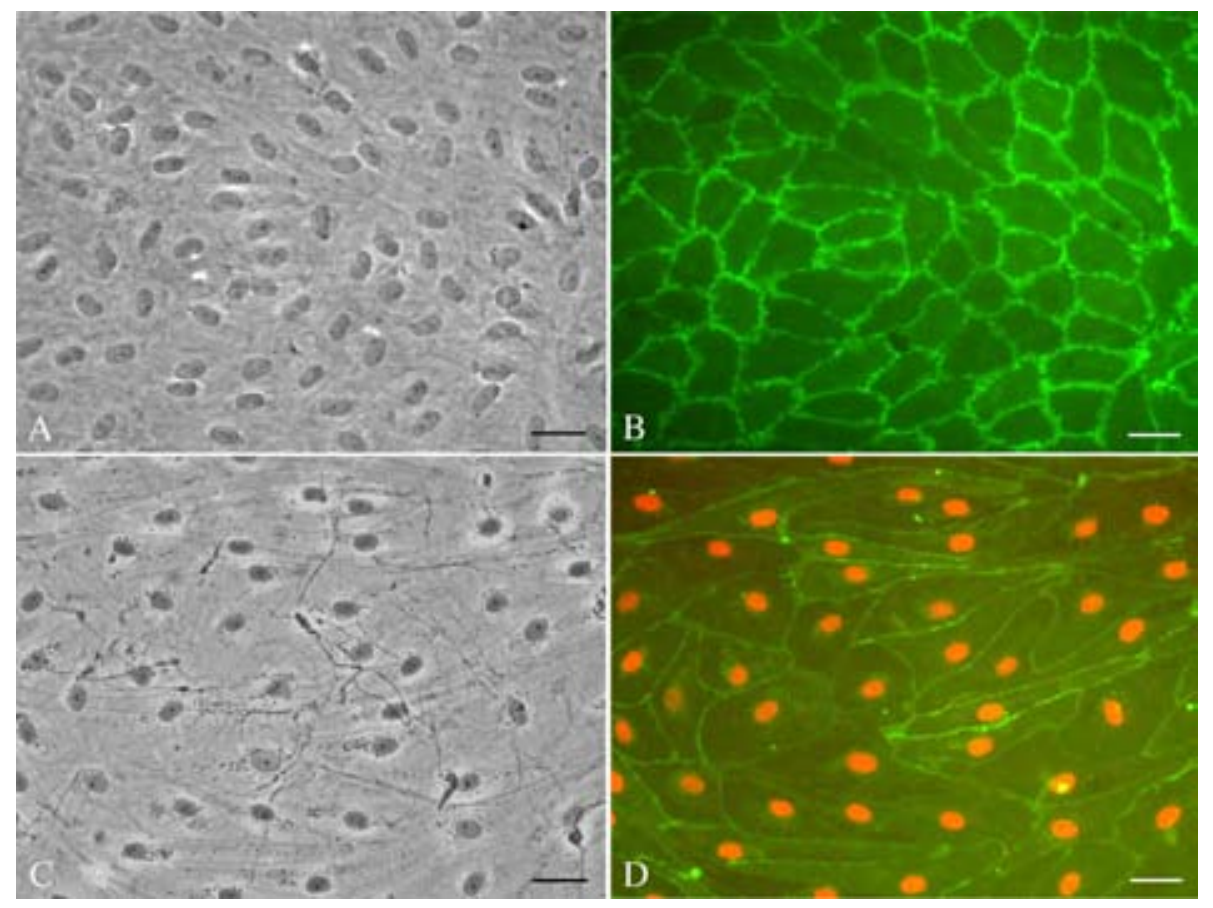

Abb. 30: Blut- (HUVECs) und Lymphendothelzellen (LECs) in vitro. A) HUVECs in phasenkontrast-mikroskopischer Darstellung. B) Immunzytologie der HUVECs mit anti-CD31 (grün) und anti-Prox1 (rot). Die Zellen exprimieren CD31 und sind Prox1-negativ. C) LECs in phasenkontrast-mikroskopischer Darstellung. D) Immunzytologie der LECs mit anti-CD31 (grün) und anti-Prox 1 (rot). Die Zellen koexprimieren beide Marker. Balken in A-D) $20 \mu \mathrm{m}$.

Duch einen Vergleich des Transkriptoms von LECs und HUVECs erhielten wir eine Liste von Genen, die im Lymphendothel hoch exprimiert waren. Zu diesen Molekülen gehörte Peroxisome Proliferator-activated Receptor gamma (PPAR $\gamma$ ), der in LECs 64-mal höher exprimiert war als in HUVECs. Aus später noch zu erläuternden Gründen habe ich PPAR $\gamma$ in LECs näher untersucht. 


\subsubsection{Quantifizierung der RNA-Expression von PPAR $\gamma$ in LECs und HUVECs}

Die Mitglieder der PPAR-Genfamilie werden im Zusammenhang mit der Angiogenese diskutiert. Um die Ergebnisse der Genchipanalyse zu validieren, habe ich Real-time RTPCR-Untersuchungen mit der RNA von LECs und HUVECs durchgeführt. Die Ergebnisse zeigen, dass in den drei untersuchten LEC-Präparationen PPAR $\gamma$ auf einem konstanten Niveau nachzuweisen war, während in HUVECs die Expression des PPAR $\gamma$-Gens unter der Nachweisgrenze lag (Abb. 31). Da PPAR $\gamma$ bei der Entwicklung von Adipozyten eine essentielle Rolle spielt, aber bei der Entwicklung von LECs noch nicht untersucht worden ist, habe ich Untersuchungen dieses Moleküls bei Knock-out-Mäusen durchgeführt.

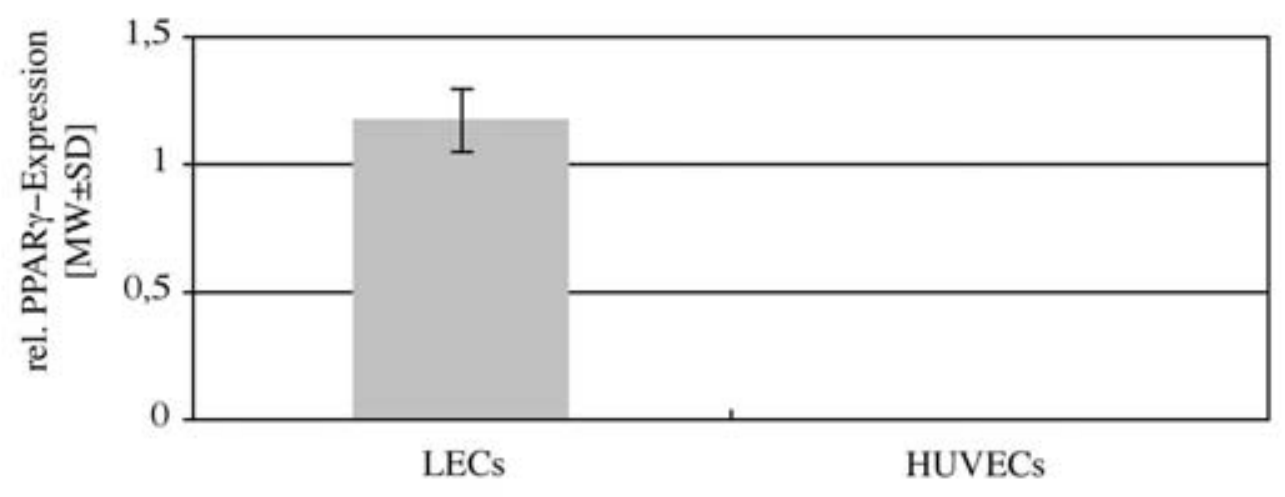

Abb. 31: Relative PPAR $\gamma$-Expression von LECs und HUVECs. Dargestellt ist der Mittelwert (MW) und die Standardabweichung (SD) der relativen PPAR $\gamma$-Expression in LECs. In HUVECs liegt die Expressionsrate unter der Nachweisgrenze. Es wurden jeweils 3 Proben für die Analyse verwendet.

\subsection{Lymphgefäßentwicklung bei PPAR $\gamma$-knock-out-Mäusen}

Mit Hilfe meiner neu etablierten Schnittkultur an Mausembryonen ist es möglich, weitere relevante Gene für die Lymphgefäßentwicklung auch bei solchen Mäusen zu identifizieren, die aufgrund von Gefäßdefekten vor ET 12,5 sterben. Da unsere Untersuchungen gezeigt haben, dass PPAR $\gamma$ im Lymphendothel hoch exprimiert ist und PPAR $\gamma$-knock-out-Mäuse frühembryonal (ET 10) sterben (Barak et al., 1999), habe ich die Schnittkultur bei diesen Mäusen im Labor von Herrn Prof. Dr. W. Wahli (Universität Lausanne, Schweiz) durchgeführt. 


\subsubsection{Genotypisierung der Mausembryonen}

Für die Identifizierung von Knock-out-Mäusen habe ich eine Gewebeprobe (Kopf oder Teil der Schwanzknospe) jeder Maus auf das $P P A R \gamma$-Gen hin getestet. Für das WildtypAllel und das mutierte Allel habe ich PCR-Analysen mit den genannten Oligonukleotiden (siehe 2.6) durchgeführt. Das PCR-Produkt für das Wildtypallel hatte eine Größe von 424 bp (Primer in Exon 2 / Intron 2), das mutierte Allel 850 bp (Primer in veränderter Sequenz von Intron 1 / Intron 2) (Abb. 32). Insgesamt wurden 54 Mausembryonen (ET 9,5: $\mathrm{n}=21$; ET 10,5: $\mathrm{n}=4$; ET 11,5: $\mathrm{n}=5$; ET 12,5: $\mathrm{n}=13$; ET 13,5: $\mathrm{n}=11$ ) genotypisiert. Die Genotypisierung der Mausembryonen ergab, dass diese entweder einen homozygoten Wildtyp besaßen $(n=19)$, oder aber heterozygot waren $(n=34)$. Nur ein Tier des ET 12,5 wies das defekte PPAR $\gamma$-Allel homozygot auf. Der Embryo war aber so stark retardiert und degeneriert, dass keine weiteren Untersuchungen möglich waren.

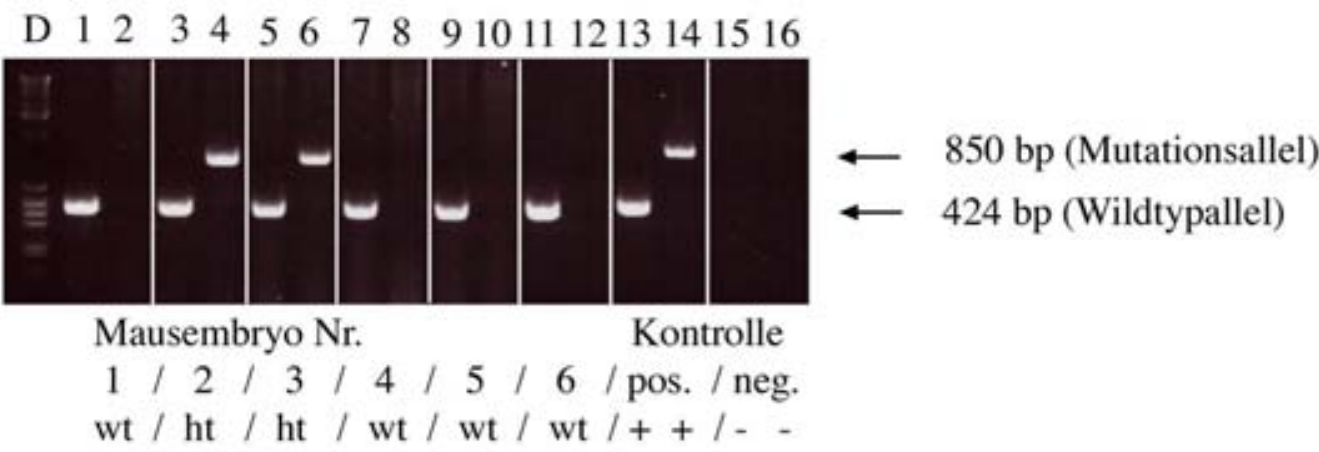

Abb. 32: Gelelektrophoretische Auftrennung von PCR-Produkten für den Nachweis des PPAR $\gamma$-Wildtyp- und Mutationsallels. Banden Nr. 1, 3, 5, 7, 9, 11 und 13 weisen jeweils das Wildtypallel (Größe 424 bp) auf, die Banden Nr. 4, 6 und 14 das Mutationsallel (Größe 850 bp), wobei 13 und 14 die Positivkontrollen, 15 und 16 die Negativkontrollen darstellen. Demnach sind die Mausembryonen Nr. 1, 4, 5 und 6 Wildtypmäuse (wt), Nr. 2 und 3 Mäuse mit heterozygotem Genotyp (ht). D, DNA-Größenstandard.

Dies zeigt, dass PPAR $\gamma$-knock-out-Mäuse entgegen den publizierten Daten (Barak et al., 1999) bereits vor ET 9,5 absterben und somit für die in vitro Untersuchungen der Lymphangiogenese nicht zur Verfügung standen. Die Kultivierung der Schnitte erfolgte immer unmittelbar nach Entnahme der Embryonen, also vor der Genotypisierung. Ich habe die Schnittkulturen somit an Wildtypmäusen und heterozygoten Tieren durchgeführt. 
Weiterhin habe ich einen makroskopischen und immunhistologischen Vergleich der Embryonen vorgenommen.

\subsubsection{Untersuchung der lymphangiogenen Potenz von Wildtyp und heterozygoten Mausembryonen an Schnittkulturen}

Die Schnittkulturen der Embryonen wurden wie unter 3.2.3 beschrieben durchgeführt. Da die Mausembryonen an ET 9,5 noch sehr klein waren, wurden sie lediglich in $5-7$ Abschnitte unterteilt (siehe Schema in Abb. 6). Ich habe die Schnittkulturen unmittelbar nach Entnahme mit 25 Embryonen durchgeführt, da die Genotypisierung erst einen Tag später erfolgte und ich auch homozygote Knock-out-Mäuse erwartete. Einige Mausembryonen mit heterozygotem Genotyp waren leicht retardiert. Diese wurden dann als ganze Embryonen (aber ohne Kopf) in Kultur genommen und nicht in Schnitte unterteilt. Anhand der Schnitte konnte ich beobachten, dass sich sowohl bei den Wildtypmäusen als auch bei den heterozygoten Tieren Lyve-1 / Prox1-positive Lymphgefäße entwickelten (Abb. 33). Zwischen den beiden Genotypen konnte ich keine Unterschiede festellen. Ebenso entwickelten sich Blutgefäße in netzartigen Strukturen, die nur CD31 exprimierten. 

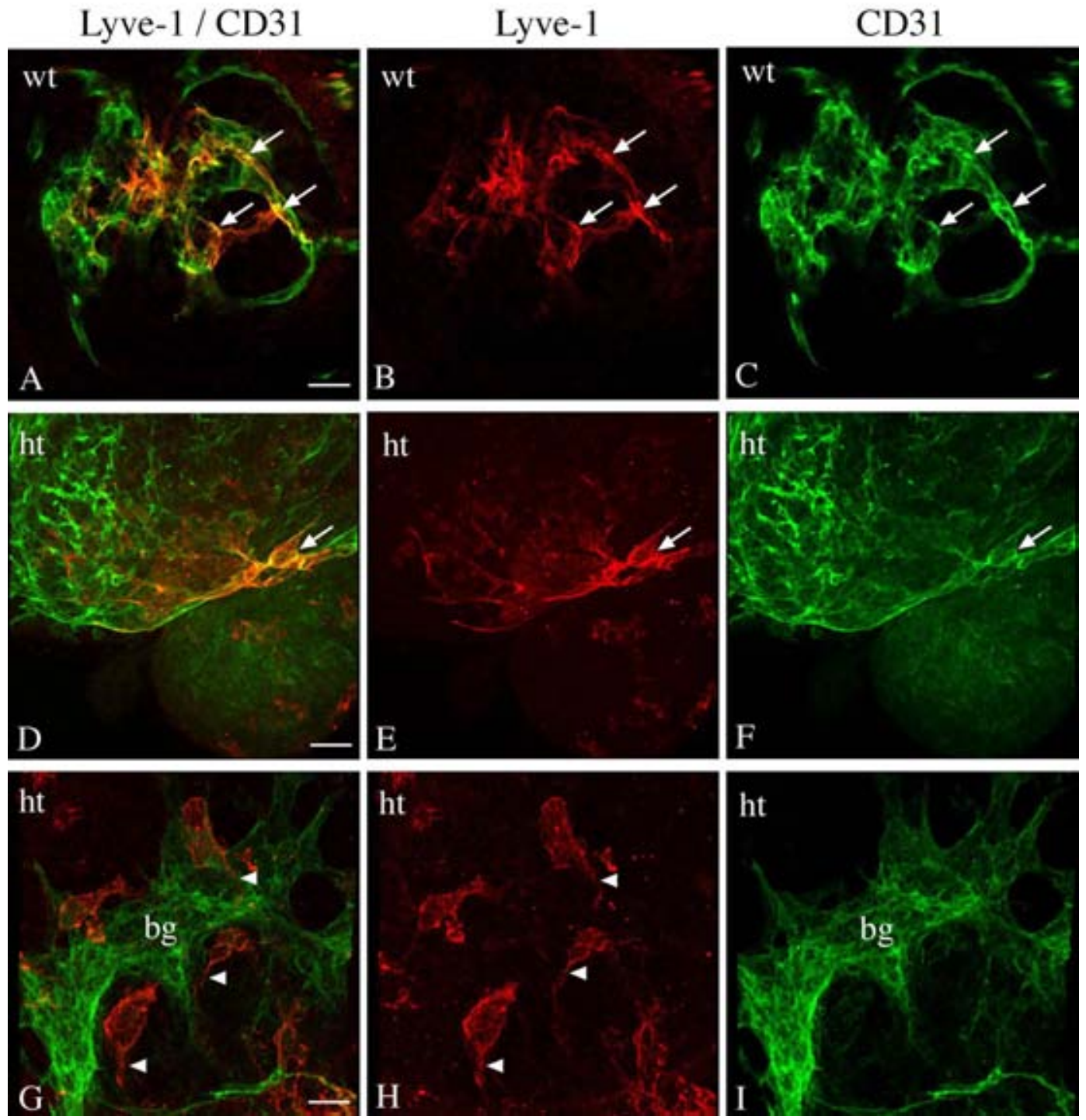

Abb. 33: Anti-Lyve-1 / CD31-Färbung der Schnittkulturen von Wildtyp (wt) und heterozygoten (ht) PPAR $\gamma$-Mäusen. A-C) Lyve-1 (rot) und CD31- (grün) positive Lymphgefäße in Wildtypmäusen (Pfeile). D-F) Lymphgefäßentwicklung ist auch bei heterozygoten Mausembryonen zu beobachten (Pfeil). G-I) Lyve-1- positive Strukturen sind um Blutgefäße (bg) herum gruppiert und besitzen sprossenartige Fortsätze (Pfeilköpfe). CD31-positive Blutgefäße sind in allen Präparaten vorhanden. Balken in A,D) $100 \mu \mathrm{m}, \mathrm{G}) 50 \mu \mathrm{m}$.

\subsubsection{Makroskopische und immunhistologische Untersuchungen von Wildtyp und heterozygoten Mausembryonen}

Um makroskopische Veränderungen bei Wildtyp und heterozygoten PPAR $\gamma$-Mäusen aufzeigen zu können, habe ich einen Vergleich von ET 13,5 Embryonen durchgeführt. Ich konnte keine Retardierung oder andere morphologische Auffälligkeiten bei den heterozygoten Mäusen im Vergleich zu den Wildtypmäusen festgestellen. Auch 
Veränderungen am Gefäßsystem waren nicht ersichtlich (Abb. 34A,B). Die Entwicklung der Lymphgefäße bei transgenen PPAR $\gamma$-Mäusen habe ich mit Hilfe der in 3.1.4.1 und 3.1.4.2 beschriebenen immunhistologischen Methoden untersucht. Vergleiche von Paraffinpräparaten zeigten bei Mäusen beider Genotypen gleichermaßen eine Entwicklung der jugulären Lymphsäcke und den Nachweis Lyve-1-positiver Einzelzellen im Mesenchym der Hautanlage, des Mediastinums und der primitiven Meningen (Abb. 34C,D).

Ähnliche Ergebnisse konnte ich mittels Immunfluoreszenz-Doppelfärbungen mit den Antikörpern gegen Lyve-1 und CD31 generieren. Die jugulären Lymphsäcke sowie Teile der Kardinalvenen der Wildtyp-Tiere wiesen eine Koexpression beider Marker auf. Allerdings exprimierten die Lymphsackendothelzellen der heterzygoten Mäuse den PanEndothelmarker CD31 nicht so stark, wie die der Wildtypmäuse. In einigen Fällen fehlte das CD31-Signal völlig (Abb. 34E-J). Einen Unterschied von Lyve-1-positiven Einzelzellen in der Dermisanlage konnte ich in Anzahl und Morphologie nicht festgestellen.

Meine Untersuchungen der transgenen PPAR $\gamma$-Mausembryonen haben gezeigt, dass es nicht möglich war, homozygote Knock-out-Mäuse als Nachkommen zu erhalten und für in vitro Versuche und immunhistologische Charakterisierungen einzusetzen. Heterozygote Embryonen lassen im Vergleich zu Wildtypmäusen makroskopisch und immunhistologisch keine Unterschiede bei der Lymphangiogenese erkennen. 

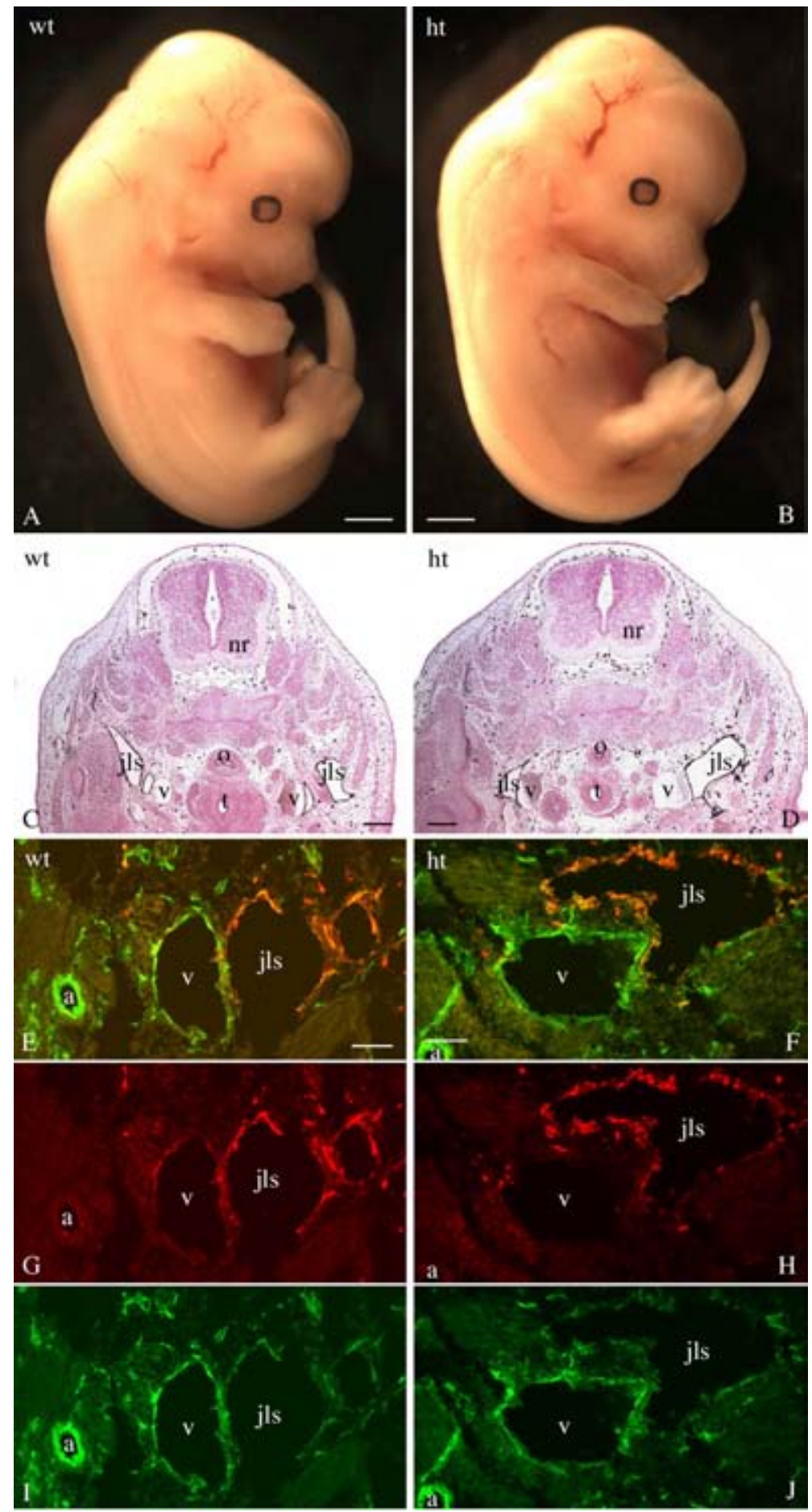

Abb. 34: Makroskopischer und mikroskopischer Vergleich von PPAR $\gamma$-Wildtyp- (wt) und heterozygoten (ht) ET 13,5 Mäusen. A,B) Die Mausembryonen zeigen makroskopisch keine auffälligen Unterschiede zwischen den zwei Genotypen. C,D) Lyve-1-Färbung von Paraffinpräparaten. Die jugulären Lymphsäcke (jls), Lymphgefäße (lg) und Einzelzellen in der Hautanlage sind Lyve-1-positiv; nr, Neuralrohr; o, Oesophagus; t, Trachea. E-J) Lyve-1 (rot) / CD31- (grün) Doppelfärbung von Kryopräparaten. Bei den Wildtypembryonen (wt) exprimieren die jugulären Lymphsäcke (jls) und Teile der Kardinalvenen (v) beide Marker. Dagegen weisen die Lymphsackendothelzellen der heterozygoten Mäuse (ht) so gut wie keine CD31-Expression auf, die Kardinalvenen exprimieren kein Lyve-1. Balken in A,B) $1 \mathrm{~mm}, \mathrm{C}, \mathrm{D}) 300 \mu \mathrm{m}, \mathrm{E}, \mathrm{F}) 150 \mu \mathrm{m}$. 


\section{Diskussion}

Das Lymphgefäßsystem ist aufgrund seiner physiologischen und pathophysiologischen Funktionen für Flüssigkeits-Homöostase, Immunabwehr, Entzündungsreaktionen und Tumormetastasierung von großer Bedeutung (Witte et al., 2001; Wilting et al., 2005). Das Wissen über die Entwicklung, Struktur und Funktion von Lymphgefäßen sowie der molekularen Charakteristika von Lymphendothelzellen hat in den letzten Jahren aufgrund der Identifizierung spezifischer Marker für Lymphendothelzellen erheblich zugenommen (Jeltsch et al., 2003; Alitalo et al., 2005). Die Frage des embryonalen Ursprungs des Lymphgefäßsystems wird trotz alledem bis heute kontrovers diskutiert. Es sind bislang auch nur wenige Moleküle bekannt, die die Entwicklung und Differenzierung von Lymphendothelzellen steuern; wie z.B. der Vascular Endothelial Growth Factor-C (VEGFC) und die Transkriptionsfaktoren Prox1, FoxC2 und Sox18 (Witte et al., 2006). Ziel meiner Arbeit war, den zellulären Ursprung der Lymphgefäße bei Mäusen zu untersuchen und neue Lymphangiogenesegene zu definieren.

\subsection{Lymphangiogenese}

Die Entwicklung von Lymphgefäßen ist weit weniger untersucht als die Bildung der Blutgefäße. Bei dem ersten Schritt der Blutgefäßentwicklung, der Vaskulogenese, bilden endotheliale Vorläuferzellen (Angioblasten) durch Proliferation und Differenzierung ein primitives Gefäßnetzwerk. Durch Sprossung der Endothelzellen verzweigt sich dieses Netzwerk anschließend weiter und vergrößert sich (Angiogenese) (Hanahan, 1997; Ferrara und Alitalo, 1999; Yancopoulos et al., 2000). Ähnliche Prozesse sind vermutlich bei der normalen und pathologischen Lymphangiogenese involviert. Die Entstehung von Lymphgefäßen findet sowohl während der Embryonalentwicklung als auch bei adulten Lebewesen z.B. in der Uterusschleimhaut, nach Verletzungen und bei der Tumorigenese statt. Als Ursachen für die Entstehung von Lymphangiomen, die mit einer Häufigkeit von 1,2 bis 2,8 \%o bei Kindern auftreten, werden Hyperplasien lymphendothelialer Zellen oder strukturelle Malformationen von Lymphgefäßen vermutet (Filston, 1994; Nobuhara et al., 2006). Eine andere Form der Lymphendothelzell-Hyperplasie repräsentiert vermutlich das Kaposi Sarkom, das bei immunsupprimierten Patienten auftreten kann. Es gibt aber auch 
Hinweise, dass zirkulierende Vorläuferzellen eine Rolle bei der Pathogenese spielen könnten (Barozzi et al., 2003; Cheung und Rockson, 2005). Fehlentwicklungen von Lymphgefäßen, verursacht durch Genmutationen oder Verletzungen, resultieren häufig in Lymphödemen, die überwiegend an den Extremitäten und in der Genitalregion auftreten. Mutationen im VEGFR-3 Gen sowie im FoxC2 Gen sind bei hereditären und sporadischen Lymphödemen beschrieben worden (Fang et al., 2000; Irrthum et al., 2000; Karkkainen et al., 2000). Lymphangiogenese konnte auch in Tumoren nachgewiesen werden und ist potentiell an der Tumormetastasierung beteiligt (Papoutsi et al., 2000; Skobe et al., 2001b; Stacker et al., 2001). Um die Ursachen Lymphgefäß-assoziierter Erkrankungen besser verstehen zu können ist es notwendig, zelluläre und molekulare Mechanismen bei der Lymphangiogenese in der Embryonalentwicklung und bei Erwachsenen aufzuklären.

\subsection{Entwicklung des Lymphgefäßsystems in der Ontogenese von Vertebraten}

Entwicklungsbiologische Studien über die Entstehung des Lymphgefäßsystems wurden bereits Ende des 19. / Anfang des 20. Jahrhunderts an Embryonen von Hühnern und verschiedenen Säugetieren wie dem Hausschwein, dem Kaninchen, der Katze und auch von Menschen durchgeführt. Dabei zeigte sich, dass die ersten offensichtlichen morphologischen Strukturen der sich entwickelnden Lymphgefäße die Lymphsäcke sind, lokalisiert in unmittelbarer Nähe von tiefen embryonalen Venen (Ranvier, 1895; Sabin, 1904; Sabin, 1909; van der Putte, 1975a; van der Putte, 1975b). Frühe Studien an humanen Embryonen zeigten acht dieser Lymphsäcke, wovon drei paarig und zwei unpaar angelegt sind (Sabin, 1909). In der Jugularregion entstehen die ersten paarigen Lymphsäcke. Die Jugularregion ist durch den Zusammenfluss der kranialen und kaudalen Kardinalvene zur allgemeinen Kardinalvene gekennzeichnet.

Es existieren zwei grundlegende Hypothesen über den Ursprung des Lymphgefäßsystems. Eine Theorie besagt, dass die Lymphsäcke von venösen Blutgefäßen abstammen und alle übrigen Lymphgefäße aus den Lymphsäcken in die umgebenden Gewebe und Organe sprossen (Sabin, 1902; Lewis, 1905; Sabin, 1909). Die zweite Hypothese über die Entstehung der Lymphgefäße wurde ebenfalls Anfang des 20. Jahrhunderts postuliert. 
Huntington und McClure vertraten die Ansicht, dass mesenchymale Zellen für die Bildung der Lymphgefäße verantwortlich seien (Huntington und Mc Clure, 1910). Diese Vorläuferzellen vereinigen sich zu Gefäßanlagen, die zu Lymphsäcken fusionieren und erst später Verbindungen zum Venensystem herstellen. Andere Wissenschaftler vermuteten eine Beteiligung beider Mechanismen bei der Entwicklung der Lymphgefäße (Kampmeier, 1912a).

\subsubsection{Lyve-1-Expression bei der Lymphgefäßentwicklung von Mäusen}

In meiner Arbeit konnte anhand von histologischen Untersuchungen an Mausembryonen gezeigt werden, dass als erste morphologisch sichtbare Zeichen des Lymphgefäßsystems die jugulären Lymphsäcke lateral der Kardinalvenen auftreten. Sie besitzen Fortsätze in Richtung der Hautanlage und des Mediastinums. Die Lymphsäcke verlaufen entlang des Halses und erstrecken sich kaudal bis zur Thymusregion. Diese Ergebnisse stützen die Aussagen von früheren Studien (Ranvier, 1895; Sabin, 1904; Sabin, 1909; van der Putte, 1975a; van der Putte, 1975b). Um die Begrenzung der jugulären Lymphsäcke klarer definieren zu können, habe ich den Antikörper Lyve-1 zur Identifikation der Lymphendothelzellen eingesetzt. Lyve-1 ist einer der gebräuchlichsten Marker für Lymphendothelzellen (Jackson et al., 2001; Prevo et al., 2001). Die Lymphsäcke und ihre Fortsätze exprimieren Lyve-1 in Mausembryonen der ET 12,5 und 13,5. Positiv sind auch einige spezifische Bereiche der Kardinalvenen, der Dottersackvene und Teile des vaskulären Mitteldarmplexus in früheren Entwicklungsstadien (ET 10,5 und 11,5). Meine Untersuchungen weisen ebenfalls eine Expression von Lyve-1 im Endothel der Leberanlage auf. Es hat sich gezeigt, dass Leber- und Milzsinusoide die einzigen Blutgefäße sind, die Lyve-1 exprimieren. Lyve-1 ist ein CD44 homologer Hyaluronsäurerezeptor und ist beim Transport von Hyaluronsäure von Bedeutung (Banerji et al., 1999; Jackson et al., 2001; Prevo et al., 2001). Hierin dürfte die gemeinsame Expression von Lyve-1 in Lymphendothelzellen und Lebersinusoiden begründet sein.

Ich konnte, übereinstimmend mit Wigle und Mitarbeitern (2002), keine Lyve-1-Expression in Endothelzellen der Kardinalvenen an ET 13,5 nachweisen. Im Gegensatz zur o.g. Studie habe ich in meiner Arbeit jedoch gezeigt, dass Lyve-1 nur in bestimmten Regionen der Kardinalvenen und nicht, wie beschrieben, gleichmäßig in allen Endothelzellen der 
Kardinalvene bei der Sprossung exprimiert wird. Außerdem konnte ich eine schwache Lyve-1-Expression in spezifischen Bereichen der Kardinalvenen an ET 12,5 detektieren, wohingegen Wigle et al. (2002) in den Kardinalvenen dieser Entwicklungsstadien kein Signal mehr nachweisen konnten. Diese abweichenden Beobachtungen könnten darauf zurückzuführen sein, dass der Zeitpunkt der Befruchtung bei Mäusen schwer feststellbar ist und damit die Entwicklungsstadien sich leicht verschieben können. Meine Untersuchungen haben gezeigt, dass neben den Lyve-1-positiven Lymphsäcken und ihren Ausläufern auch verstreute Einzelzellen ab ET 10,5 Lyve-1 exprimieren. Diese treten überwiegend im dorsalen Mesenchym der Hautanlage, im Mediastinum, in den primitiven Meningen und in dem umgebenden Gewebe der Kardinalvenen und der jugulären Lymphsäcke auf. Ihre Anzahl erhöht sich mit zunehmendem Alter der Embryonen. Diese mesenchymalen Zellen könnten Vorläuferzellen des lymphatischen Endothels repräsentieren und an der Entwicklung der Lymphgefäße beteiligt sein. Auch Wigle und Oliver (1999) haben Lyve1-positive Einzelzellen in Mausembryonen früher Entwicklungsstadien nachgewiesen. Sie bezeichnen diese Zellen als nicht-endothelial und vermuten, dass es sich hierbei um Makrophagen handelt. Nähere Untersuchungen wurden jedoch nicht durchgeführt.

\subsubsection{Prox1-Expression bei der Lymphgefäßentwicklung von Mäusen}

Ein weiterer spezifischer und früher Marker für Lymphendothelzellen ist der Transkriptionsfaktor Prox1 (Wigle und Oliver, 1999). Für die weitere Charakterisierung der Lyve-1-positiven Einzelzellen, habe ich Prox1 Antikörper verwendet. In frühen Entwicklungsstadien (ET 9,5 und 10,5) habe ich Prox1 ebenfalls nur in einer kleinen Subpopulation von Endothelzellen der anterioren Kardinalvene nachweisen können. Ab ET 11,5 exprimieren die sich entwickelnden jugulären Lymphsäcke ebenfalls Prox1. An ET 13,5 konnte ich in Zellen der Kardinalvenen kein Prox1 mehr detektieren. Diese Beobachtungen bestätigen weitgehend die Daten der Studie von Wigle et al. (2002). Ein Unterschied besteht darin, dass in meiner Arbeit die Kardinalvenen Prox1 bis einschließlich ET 12,5 exprimieren, während dieses bei Wigle et al. (2002) nur bis zum ET 11,5 beobachtet werden konnte. Sie postulierten aufgrund ihrer Ergebnisse eine Bildung der jugulären Lymphsäcke aus sprossenden Endothelzellen der Kardinalvenen. Anschließendes gerichtetes Sprossen von Lyve-1- und Prox1-positiven Zellen aus den Lymphsäcken in dorso-lateraler Richtung wurde als Ursprung für die Entwicklung aller 
anderen Lymphgefäße in den Geweben und Organen der kranialen Körperregion interpretiert. Meine Untersuchungen zeigen im Gegensatz $\mathrm{zu}$ den o.g. Arbeiten ein Sprossen der Lymphsäcke in lateraler, dorsaler, medialer und ventraler Richtung. Trotz dieser geringfügigen Unterschiede unterstützen die Ergebnisse meiner Arbeit die Aussage von Sabin (1902), Lewis (1905) und Wigle et al. (2002) über einen venösen Ursprung der Lymphsäcke. Um die Bedeutung des Sprossens aus den Kardinalvenen für die Entwicklung des Lymphgefäßsystems zu untersuchen, haben Wigle und Oliver (1999) genetisch veränderte Mäuse für das Prox1-Gen generiert. Mäuse, bei denen das Prox1-Gen ausgeschaltet wurde oder nur noch ein Allel funktionsfähig war, begannen starke Ödeme an ET 14,5 zu bilden. Homozygot mutierte Mausembryonen starben an Tag 14,5 / 15,0 wahrscheinlich aufgrund multipler Entwicklungsdefekte. Heterozygote Tiere bildeten in wenigen Fällen ein normales oberflächliches Lymph-Kapillarnetzwerk aus, während dieses bei den homozygoten Mäusen komplett fehlte. Das beschriebene anfängliche Sprossen der Endothelzellen aus den Venen hatte zwar stattgefunden, schien aber ab ET 11,5 zu stagnieren. Infolge dessen blieb die Entwicklung der Lymphsäcke, des Netzwerks von tiefen Lymphgefäßen und der oberflächlichen Kapillargefäße aus. Die Autoren schlossen daraus, dass Prox1 spezifisch und zugleich notwendig für die Entwicklung des Lymphgefäßsystems ist, nicht aber für die initiale Sprossung aus den Venen verantwortlich zu sein scheint (Wigle und Oliver, 1999). Neben der Aufrechterhaltung des Sprossens aus venösen Endothelzellen, weisen Untersuchungen des Transkriptoms darauf hin, dass Prox1 die Determination der Zellen in Richtung Lymphendothelzelle beeinflusst (Hong et al., 2002; Petrova et al., 2002). Die ersten Prox1-positiven Endothelzellen in den jugulären Segmenten der Kardinalvenen gelten somit als Vorläuferzellen des Lymphendothels im Embryo (Oliver und Harvey, 2002).

Immunhistologische Untersuchungen der Prox1-knock-out-Mäuse mit den allgemeinen Endothelmarkern CD31 (PECAM-1) und VE-Cadherin zeigten, dass der Verlust von Prox1 keine Auswirkungen auf die Entwicklung des Blutgefäßsystems hat. Dieses scheint sich also unabhängig vom Lymphgefäßsystem zu entwickeln (Wigle und Oliver, 1999). Neben den Prox1-exprimierenden Endothelzellen der Kardinalvenen, haben mehrere Arbeitsgruppen verstreute, Prox1-positive Einzelzellen ab dem ET 9,5 im paraxialen Mesoderm der Halsregion nachgewiesen (Wigle und Oliver, 1999; Wigle et al., 2002; Srinivasan et al., 2007). Die Anzahl dieser Zellen erhöht sich im Laufe der Entwicklung, so 
dass sie an ET 12,5 entlang der gesamten anterior-posterioren Achse des Embryos nachweisbar sind. Weitere Charakterisierungen der Zellen wurden bislang jedoch nicht durchgeführt. Wigle und Oliver (1999) vermuteten, dass sich die Einzelzellen aus der Kardinalvene entwickeln, was aufgrund der räumlichen Distanz schwer nachvollziehbar ist. Ich habe in meinen Untersuchungen diese Prox1-positiven Einzelzellen charakterisiert. Sie sind in verschiedenen mesodermalen Abschnitten des Embryos wie beispielsweise im Dermatom entlang der Körperachse nachweisbar. Da diese Zellen zeitlich bereits vor der Entstehung der jugulären Lymphsäcke auftreten und zusätzlich eine große Distanz zu den Kardinalvenen aufweisen, ist dies ein deutlicher Hinweis auf die Existenz mesenchymaler Vorläuferzellen des Lymphendothels. Neben dem Ursprung aus den Venen, könnten diese verstreuten Zellen eine weitere Quelle von Lymphendothelzellen darstellen, aus dem ein Teil des Lymphgefäßsystems hervorgeht.

\subsubsection{Lymphangioblasten im Mesenchym von Mausembryonen}

Meine Vermutung, dass in Mäusen lymphendotheliale Vorläuferzellen in anderen Bereichen als den Kardinalvenen und jugulären Lymphsäcken vorhanden sein könnten, veranlasste mich $\mathrm{zu}$ weiteren Untersuchungen dieser mesenchymalen Einzelzellen. Die Anwendung des allgemeinen Endothelmarkers CD31 in Verbindung mit Lyve-1 und Prox1 sollte zum einen eine Differenzierung zwischen Blut- und Lymphendothel ermöglichen und zum anderen den endothelialen Charakter der Zellen bestätigen. CD31 markiert Blutund Lymphendothelzellen, wird aber ebenfalls auf diversen hämatopoetischen Zellen wie Stammzellen des Knochenmarks, Monozyten, neutrophilen Granulozyten und Thrombozyten gefunden (Parums et al., 1990; Burgio et al., 1994; Sauter et al., 1998). Das Molekül ist in Zelladhäsion involviert und vermittelt Transmigration von Leukozyten vom Blutgefäßlumen in den extravaskulären Raum (Hirschberg et al., 1980; Muller et al., 1993; Newman, 1994; Liao et al., 1995; Muller, 1995). Eine Koexpression des Lymphendothelmarkers Lyve-1 und CD31 konnte ich in Lymphendothelzellen der jugulären Lymphsäcke, der Lymphgefäße sowie in Einzelzellen des Mesenchyms nachweisen. Blutgefäße exprimieren dagegen nur CD31. Die Anzahl der verstreuten Lyve1-positiven mesenchymalen Zellen, die in der Hautanlage, im Mediastinum und in den

primitiven Meningen lokalisiert sind, steigt mit dem Alter des Embryos an. Ähnliche Ergebnisse habe ich mit Antikörperfärbungen gegen Prox1 und CD31 generiert, obwohl 
die Anzahl dieser Zellen in den gleichen mesenchymalen Bereichen deutlich geringer ist. Dabei treten Prox1-positive Einzelzellen dorsal des Neuralrohrs später auf als Lyve1positve Zellen. Lyve-1 könnte demnach ein früherer Marker von Lymphangioblasten in diesen Kompartimenten des Embryos sein als Prox1. Meine Untersuchungen haben gezeigt, dass die Expression von CD31 bei Blutgefäßendothelzellen deutlich stärker ausfällt als bei Lymphendothelzellen. Dieses ist auch in anderen Studien beobachtet worden (Wilting et al., 2002; Norgall et al., 2007). Außerdem habe ich einen zunehmenden CD31-Expressionsgradienten bei Lyve-1-positiven Einzelzellen der Hautanlage von medial nach lateral festgestellt. Je näher die Lymphangioblasten an den jugulären Lymphsäcken gelegen sind, desto höher scheint die CD31-Expression zu sein. Ebenfalls verändert sich die Form dieser Zellen von rundlich zu flach und verästelt bei Annäherung an die Lymphsäcke. Diese Beobachtungen deuten darauf hin, dass Lyve-1-positive Zellen sich in Richtung eines lymphendothelialen Phänotyps differenzieren, sobald sie sich der Mikroumgebung eines Lymphgefäßes nähern, oder ein lymphangiogener Wachstumsfaktor wie z.B. VEGF-C in dem Gewebe vorhanden ist. Der Mechanismus ähnelt dem der Transdifferenzierung von Blutendothel zu Lymphendothel bei Prox1-transfizierten Endothelzellen (Hong et al., 2002; Petrova et al., 2002), oder der Differenzierung venöser Blutendothelzellen in Richtung Lymphendothelzellen in den Kardinalvenen.

Eine gleichzeitige Anwendung von Antikörpern gegen Lyve-1 und Prox1 ist bisher nicht durchgeführt worden, da beide polyklonal in Kaninchen hergestellt werden. Durch zusätzliche Fixierungsschritte habe ich diese Doppelfärbung erfolgreich anwenden können. Mit Hilfe dieser Methode ist es möglich, den lymphendothelialen Charakter der von mir detektierten mesenchymalen Einzelzellen näher zu untersuchen. Eine Population mesenchymaler Zellen mit Koexpression beider Lymphendothelmarker konnte ich in Mausembryonen unterschiedlicher Entwicklungsstadien in verschiedenen Körperarealen nachweisen. Das Expressionsmuster dieser Einzelzellen unterscheidet sich nicht von dem der Lymphendothelzellen der jugulären Lymphsäcke und der Lymphgefäße, die auch beide Marker koexprimieren. Die Lokalisation der Lyve-1-Expression in der Zellmembran (Banerji et al., 1999) und der Prox1-Expression im Zellkern (Wilting et al., 2002) lassen keine Zweifel darüber aufkommen, dass diese Methode spezifisch lymphendotheliale Zellen markiert. 
Ein erst kürzlich publizierter Lymphendothelmarker, LA102, wurde bisher nur in adulten Mäusen angewandt. Er reagiert spezifisch mit Lymphgefäßen mit Ausnahme des Ductus thoracicus und der Sinusendothelzellen von Lymphknoten. Der monoklonale Antikörper erkennt ein 25 - $27 \mathrm{kDa}$ großes Protein, das auf Blutgefäßen nicht vorhanden ist, aber Thymozyten, wenige Knochenmarkszellen und T- und B-Zelllinien markiert (Ezaki et al., 2006). Ich habe LA102 an Mausembryonen während der Lymphgefäßentwicklung zusammen mit Prox1 und Lyve-1 untersucht. Die Koexpression von Prox1 und LA102 sowie Lyve-1 und LA102 in Lymphendothelzellen der jugulären Lymphsäcke und in Lymphgefäßen der Haut bestätigt die Spezifität von LA102 für LECs auch in der Embryonalentwicklung von Mäusen. Weiterhin habe ich aber im Mediastinum Lymphgefäße nachgewiesen, die Lyve-1 oder Prox1 exprimieren aber kein LA102. Das spricht für eine Heterogenität der LA102-Expression während der Entwicklung von Lymphgefäßen. Möglicherweise liegen die Ursachen hierfür in der Entwicklung unterschiedlicher Gefäßtypen (Kapillaren, Kollektoren, Lymphstämme). Im Mesenchym der Hautanlage habe ich LA102-positive Einzelzellen nachgewiesen, die Prox1 oder Lyve1 koexprimieren. Einige dieser Einzelzellen lagen weit entfernt von den jugulären Lymphsäcken oder anderen Lymphgefäßen und könnten Lymphangioblasten darstellen. Offensichtlich können diese Zellen durch Applikation des lymphangiogenen Wachstumsfaktors VEGF-C zur Lymphgefäßbildung stimuliert werden. Meine Schnittkulturexperimente zeigen, dass nach Applikation von VEGF-C auch in den Bereichen von Mausembryonen Lymphangiogenese induziert werden kann, die ohne Zugabe dieses Wachstumsfaktors lymphgefäßfrei bleiben. Dieses deutet auf die Existenz von mesenchymalen Zellen mit lymphangiogener Potenz hin, die sich bei spezifischer Stimulation zu Lymphendothelzellen differenzieren können.

\subsubsection{Lymphgefäßentwicklung bei Zebrafischen}

Ein weiteres Modell zur Untersuchung der Lymphgefäßentwicklung stellt der Zebrafisch dar. Er ist für direkte Beobachtungen im Tier gut geeignet, da er weitgehend durchsichtig ist. Im Gegensatz zu anderen Vertebraten entwickeln Zebrafische keine Lymphsäcke, wohl aber ein primitives Lymphgefäßsystem, das den großen Blutgefäßen unmittelbar anliegt. Ein dem Ductus thoracicus ähnliches Gefäß begleitet die Aorta (Yaniv et al., 2006). In vivo Beobachtungen fluoreszierender Zellen haben gezeigt, dass die Entwicklung dieses 
Lymphgefäßsystems recht einzigartig ist. Es lösen sich Zellen aus der dorsalen Vene, wandern im Mesenchym entlang der intersomitischen Arterien und sammeln sich ventral der Aorta. Dort fusionieren sie und bilden in anteriorer-posteriorer Richtung ein Lymphgefäß aus. Im Zebrafisch entstehen Lymphendothelzellen offensichtlich aus venösen Vorläufern, die eine transiente mesenchymale Phase durchlaufen.

\subsubsection{Lymphgefäßentwicklung bei Xenopus laevis}

Um molekulare Mechanismen der Lymphangiogenese zu untersuchen, eigenen sich kleine Tiermodelle, die genetisch verändert werden können, besonders gut. Mit Xenopus laevis Kaulquappen wurde ein Modell zur Erforschung der Funktionen von Kandidatengenen etabliert (Ny et al., 2005). Für den Nachweis von Lymphgefäßen am Kopf (rostrale Lymphsäcke) sowie am anterioren (Lymphherzen) und posterioren Stamm (kaudale Lymphgefäße) eignet sich die In-situ-Hybridisierung zur Darstellung des Transkriptionsfaktors Prox1. Die Lymphherzen und die kaudalen Lymphgefäße entwickeln sich partiell aus dem Venensystem. Jedoch bilden Prox1-positive Zellcluster (offensichtlich Lymphangioblasten) in späteren Entwicklungsstadien das Lumen der rostralen Lymphsäcke und der kaudalen Lymphgefäße (Ny et al., 2005). Das Herunterregulieren (Knockdown) von Prox1 beeinträchtigt die Lymphangiogenese bei Kaulquappen. Dabei sind die Lymphgefäße hypoplastisch und unregelmäßig geformt. In VEGF-C Knockdown-Kaulquappen kommt es zu einer Beeinträchtigung des Aussprossens von Lymphendothelzellen. Die Blutgefäße dieser transgenen Tiere weisen keine phänotypischen Veränderungen auf. Die Untersuchungen zeigen, dass es bei Xenopus laevis einen doppelten Ursprung von Lymphendothelzellen aus Venen und aus Lymphangioblasten gibt.

\subsubsection{Lymphgefäßentwicklung bei Vogelembryonen}

Arbeiten über die Entwicklung des Lymphgefäßsystems bei Vogelembryonen weisen ebenfalls auf einen dualen Ursprung hin. Das Expressionsmuster von Prox1 ähnelt in Vogelembryonen dem der Mäuse. Endothelzellen in spezifischen Segmenten der jugulären Kardinalvenen exprimieren Prox1. Intravenöse Applikationen von DiI-konjugiertem acetylierten Low-Density-Lipoprotein in 4 Tage alte Hühnerembryonen führt nach 2,5 
Tagen zu einem Signal in den jugulären Lymphsäcken (Wilting et al., 2006) und bestätigt somit, dass die Lymphsäcke aus embryonalen Venen entstehen. Experimentelle Transplantationsstudien mit Hühner- und Wachtelembryonen geben jedoch Hinweise darauf, dass Zellen des paraxialen Mesoderms und des Mesoderms der Splanchnopleura lymphangiogenes Potential besitzen. Transplantierte Zellen aus diesen Bereichen weisen die Fähigkeit auf, sich in Lymphgefäße zu integrieren. Lymphendotheliales Potential ist bereits vorhanden, bevor sich die jugulären Lymphsäcke entwickeln (Schneider et al., 1999; Papoutsi et al., 2001; Wilting et al., 2006). Die Koexpression von Prox1 mit dem Blut- und Lymphendothelmarker QH1 (quail endothelial and hematopoietic marker) in verstreuten mesodermalen Zellen von Wachtelembryonen deutet auf die Existenz von Lymphangioblasten hin (Wilting et al., 2006). Charakteristischerweise liegen diese Zellen genau in den mesodermalen Kompartimenten, z.B. im Dermatom, in denen ich auch in der Maus Prox1 / CD31-positive Einzelzellen nachweisen konnte.

\subsubsection{Leukozyten bei der Lymphgefäßentwicklung von Mäusen}

Den allgemeinen Leukozytenmarker CD45 habe ich zur Unterscheidung von Lymphendothelzellen und Leukozyten verwendet. Viele Einzelzellen exprimieren dorsal und lateral des Neuralrohrs Lyve-1 und CD45 schon in frühen Embryonalstadien, während nur eine kleinere Population von Zellen Prox1 und CD45 koexprimiert. Ich konnte keine Lyve-1-positiven Zellen im Neuralrohr nachweisen. Dieses ist ein bestätigender Hinweis darauf, dass sich im zentralen Nervensystem keine Lymphgefäße entwickeln. Zellen mit Lyve-1 / CD45-Expression sind in der Nähe der jugulären Lymphsäcke erst in späteren Entwicklungsstadien nachweisbar. Lymphendothelzellen der jugulären Lymphsäcke oder der Kardinalvenen koexprimieren CD45 mit Lyve-1 oder Prox1 jedoch nicht. Ich habe Prox1-positive Zellen früher Lymphgefäße mit geringer CD45-Expression bei meinen Untersuchungen detektieren können, obwohl Lymphgefäßstrukturen normalerweise CD45negativ sind (Kreuger et al., 2006). Die Expressionsstärke scheint im Vergleich zu CD45postiven Leukozyten deutlich schwächer zu sein. Dieses könnte ein Hinweis darauf sein, dass die Zellen CD45 herunterregulieren, nachdem sie sich in die Lymphgefäße integriert haben. Das Prinzip der Transdifferenzierung eines Leukozyten in Richtung Lymphendothelzelle könnte auch hier vorliegen. In menschlichen Nierentransplantaten wurden CD45-positive Makrophagen nachgewiesen, die sich offensichtlich in Lyve- 
1 / Podoplanin-exprimierendes Lymphendothel transdifferenzierten (Kerjaschki et al., 2006). Außerdem besteht die Möglichkeit, dass eine lymphendotheliale Vorläuferzelle auch molekulare Charakteristika einer hämatopoetischen Zelle besitzt. Dieses wäre ein Hinweis auf eine gemeinsame Vorläuferzelle von Lymphendothelzellen und hämatopoetischen Zellen.

\subsection{Makrophagen in der Lymphangiogenese}

Der von mir erbrachte Nachweis von Lymphendothelzellen, die einen Leukozytenmarker exprimieren, veranlasste mich $\mathrm{zu}$ weiteren Studien dieser Zellen in Mausembryonen. Untersuchungen der Lymphangiogenese adulter Mäuse unter normalen und pathologischen Bedingungen haben Hinweise auf ein Mitwirken von Makrophagen bei der Entwicklung von Lymphgefäßen erbracht (Maruyama et al., 2005; Schledzewski et al., 2006; Xu et al., 2007). Makrophagen gehören zu den Zellen der hämatopoetischen Reihe und sind ausdifferenzierte Monozyten. Ich habe zwei weitere Moleküle für detailliertere Charakterisierungen der Lymphendothelzellen in meine Untersuchungen einbezogen, die als Makrophagenmarker bei Mäusen breite Anwendung gefunden haben. Zum einen handelt es sich um CD11b, auch bekannt als Mac-1 oder Komplement-Rezeptor-3. Exprimiert wird das Molekül auf Granulozyten, Makrophagen, NK-Zellen und BLymphozyten der Peritoneal- und Pleuralhöhle, nicht aber auf dendritischen Zellen (Flotte et al., 1983). Ich konnte nur wenige Zellen detektieren, die Lyve-1 oder Prox1 zusammen mit CD11b koexprimieren. Einige Zellen sind im lockeren Bindegewebe der Hautanlage, andere in der Nähe der jugulären Lymphsäcke lokalisiert. In einer Studie über induzierte Lymphangiogenese durch Entzündungsreaktionen in der Kornea von Mäusen haben Maruyama et al. (2005) gezeigt, dass CD11b-positive Makrophagen lymphendotheliale Charakteristika besitzen und möglicherweise zur Entwicklung von Lymphgefäßen beitragen. Diese Makrophagen sind in vitro in der Lage, röhrenartige Strukturen zu bilden und exprimieren Lymphendothelmarker wie Lyve-1 und Podoplanin (Maruyama et al., 2005). In malignen Tumoren und bei normaler Wundheilung der Haut sind Lyve-1-positive Makrophagen mit CD11b- bzw. F4/80-Expression, einem weiteren Marker für Makrophagen, nachgewiesen worden. Es scheint offensichtlich, dass diese Makrophagen sprossende und kollabierende Lymphgefäße imitieren (Schledzewski et al., 2006). Der zweite Makrophagenmarker, den ich in dieser Arbeit verwendet habe, F4/80, konnte in 
vorherigen Studien in Gewebsmakrophagen von Milz, Lymphknoten, Haut und Thymus nachgewiesen werden. Ebenfalls positiv getestet wurde er in Langerhans Zellen der Haut und in Kupffer-Zellen der Leber, während Granulozyten, Lymphozyten, Thrombozyten, Endothelzellen und Monozyten kein F4/80 exprimieren. Eine Hochregulation findet nach Reifung von Vorläuferzellen der Makrophagen im Knochenmark und Blut statt (Malorny et al., 1986). Ich habe Dreifachfärbungen mit Lyve-1 und Prox1 sowie dem Makrophagenmarker F4/80 an Mausembryonen durchgeführt. Einige Zellen in Lymphgefäßen und den jugulären Lymphsäcken koexprimieren alle drei Marker. Diese wenigen lymphendothelialen Zellen besitzen demnach zusätzlich molekulare Charakteristika von Makrophagen. Jüngere Studien bezeichnen Zellen, die Lyve-1 und einen Makrophagenmarker exprimieren, ausschließlich als Makrophagen. Prox1 wurde dabei nicht als zusätzlicher Marker eingesetzt (Wigle et al., 2002). Dabei kann es sich bei diesen Zellen um Vorläuferzellen des lymphatischen Endothels handeln, die aufgrund eines gemeinsamen Ursprungs sowohl hämatopoetische (Hämangioblasten) als auch endotheliale (Angioblasten) Charakteristika aufweisen. Auch F4/80 wurde in Verbindung mit Wundheilung der Haut bei adulten Mäusen untersucht. Die Tatsache, dass Lymphgefäße in der Wunde nach einiger Zeit geringe Mengen an F4/80 exprimieren, spricht für eine Beteiligung von F4/80-positiven Makrophagen an der Lymphgefäßneubildung (Maruyama et al., 2007). Obwohl ich diese dreifach positiven Zellen nur relativ selten beobachten konnte, demonstrieren die Ergebnisse doch eine Heterogenität von Lymphendothelzellen. Dieses Phänomen könnte nicht nur bei der embryonalen und pathologischen Lymphangiogenese sondern bereits bei der Phylogenese der Lymphgefäße relevant sein.

\subsection{Lymphangiogenese in der Phylogenese}

Die Entwicklung von Lymphendothelzellen aus makrophagenähnlichen Vorläuferzellen kann möglicherweise auf phylogenetische Gegebenheiten vor der Entwicklung eines Lymphgefäßsystems zurückgeführt werden. Diese Annahme stützt sich auf die Tatsache, dass Insekten keine Endothelzellen besitzen (Popichenko und Paululat, 2004), wohl aber makrophagenähnliche Zellen. In Drosophila melanogaster erfolgt die Versorgung mit Sauerstoff durch ein Tracheensystem. Rote Blutzellen existieren nicht und das sogenannte hämolymphatische System übernimmt typische Aufgaben des Lymphgefäßsystems. Es 
könnte daher vermutet werden, dass sich das Lymphgefäßsystem vor dem Blutgefäßsystem entwickelt hat, obwohl in der Ontogenese zuerst Blut- und später Lymphgefäße entstehen (Wilting et al., 2004). Kontraktile Muskelzellen eines dorsalen Gefäßes, das keine Endothelzellen besitzt, pumpen interstitielle Flüssigkeit und Immunzellen durch den Insektenkörper. In Drosophila melanogaster gibt es drei Arten von Immunzellen. Plasmatozyten sind zur Phagozytose befähigt und deshalb vergleichbar mit der Linie der Monozyten / Makrophagen in Vertebraten. Kristallzellen scheinen in ihrer Funktion den NK-Zellen ähnlich, während Lamellozyten sich erst bei Parasitenbefall differenzieren. Plasmatozyten (Makrophagen) exprimieren typische Angiogenese-assoziierte Vorläufermoleküle aus der PDGF/VEGF-Familie der Vertebraten wie beispielsweise den PV-Rezeptor (PVR) (Duchek und Rorth, 2001; Duchek et al., 2001; Heino et al., 2001). PVR ist der Vorläufer der gesamten Rezeptoren der PDGF- und VEGF-Familien. PVR steuert die Migration von Immunzellen der Fliege (Duchek et al., 2001; Heino et al., 2001; Cho et al., 2002). Da das PDGF/VEGF Rezeptor-System für die Entwicklung von Gefäßen bei Vertebraten essentiell ist, liegt die Vermutung nahe, dass sich die Zellen der Gefäßwand in der Phylogenese von Immunzellen ausgehend entwickelt haben. Dieser Ursprung scheint bis heute auch noch während der Ontogenese eine gewisse Rolle zu spielen.

\subsection{Pathologische Lymphangiogenese}

Bei der pathologischen und der embryonalen Lmyphgefäßentwicklung spielen ähnliche Mechanismen eine Rolle wie z.B. die Proliferation von Lymphendothelzellen. Vor einigen Jahren wurde schon bei der Wundheilung und Regeneration die Bildung von Lymphgefäßen durch Sprossung beobachtet (Reichert, 1926; Pullinger and Florey, 1937). Die Mauserung von Lymphendothelzellen ist bei Erwachsenen extrem gering. In einem Ratten-Kornea-Modell wurde eine Rate von 0,6\% proliferierender Lymphendothelzellen unter normalen Bedingungen nachgewiesen. Nach Hitzekauterisation stieg diese bis auf ein Maximum von 6,8\% an (Junghans und Collin, 1989). 2,3\% der Lymphkollektoren von nierentransplantierten Patienten zeigten eine Expression des Proliferationsmarkers Ki-67 (Kerjaschki et al., 2006). Um Proliferationsraten von Lymphendothelzellen während der Entwicklung von Mäusen bestimmen zu können, habe ich mit Hilfe der Marker Ki-67 und Lyve-1 die jugulären Lymphsäcke, sprossende Lymphendothelzellen und mesenchymale 
Einzelzellen der Hautanlage untersucht. Die Werte von 22\% bis 55\% lagen deutlich höher als die beobachteten Proliferationsraten bei Erwachsenen. Der Hauptgrund für diesen Unterschied liegt wahrscheinlich darin, dass das gesamte Lymphgefäßnetzwerk bei Embryonen erst gebildet werden muss und dafür deutlich mehr Zellen innerhalb einer kürzeren Zeit notwendig sind als bei der Wundheilung. Auf der anderen Seite können durch die Anwendung unterschiedlicher Methoden nicht absolut vergleichbare Ergebnisse erzielt werden. Während bei den meisten Regenerationsmodellen bei Tieren mit Bromdesoxyuridin gearbeitet wurde, habe ich in meiner Arbeit die proliferierenden Zellen mit Ki-67 dargestellt. Die Expressionsintensitäten unterscheiden sich von Zelle zu Zelle je nach Zellzyklusphase, so dass es in einigen Fällen schwierig war, eine klare ja-neinEntscheidung zu treffen.

Für eine erfolgreiche Geweberegeneration sind Lymphgefäßwachstum und die Verbindung zu einem funktionellen Lymphgefäßsystem notwendig. Während der Wundheilung findet eine Bildung homophiler vaskulärer Anastomosen statt, d.h. es fusionieren nur Lymphgefäße mit Lymphgefäßen und Blutgefäße untereinander (Pullinger und Florey, 1937; Kriehuber et al., 2001). Ausnahmen wurden aber bei Frauen beobachtet, deren axilläre Lymphknoten im Zuge einer kompletten Mastektomie entfernt worden waren. Hier bildeten sich funktionelle lympho-venöse Anastomosen, die wahrscheinlich einer Entstehung von Lymphödemen im Arm entgegenwirken (Aboul-Enein et al., 1984). Molekulare Determinanten scheinen hierbei Syk (Spleen Tyrosinkinase) und Slp76 (SH2 domain-containing leukocyte protein of $76 \mathrm{kDa}$ ) zu sein. Diese Moleküle werden in hämatopoetischen Zellen, nicht aber in Endothelzellen exprimiert. Sie sind für die Weiterleitung von Signalen aktivierter Immunrezeptoren notwendig und spielen bei der Interaktion von Integrinen eine wesentliche Rolle (Obergfell et al., 2001; Mocsai et al., 2002). Mäuse, denen diese Moleküle fehlen, entwickeln abnormale blut-lymphendotheliale Verbindungen. Die Inkorporation von Slp76-defizienten Zellen in die abnormalen Lymphgefäße und das Wiederherstellen eines gesunden Phänotpys durch GFPSlp76exprimierende zirkulierende Zellen deuten auf einen hämatopoetischen Ursprung von Lymphendothelzellen hin (Abtahian et al., 2003; Sebzda et al., 2006). Wir sind aber noch weit davon entfernt, die Einflüsse zirkulierender Zellen auf die normale und pathologische Angiogenese zu verstehen. 


\subsubsection{Mesenchymale Zellen bei der Lymphgefäßregeneration}

Anhand eines Modells für Lymphangiogenese in regenerierender Haut adulter Mäuse ist die Bedeutung der lymphendothelialen Zellmigration untersucht worden. In diesem Modell wird mittels einer Zirkumzision ein Gewebeverband im Schwanz von Mäusen entfernt und der Lymphfluss von distal nach proximal unterbrochen. Boardman und Swartz (2003) vermuten einen Zusammenhang der Lymphgefäßregeneration mit der Fließrichtung der interstitiellen Flüssigkeit. Es zeigte sich, dass Flüssigkeitskanäle im Interstitium entstanden, entlang derer Zellmigration, die Bildung eines Lymphkapillarnetzes und die Expression von VEGF-C vornehmlich in Richtung des Lymphflusses beobachtet werden konnte (Boardman und Swartz, 2003). Eine weiterführende Studie zeigte, dass sich migrierende Lyve-1-positive Einzelzellen in der regenerierenden Region in Richtung des Lymphflusses ansiedeln, zusammenlagern und ein neues untereinander verbundenes Netzwerk von Lymphkapillaren bilden. Die höchste VEGF-C-Expression konnte während der Initiation der Lymphangiogenese gemessen werden, sank während der Organisation und Reifung der Kapillaren aber wieder ab. Die Mechanismen der adulten Lymphangiogenese bei der Regeneration unterscheiden sich demnach nicht gravierend von denen bei der Entwicklung (Rutkowski et al., 2006). Auf die Bedeutung mesenchymaler Lymphangioblasten im Embryo habe ich weiter oben bereits hingewiesen. Ob Makrophagen unmittelbar bei der Regeneration der Lymphgefäße involviert sind, konnte nicht abschließend geklärt werden. Makrophagen sind aber vermutlich für die Sekretion von VEGF-C und damit für die Entstehung eines VEGF-C-Gradienten verantwortlich und üben somit einen Einfluss auf die Lympendothelzellmigration aus (Skobe et al., 2001a; Schoppmann et al., 2002).

\subsubsection{Zirkulierende Vorläuferzellen bei der pathologischen Lymphangiogenese}

Die mögliche Beteiligung zirkulierender Vorläuferzellen des lymphatischen Endothels ist bei Menschen nach Organtransplantation und Organabstoßung untersucht worden. In abgestoßenen Nierentransplantaten zeigen sich hohe Proliferationsraten des lymphatischen Endothels und massive chronische Entzündungsreaktionen. Bei Transplantationen zwischen männlichem Donor und weiblichem Empfänger (oder umgekehrt) konnte eine de novo Lymphangiogenese durch Inkorporation von lymphatischen Vorläuferzellen in die Lymphgefäße des Transplantats nachgewiesen werden. Diese offensichtlich mobilen 
Lymphangioblasten aus der Zirkulation transmigrieren offensichtlich durch das Bindegewebsstroma und integrieren sich in wachsende Lymphgefäße (Kerjaschki et al., 2006).

Ich habe immunzytologisch im Blut von Kindern Zellen nachweisen können, die durch die Koexpression lymphendothelialer, leukozytärer und pan-endothelialer Marker charakterisiert sind. Dabei weisen die Zellen, je nach verwendeten Markern, mit 1,4 bis 175 Zellen pro $\mu 1$ Blut unterschiedliche Häufigkeiten auf. Dieses Ergebnis spiegelt sich auch im Nachweis der RNA-Expression wider. Die selten auftretenden Podoplaninpositiven Zellen (1,4 Zellen/ $\mu$ l Blut) konnte ich in RNA-Expressionsanalysen nicht nachweisen, während Lyve-1- und Prox1-positive Zellen bei den zytologischen Untersuchungen häufiger auftraten und auch auf der Ebene der RNA-Expression nachgewiesen werden konnten. Neueste Studien über die Anzahl zirkulierender Vorläuferzellen besagen, dass bei Kindern CD34/VEGFR-2-positive endotheliale Vorläuferzellen (ca. 5 Zellen / $\mu$ 1 Blut) dreimal und CD34-positive hämatopoetische Vorläuferzellen zweimal häufiger auftreten als bei Erwachsenen (Jie et al., 2008). Ein weiterer Nachweis zirkulierender endothelialer Vorläuferzellen ist anhand von Genotypisierungen von Endothelzellkulturen aus dem Blut von Patienten durchgeführt worden, die eine Knochenmarktransplantation erhalten hatten. Die Zellen zeigten nach 9 Tagen einen Empfängergenotyp, während nach einem Monat die meisten Zellen den Genotyp der Spender aufwiesen. Demnach stammten die frühen zirkulierenden Endothelzellen vom Empfänger ab, die späteren jedoch aus dem Knochenmarktransplantat des Spenders (Lin et al., 2000). Salven und Mitarbeiter isolierten VEGFR-3-positive Endothelzellen aus fetaler Leber, Nabelschnurblut und Blut von gesunden Erwachsenen. Eine Subpopulation koexprimierte CD34 und CD133 und besitzt insofern Charakteristika einer endothelialen Vorläufer- bzw. Stammzelle, die möglicherweise eine Rolle bei der postnatalen Lymphangiogenese bzw. Angiogenese spielt. Kultivierten sie diese Zellen, konnten verschiedene Blut- und Lymphendothelmarker wie VE-Cadherin, Lyve-1 und Podoplanin nachgewiesen werden (Salven et al., 2003). In meinen Untersuchungen habe ich zum Teil andere Marker verwendet, als in den oben aufgeführten Studien. Während CD34 für die Isolierung von Vorläuferzellen verwendet wird, exprimieren die von mir detektierten lymphendothelialen Zellen dieses Molekül nicht. Zirkulierende 
Lymphendothelzellen scheinen somit in ihrer Differenzierung weiter fortgeschritten zu sein.

\subsubsection{Zirkulierende Vorläuferzellen beim Kaposi-Sarkom}

Eine weitere Erkrankung, die mit zirkulierenden lymphendothelialen Vorläuferzellen assoziiert wird, ist das Kaposi-Sarkom (KS). Das klassische KS, das afrikanische endemische KS, das Transplantations-assoziierte KS und das HIV-assoziierte KS sind verschiedene Formen dieser Erkrankung (Antman und Chang, 2000; Cheung nd Rockson, 2005). In fast allen untersuchten Läsionen konnte ein KS-assoziiertes Herpesvirus (KSHV, HHV-8) gefunden werden (Chang et al., 1994). Dieses Virus gehört zur Familie der Gamma-Herpesviren. Viren dieses Typs werden oft mit lymphoproliferativen Erkrankungen in Verbindung gebracht. Als mögliche Ursprungszelle des KS sind früher glatte Muskelzellen, Blut- oder Lymphendothelzellen, Schwann-Zellen und Fibroblasten diskutiert worden (Regezi et al., 1993; Kaaya et al., 1995; Gallo, 1998). Ein endothelialer Ursprung schien aber am wahrscheinlichsten, wobei man sich aber nicht einig war, ob es sich dabei um Blut- oder Lymphendothelzellen handelte (Dictor, 1986; Rutgers et al., 1986). Die Expression von VEGFR-3, Podoplanin und Lyve-1 und der mitogene Effekt von VEGF-C auf KS-Zellen legten dann einen Ursprung des Kaposi-Sarkoms aus Lymphendothelzellen nahe (Cheung und Rockson, 2005). Aus peripherem Blut isolierte mononukleäre Zellen von KS Patienten weisen Charakteristika von Makrophagen und Endothelzellen auf und zeigen in Kultur die typische Spindelzell-Morphologie der KSZellen (Uccini et al., 1997). Biopsien von KS Hautläsionen, die sich 9 - 40 Monate nach einer Nierentransplantation bei sechs weiblichen und zwei männlichen Nieren-Empfängern entwickelt hatten, zeigten, dass ein hoher Anteil der KS-Zellen von den Spendernieren stammte (Barozzi et al., 2003). Diese Beobachtungen lassen darauf schließen, dass KSZellen von hochgradig mobilen Zellen abstammen, die in der Lage sind, ausgehend vom Transplantat (Niere) die Haut zu besiedeln. Meine zytologischen Untersuchungen der PBMCs haben gezeigt, dass im peripheren Blut Zellen vorhanden sind, die lymphendotheliale und leukozytäre Charakteristika vereinen. Ich gehe davon aus, dass diese Zellen die Ursprungszellen des KS sind. 


\subsection{PPAR $\gamma$ in der Lymphangiogenese}

Die von mir etablierten Schnittkulturen machen es möglich, Mausembryonen (z.B. von Knock-out-Mäusen) zu untersuchen, die während der Embryonalentwicklung früh absterben. Mit der Methode können verschiedene Bereiche der Mausembryonen getrennt voneinander für einen Zeitraum von drei Tagen kultiviert werden. Dieser Zeitraum ist ausreichend, um die Spanne zwischen beginnender Blutgefäßentwicklung und beginnender Lymphgefäßentwicklung zu überbrücken. Durch vergleichende Gen-Mikroarray Analysen von Blutendothelzellen und Lymphendothelzellen hat unsere Arbeitsgruppe PPAR $\gamma$ (Peroxisome Proliferator-associated Receptor gamma) als Kandidat für regulatorische Prozesse in der Lymphgefäßentwicklung identifiziert. Ich konnte die Expression von PPAR $\gamma$ in Lymphendothelzellen mittels real-time RT-PCR bestätigen.

PPAR $\gamma$ wird in braunem Fettgewebe, in späten Entwicklungsstadien des ZNS und in Tumoren exprimiert (Braissant und Wahli, 1998). Dabei ist das braune Fettgewebe in der Entwicklung in der Jugularregion mit den jugulären Lymphsäcken kolokalisiert (Barak et al., 1999). Da die Adipozytenentwicklung und die Lymphgefäßentwicklung in engem Zusammenhang zu stehen scheinen (Harvey et al., 2005), habe ich Untersuchungen der Lymphangiogenese bei PPAR $\gamma$ Knock-out-Mäusen durchgeführt. Diese Mäuse zeigen Plazentationsdefekte, Lipodystrophie und Fettleber sowie sekundär Hämorrhagien und eine Verdünnung des Myokards. Nach den Mendelschen Regeln sind $25 \%$ der Nachkommen heterozygoter PPAR $\gamma$-knock-out-Mäuse homozygot mutiert. Diese sind aber ab ET 10 nicht mehr lebensfähig (Barak et al., 1999). Lymphangiogenese ist in diesen Tieren bisher nicht untersucht worden, da sie bereits vor Beginn der Entwicklung der ersten Lymphgefäßanlagen sterben. Ich habe 25 Tiere an ET 9,5 isoliert und mit der Schnittkulturtechnik weiter kultiviert. Die Genotypisierung der Mausembryonen ergab aber, dass keine homozygot mutierten Tiere für die Schnittkulturen gewonnen werden konnten. Offensichtlich sterben homozygote PPAR $\gamma$-knock-out-Mäuse vor ET 9,5 und werden im Uterus resorbiert. Infolge dessen habe ich heterozygote Mausembryonen untersucht und mit Wildtypmäusen verglichen, konnte aber keine morphologischen Veränderungen bei der Entwicklung der Lymphgefäße beobachten. Jedoch schien die Expression des Pan-Endothelmarkers CD31 in Lymphgefäßen heterozygoter Mäuse geringer zu sein als bei Wildtypmäusen. Makroskopisch konnte ich keine Unterschiede im 
Vergleich zu den Wildtypmäusen feststellen. Auch die Untersuchungen von Barak et al. (1999) zeigten, dass heterozygote Tiere sich normal entwickeln. Sie sind fruchtbar und zeigen äußerlich keine Krankheitssymptome.

Ich konnte keine Expression von PPAR $\gamma$ in frisch isolierten venösen Endothelzellen aus Nabelschnüren nachweisen. Es gibt aber Untersuchungen, die PPAR $\gamma$ in solchen Zellen (von der Firma Clonetics) zeigen und mit der Angiogenese in Verbindung bringen (Xin et al., 1999). In vitro inhibiert das Fehlen der PPAR $\gamma$-Expression die Apoptose von Endothelzellen und fördert somit Zellwachstum und Angiogenese (Ameshima et al., 2003). Eine Aktivierung von PPAR $\gamma$ durch spezifische (natürliche und synthetische) Liganden dagegen inhibiert die Differenzierung von Endothelzellen zu röhrenartigen Strukturen, aber auch die Proliferation in vitro und die VEGF-stimulierte Angiogenese in vivo (Xin et al., 1999). Dazu ist aber anzumerken, dass die PPAR $\gamma$ Aktivatoren im Mikromolarbereich eingesetzt wurden, obwohl sie in anderen Systemen im Nanomolarbereich wirksam sind. Außerdem ist das Kornea-Angiogeneseassay in seinem Ausgang sehr vom Anwender abhängig. Andere Arbeiten wurden mit immortalisierten Endothelzellen durchgeführt (Ameshima et al., 2003) und sind damit wahrscheinlich nicht repräsentativ. Die Bedeutung von PPAR $\gamma$ für die Blutgefäßentwicklung muss also noch eingehender untersucht werden.

\subsection{Ausblick}

Eine Vertiefung meiner Ergebnisse durch weiterführende Analysen könnte zum besseren Verständnis von Regulationsmechanismen bei der Lymphangiogenese beitragen. Neben weiteren Analysen zur Charakterisierung von Lymphendothelzellen bei Mäusen und beim Menschen könnten Untersuchungen der Genexpression und des in vitro Verhaltens von peripheren mononukleären Blutzellen von Kindern Aufschluß darüber geben, ob zirkulierende Lymphangioblasten bei der Entwicklung von Lymphgefäßen beteiligt sind. Vergleichende Gen-Expressionsstudien dieser peripheren Zellen mit humanen Lymphendothelzellen ermöglichen gegebenenfalls die Identifizierung von weiteren Genen, die für die Regulation der Lymphangiogenese von Bedeutung sind. Vergleichbare Untersuchungen an peripheren Blutzellen von KS Patienten können weiteren Aufschluss über die Ursprungszelle der KS-Läsionen erbringen. Weiterhin besteht die Möglichkeit, 
Lymphangiogenese bei PPAR $\gamma$-knock-out-Mäusen $\mathrm{zu}$ untersuchen, deren Entwicklung durch einen ,Tetraploid-Rescue' weiter voranschreitet. Das Modell der Schnittkulturen kann ich nutzen, um weitere Angiogenesegene, z.B. VEGFR-2, bei der Lymphangiogenese $\mathrm{zu}$ untersuchen. 


\section{Zusammenfassung}

Seit mehr als einhundert Jahren wird der Ursprung des Lymphgefäßsystems kontrovers diskutiert. Die ersten morphologisch erfassbaren Lymphgefäßanlagen bei Vögeln, Säugetieren und dem Menschen sind die sogenannten Lymphsäcke. Sie entstehen in enger Assoziation zum Venensystem. Die tradierte Lehrmeinung über die Lymphgefäßentwicklung beschreibt die Entstehung der Lymphsäcke aus spezifischen Segmenten der tiefen embryonalen Venen. Lymphgefäße entstehen dann durch Sprossung von Lymphendothelzellen (LECs) aus den Lymphsäcken. Diese Ansicht wurde vor kurzem durch experimentelle Studien an Mausembryonen gestützt. Spezifische Marker für LECs, der Homeobox-Transkriptionsfaktor Prox1 und der Hyaluronsäure-Rezeptor Lyve-1, werden in spezifischen Segmenten des Venensystems exprimiert, aus denen die Lymphsäcke hervorgehen. Im Gegensatz dazu wurde vor einhundert Jahren eine Theorie veröffentlicht, die die Entstehung der Lymphsäcke und Lymphgefäße aus mesenchymalen Vorläuferzellen (Lymphangioblasten) postuliert. Neuere Transplantationsexperimente bei Vogelembryonen haben gezeigt, dass Zellen des paraxialen Mesoderms in der Lage sind, sich in das Endothel der Lymphsäcke und Lymphgefäße zu integrieren. Auch bei Fischen und Reptilien gibt es Hinweise auf einen mesenchymalen Ursprung des Lymphendothels.

Um die Existenz von Lymphangioblasten bei Mäusen und in humanem Blut auf zellulärer und molekularer Ebene $\mathrm{zu}$ untersuchen, habe ich deskriptive und experimentelle Untersuchungen durchgeführt. Mausembryonen früher Entwicklungsstadien wurden mit Antikörpern gegen Blut- und Lymphendothel, hämatopoetische Zellen und Makrophagen untersucht. Als erste Anlagen des Lymphgefäßsystems im Embryo sind lymphendotheliale Segmente der Kardinal- und Dottersackvenen an Embryonaltag (ET) 10,5 nachweisbar. Lymphsäcke, die in der Jugularregion von Mäusen an ET 11,5 entstehen, exprimieren Lymphendothel- und Pan-Endothelmarker, wenige Zellen auch Leukozytenmarker. Ein ähnliches Expressionsprofil weisen verstreute Einzelzellen im Mesenchym der Dermatome und des Mediastinums auf. Diese Einzelzellen liegen zum Teil in großem Abstand von den sich entwickelnden Lymphsäcken und sind zeitlich auch schon vor deren Entstehung vorhanden. Proliferationsstudien zeigen, dass die Lymphendothelzellen der Lymphsäcke und die lymphendothelialen Einzelzellen vergleichbar hohe Teilungsraten aufweisen. Eine Beteiligung der mesenchymalen Einzelzellen an der Entstehung von Lymphgefäßen könnte 
in einer Integration dieser Zellen in bereits bestehende Lymphgefäße liegen. Den deutlichsten Hinweis zur Unterstützung dieser Theorie konnte ich mit Dreifachfärbungen erzielen, in denen ich zwei Lymphendothelzell-Marker mit einem Makrophagen-Marker kombiniert habe. Diese Daten deuten auf einen dualen Ursprung der Lymphgefäße in Mäusen hin. Die primäre Quelle der Lymphendothelzellen liegt in spezifischen Abschnitten embryonaler Venen, während sich mesenchymale Lymphangioblasten, die Makrophagen-Charakteristika besitzen, offenbar sekundär in die Lymphgefäße integrieren. Dabei wird die Entwicklung der Lymphgefäße durch den Vascular Endothelial Growth Factor-C (VEGF-C) gefördert. Das habe ich an Schnittkulturen von Mausembryonen untersucht. Nach Applikation von VEGF-C konnte ich in den Kulturen Lymphangiogenese auch in solchen embryonalen Segmenten beobachten, die ohne VEGF-C keine Lymphgefäße ausbildeten. Dieses zeigt, dass weite Bereiche des Embryos lymphangiogenes Potential besitzen.

Ich bin dann der Frage nachgegangen, ob Einzelzellen mit lymphendothelialen Charakteristika auch beim Menschen, insbesondere bei Kindern, vorkommen. Es gibt Hinweise darauf, dass endotheliale Vorläuferzellen im peripheren Blut von Menschen zirkulieren. Zur Identifizierung und Charakterisierung von Lymphangioblasten habe ich mononukleäre Zellen aus peripherem Blut (PBMCs) von Kindern und Erwachsenen mit Lymphendothel-, Blutendothel- und Leukozytenmarkern sowie mit Markern für Vorläuferzellen untersucht. In Analogie zu den Lymphangioblasten in Mausembryonen weisen Subpopulationen der PBMCs charakteristische Marker von Lymphendothelzellen auf. RNA-Expressionsstudien bestätigen dieses Resultat. Meine Befunde zeigen, dass lymphendotheliale Zellen, die den mittelgroßen Lymphozyten zugerechnet werden können, bei Kindern mit einer Häufigkeit von 1 - 175 / $\mu$ 1 Blut vorkommen. Diese Zellen scheinen vor allem bei der pahologischen Lymphangiogenese von Bedeutung $\mathrm{zu}$ sein und stellen vermutlich die Ursprungszelle des Kaposi-Sarkoms dar.

In weiteren Untersuchungen habe ich primäre, humane Blut- und Lymphendothelzellen molekular verglichen und dabei die Expression von PPAR $\gamma$ (Peroxisome Proliferatorassociated Receptor gamma) in Lymphendothelzellen detektiert. Um die Bedeutung von PPAR $\gamma$ bei der Lymphangiogenese zu charakterisieren, habe ich PPAR $\gamma$-knock-out-Mäuse immunhistologisch und an Schnittkulturen untersucht. Da laut Literatur PPAR $\gamma$-knock-out- 
Mäuse an ET 10 sterben, habe ich 25 Mausembryonen an ET 9,5 drei Tage lang in Kultur genommen. Homozygot mutierte Tiere konnte ich aber, entgegen den Erwartungen, nicht gewinnen. Offensichtlich sterben diese Embryonen vor ET 9,5 aufgrund von Plazentationsdefekten. In PPAR $\gamma$-heterozygoten Mausembryonen konnte ich morphologisch keine Veränderungen der Lymphangiogenese feststellen, jedoch war das Adhäsionsmolekül CD31/PECAM-1 in den Lymphendothelzellen praktisch nicht mehr nachweisbar. Die Bedeutung meiner Befunde für die normale und pathologische Lymphangiogenese wird diskutiert. 


\section{$7 \quad$ Literaturverzeichnis}

Aboul-Enein A, Eshmawy I, Arafa S, Abboud A. 1984. The role of lymphovenous communication in the development of postmastectomy lymphedema. Surgery 95:562-566.

Abtahian F, Guerriero A, Sebzda E, Lu MM, Zhou R, Mocsai A, Myers EE, Huang B, Jackson DG, Ferrari VA, Tybulewicz V, Lowell CA, Lepore JJ, Koretzky GA, Kahn ML. 2003. Regulation of blood and lymphatic vascular separation by signaling proteins SLP-76 and Syk. Science 299:247-251.

Alitalo K, Tammela T, Petrova TV. 2005. Lymphangiogenesis in development and human disease. Nature 438:946-953.

Ameshima S, Golpon H, Cool CD, Chan D, Vandivier RW, Gardai SJ, Wick M, Nemenoff RA, Geraci MW, Voelkel NF. 2003. Peroxisome proliferator-activated receptor gamma (PPARgamma) expression is decreased in pulmonary hypertension and affects endothelial cell growth. Circ Res 92:1162-1169.

Antman K, Chang Y. 2000. Kaposi's sarcoma. N Engl J Med 342:1027-1038.

Asellius G. 1627. De lactibus sive lacteis venis, Quarto Vasorum Mesarai corum Genere novo invento. Milan: Mediolani.

Baldwin ME, Halford MM, Roufail S, Williams RA, Hibbs ML, Grail D, Kubo H, Stacker SA, Achen MG. 2005. Vascular endothelial growth factor D is dispensable for development of the lymphatic system. Mol Cell Biol 25:2441-2449.

Banerji S, Ni J, Wang SX, Clasper S, Su J, Tammi R, Jones M, Jackson DG. 1999. LYVE1 , a new homologue of the CD44 glycoprotein, is a lymph-specific receptor for hyaluronan. J Cell Biol 144:789-801.

Barak Y, Nelson MC, Ong ES, Jones YZ, Ruiz-Lozano P, Chien KR, Koder A, Evans RM. 1999. PPAR gamma is required for placental, cardiac, and adipose tissue development. Mol Cell 4:585-595.

Barozzi P, Luppi M, Facchetti F, Mecucci C, Alu M, Sarid R, Rasini V, Ravazzini L, Rossi E, Festa S, Crescenzi B, Wolf DG, Schulz TF, Torelli G. 2003. Post-transplant Kaposi sarcoma originates from the seeding of donor-derived progenitors. Nat Med 9:554-561.

Barsky SH, Baker A, Siegal GP, Togo S, Liotta LA. 1983. Use of anti-basement membrane antibodies to distinguish blood vessel capillaries from lymphatic capillaries. Am J Surg Pathol 7:667-677.

Berens von Rautenfeld D, Drenckhahn D. 1994. Bau der Lymphgefäße. In: Drenckhahn D, Zenker W, editors. Benninghoff, Alfred: Anatomie: Makroskopische Anatomie, Embryologie und Histologie des Menschen. München: Urban \& Schwarzenberg. pp 756-761. 
Boardman KC, Swartz MA. 2003. Interstitial flow as a guide for lymphangiogenesis. Circ Res 92:801-808.

Braissant O, Wahli W. 1998. Differential expression of peroxisome proliferator-activated receptor-alpha, -beta, and -gamma during rat embryonic development. Endocrinology 139:2748-2754.

Breiteneder-Geleff S, Matsui K, Soleiman A, Meraner P, Poczewski H, Kalt R, Schaffner G, Kerjaschki D. 1997. Podoplanin, novel 43-kd membrane protein of glomerular epithelial cells, is down-regulated in puromycin nephrosis. Am J Pathol 151:11411152.

Breiteneder-Geleff S, Soleiman A, Kowalski H, Horvat R, Amann G, Kriehuber E, Diem K, Weninger W, Tschachler E, Alitalo K, Kerjaschki D. 1999. Angiosarcomas express mixed endothelial phenotypes of blood and lymphatic capillaries: podoplanin as a specific marker for lymphatic endothelium. Am J Pathol 154:385394.

Budge A. 1880. Über ein Kanalsystem im Mesoderm von Hühnerembryonen. Arch Anat Entwickl-Gesch:320-328.

Budge A. 1882. Über Lymphherzen bei Hühnerembryonen. Arch Anat EntwicklGesch:350-359.

Burgio VL, Zupo S, Roncella S, Zocchi M, Ruco LP, Baroni CD. 1994. Characterization of EN4 monoclonal antibody: a reagent with CD31 specificity. Clin Exp Immunol 96:170-176.

Buttler K, Ezaki T, Wilting J. 2008. Proliferating mesodermal cells in murine embryos exhibiting macrophage and lymphendothelial characteristics. BMC Dev Biol 8:43.

Buttler K, Kreysing A, von Kaisenberg CS, Schweigerer L, Gale N, Papoutsi M, Wilting J. 2006. Mesenchymal cells with leukocyte and lymphendothelial characteristics in murine embryos. Dev Dyn 235:1554-1562.

Casley-Smith JR. 1980. The fine structure and functioning of tissue channels and lymphatics. Lymphology 13:177-183.

Chang Y, Cesarman E, Pessin MS, Lee F, Culpepper J, Knowles DM, Moore PS. 1994. Identification of herpesvirus-like DNA sequences in AIDS-associated Kaposi's sarcoma. Science 266:1865-1869.

Cheung L, Rockson SG. 2005. The lymphatic biology of Kaposi's sarcoma. Lymphat Res Biol 3:25-35.

Cho NK, Keyes L, Johnson E, Heller J, Ryner L, Karim F, Krasnow MA. 2002.

Developmental control of blood cell migration by the Drosophila VEGF pathway. Cell 108:865-876.

Clark ER. 1909. Observations on living growing lymphatics in the tail of the frog larva. Anat Rec 3:183-198. 
Dictor M. 1986. Kaposi's sarcoma. Origin and significance of lymphaticovenous connections. Virchows Arch A Pathol Anat Histopathol 409:23-35.

Duchek P, Rorth P. 2001. Guidance of cell migration by EGF receptor signaling during Drosophila oogenesis. Science 291:131-133.

Duchek P, Somogyi K, Jekely G, Beccari S, Rorth P. 2001. Guidance of cell migration by the Drosophila PDGF/VEGF receptor. Cell 107:17-26.

Dumont DJ, Jussila L, Taipale J, Lymboussaki A, Mustonen T, Pajusola K, Breitman M, Alitalo K. 1998. Cardiovascular failure in mouse embryos deficient in VEGF receptor-3. Science 282:946-949.

Eichmann A, Corbel C, Nataf V, Vaigot P, Breant C, Le Douarin NM. 1997. Liganddependent development of the endothelial and hemopoietic lineages from embryonic mesodermal cells expressing vascular endothelial growth factor receptor 2. Proc Natl Acad Sci U S A 94:5141-5146.

Eichmann A, Marcelle C, Breant C, Le Douarin NM. 1993. Two molecules related to the VEGF receptor are expressed in early endothelial cells during avian embryonic development. Mech Dev 42:33-48.

Ezaki T, Kuwahara K, Morikawa S, Shimizu K, Sakaguchi N, Matsushima K, Matsuno K. 2006. Production of two novel monoclonal antibodies that distinguish mouse lymphatic and blood vascular endothelial cells. Anat Embryol (Berl) 211:379-393.

Ezaki T, Matsuno K, Fujii H, Hayashi N, Miyakawa K, Ohmori J, Kotani M. 1990. A new approach for identification of rat lymphatic capillaries using a monoclonal antibody. Arch Histol Cytol 53 Suppl:77-86.

Fang J, Dagenais SL, Erickson RP, Arlt MF, Glynn MW, Gorski JL, Seaver LH, Glover TW. 2000. Mutations in FOXC2 (MFH-1), a forkhead family transcription factor, are responsible for the hereditary lymphedema-distichiasis syndrome. Am J Hum Genet 67:1382-1388.

Ferrara N, Alitalo K. 1999. Clinical applications of angiogenic growth factors and their inhibitors. Nat Med 5:1359-1364.

Filston HC. 1994. Hemangiomas, cystic hygromas, and teratomas of the head and neck. Semin Pediatr Surg 3:147-159.

Flotte TJ, Springer TA, Thorbecke GJ. 1983. Dendritic cell and macrophage staining by monoclonal antibodies in tissue sections and epidermal sheets. Am J Pathol 111:112-124.

Fülleborn F. 1895. Beiträge zur Entwicklung der Allantois der Vögel. In. Berlin. pp 1-17.

Gale NW, Prevo R, Espinosa J, Ferguson DJ, Dominguez MG, Yancopoulos GD, Thurston G, Jackson DG. 2007. Normal lymphatic development and function in mice deficient for the lymphatic hyaluronan receptor LYVE-1. Mol Cell Biol 27:595604. 
Gallo RC. 1998. The enigmas of Kaposi's sarcoma. Science 282:1837-1839.

Hanahan D. 1997. Signaling vascular morphogenesis and maintenance. Science 277:48-50.

Harvey NL, Srinivasan RS, Dillard ME, Johnson NC, Witte MH, Boyd K, Sleeman MW, Oliver G. 2005. Lymphatic vascular defects promoted by Prox 1 haploinsufficiency cause adult-onset obesity. Nat Genet 37:1072-1081.

Heino TI, Karpanen T, Wahlstrom G, Pulkkinen M, Eriksson U, Alitalo K, Roos C. 2001. The Drosophila VEGF receptor homolog is expressed in hemocytes. Mech Dev 109:69-77.

Hirschberg H, Bergh OJ, Thorsby E. 1980. Antigen-presenting properties of human vascular endothelial cells. J Exp Med 152:249s-255s.

Hong YK, Harvey N, Noh YH, Schacht V, Hirakawa S, Detmar M, Oliver G. 2002. Prox1 is a master control gene in the program specifying lymphatic endothelial cell fate. Dev Dyn 225:351-357.

Hoyer H, Michalski L. 1922. Das Lymphgefäßsystem von Forellenembryonen nebst Bemerkungen über die Verteilung der Blutgefäße. Gegenbaurs Morphol Jahrb. 1-89 pp.

Huber TL, Kouskoff V, Fehling HJ, Palis J, Keller G. 2004. Haemangioblast commitment is initiated in the primitive streak of the mouse embryo. Nature 432:625-630.

Huntington GS. 1914. The development of the mammalian jugular lymph sac, of the tributary primitive ulnar lymphatic and of the thoracic ducts from the view point of recent investigations of vertebrate lymphatic ontogeny, together with a consideration of the genetic relations of lymphatic and haemal vascular channels in the embryos of amnitotes. Am J Anat 16:259-316.

Huntington GS, Mc Clure CFW. 1910. The anatomy and development of the jugular lymph sacs in the domestic cat (Felis domestica). Am J Anat 10:177-311.

Irrthum A, Karkkainen MJ, Devriendt K, Alitalo K, Vikkula M. 2000. Congenital hereditary lymphedema caused by a mutation that inactivates VEGFR3 tyrosine kinase. Am J Hum Genet 67:295-301.

Jackson DG, Prevo R, Clasper S, Banerji S. 2001. LYVE-1, the lymphatic system and tumor lymphangiogenesis. Trends Immunol 22:317-321.

Jeltsch M, Kaipainen A, Joukov V, Meng X, Lakso M, Rauvala H, Swartz M, Fukumura D, Jain RK, Alitalo K. 1997. Hyperplasia of lymphatic vessels in VEGF-C transgenic mice. Science 276:1423-1425.

Jeltsch M, Tammela T, Alitalo K, Wilting J. 2003. Genesis and pathogenesis of lymphatic vessels. Cell Tissue Res 314:69-84. 
Jie KE, Goossens MH, van Oostrom O, Lilien MR, Verhaar MC. 2008. Circulating endothelial progenitor cell levels are higher during childhood than in adult life. Atherosclerosis.

Joukov V, Pajusola K, Kaipainen A, Chilov D, Lahtinen I, Kukk E, Saksela O, Kalkkinen N, Alitalo K. 1996. A novel vascular endothelial growth factor, VEGF-C, is a ligand for the Flt4 (VEGFR-3) and KDR (VEGFR-2) receptor tyrosine kinases. Embo J 15:290-298.

Junghans BM, Collin HB. 1989. Limbal lymphangiogenesis after corneal injury: an autoradiographic study. Curr Eye Res 8:91-100.

Kaaya EE, Parravicini C, Ordonez C, Gendelman R, Berti E, Gallo RC, Biberfeld P. 1995. Heterogeneity of spindle cells in Kaposi's sarcoma: comparison of cells in lesions and in culture. J Acquir Immune Defic Syndr Hum Retrovirol 10:295-305.

Kaipainen A, Korhonen J, Mustonen T, van Hinsbergh VW, Fang GH, Dumont D, Breitman M, Alitalo K. 1995. Expression of the fms-like tyrosine kinase 4 gene becomes restricted to lymphatic endothelium during development. Proc Natl Acad Sci U S A 92:3566-3570.

Kampmeier OF. 1912a. The development of the thoracic duct in the pig. Amer J Anat 13:401-476.

Kampmeier OF. 1912b. The value of the injection method in the study of lymphatic development. Anat Rec 6:223-233.

Karkkainen MJ, Ferrell RE, Lawrence EC, Kimak MA, Levinson KL, McTigue MA, Alitalo K, Finegold DN. 2000. Missense mutations interfere with VEGFR-3 signalling in primary lymphoedema. Nat Genet 25:153-159.

Karkkainen MJ, Haiko P, Sainio K, Partanen J, Taipale J, Petrova TV, Jeltsch M, Jackson DG, Talikka M, Rauvala H, Betsholtz C, Alitalo K. 2004. Vascular endothelial growth factor $\mathrm{C}$ is required for sprouting of the first lymphatic vessels from embryonic veins. Nat Immunol 5:74-80.

Kaufman MH. 2004. The Atlas of Mouse Development. London: Elsevier Academic Press.

Kerjaschki D, Huttary N, Raab I, Regele H, Bojarski-Nagy K, Bartel G, Krober SM, Greinix H, Rosenmaier A, Karlhofer F, Wick N, Mazal PR. 2006. Lymphatic endothelial progenitor cells contribute to de novo lymphangiogenesis in human renal transplants. Nat Med 12:230-234.

Kreuger J, Nilsson I, Kerjaschki D, Petrova T, Alitalo K, Claesson-Welsh L. 2006. Early lymph vessel development from embryonic stem cells. Arterioscler Thromb Vasc Biol 26:1073-1078.

Kriehuber E, Breiteneder-Geleff S, Groeger M, Soleiman A, Schoppmann SF, Stingl G, Kerjaschki D, Maurer D. 2001. Isolation and characterization of dermal lymphatic and blood endothelial cells reveal stable and functionally specialized cell lineages. J Exp Med 194:797-808. 
Kubik S, Manestar M, Molz G. 2003. Anatomy of the lymphatic system. In: Földi M, Földi E, Kubik S, editors. Textbook of Lymphology. München: Urban \& Fischer.

Kubo H, Alitalo K. 2003. The bloody fate of endothelial stem cells. Genes Dev 17:322329.

Kukk E, Lymboussaki A, Taira S, Kaipainen A, Jeltsch M, Joukov V, Alitalo K. 1996. VEGF-C receptor binding and pattern of expression with VEGFR-3 suggests a role in lymphatic vascular development. Development 122:3829-3837.

Lee J, Gray A, Yuan J, Luoh SM, Avraham H, Wood WI. 1996. Vascular endothelial growth factor-related protein: a ligand and specific activator of the tyrosine kinase receptor Flt4. Proc Natl Acad Sci U S A 93:1988-1992.

Lewis F. 1905. The development of the lymphatic system in Rabbits. Amer J Anat 5:95111.

Liao F, Huynh HK, Eiroa A, Greene T, Polizzi E, Muller WA. 1995. Migration of monocytes across endothelium and passage through extracellular matrix involve separate molecular domains of PECAM-1. J Exp Med 182:1337-1343.

Lin Y, Weisdorf DJ, Solovey A, Hebbel RP. 2000. Origins of circulating endothelial cells and endothelial outgrowth from blood. J Clin Invest 105:71-77.

Malorny U, Michels E, Sorg C. 1986. A monoclonal antibody against an antigen present on mouse macrophages and absent from monocytes. Cell Tissue Res 243:421-428.

Maruyama K, Asai J, Ii M, Thorne T, Losordo DW, D'Amore PA. 2007. Decreased macrophage number and activation lead to reduced lymphatic vessel formation and contribute to impaired diabetic wound healing. Am J Pathol 170:1178-1191.

Maruyama K, Ii M, Cursiefen C, Jackson DG, Keino H, Tomita M, Van Rooijen N, Takenaka H, D'Amore PA, Stein-Streilein J, Losordo DW, Streilein JW. 2005. Inflammation-induced lymphangiogenesis in the cornea arises from CD11bpositive macrophages. J Clin Invest 115:2363-2372.

Matsui K, Breitender-Geleff S, Soleiman A, Kowalski H, Kerjaschki D. 1999. Podoplanin, a novel 43-kDa membrane protein, controls the shape of podocytes. Nephrol Dial Transplant 14 Suppl 1:9-11.

Matsui K, Breiteneder-Geleff S, Kerjaschki D. 1998. Epitope-specific antibodies to the 43$\mathrm{kD}$ glomerular membrane protein podoplanin cause proteinuria and rapid flattening of podocytes. J Am Soc Nephrol 9:2013-2026.

Mocsai A, Zhou M, Meng F, Tybulewicz VL, Lowell CA. 2002. Syk is required for integrin signaling in neutrophils. Immunity 16:547-558.

Mouta Carreira C, Nasser SM, di Tomaso E, Padera TP, Boucher Y, Tomarev SI, Jain RK. 2001. LYVE-1 is not restricted to the lymph vessels: expression in normal liver blood sinusoids and down-regulation in human liver cancer and cirrhosis. Cancer Res 61:8079-8084. 
Muller WA. 1995. The role of PECAM-1 (CD31) in leukocyte emigration: studies in vitro and in vivo. J Leukoc Biol 57:523-528.

Muller WA, Weigl SA, Deng X, Phillips DM. 1993. PECAM-1 is required for transendothelial migration of leukocytes. J Exp Med 178:449-460.

Murray PDF. 1932. The development in vitro of the blood of the early chick embryo. Proc Roy Soc London 111:497-521.

Neufeld G, Cohen T, Gengrinovitch S, Poltorak Z. 1999. Vascular endothelial growth factor (VEGF) and its receptors. Faseb J 13:9-22.

Newman PJ. 1994. The role of PECAM-1 in vascular cell biology. Ann N Y Acad Sci 714:165-174.

Nickel R, Schummer A, Seiferle E. 1992. Lehrbuch der Anatomie der Haustiere Anatomie der Vögel. Berlin: Paul Parey.

Nobuhara Y, Onoda N, Fukai K, Hosomi N, Ishii M, Wakasa K, Nishihara T, Ishikawa T, Hirakawa K. 2006. TIE2 gain-of-function mutation in a patient with pancreatic lymphangioma associated with blue rubber-bleb nevus syndrome: report of a case. Surg Today 36:283-286.

Norgall S, Papoutsi M, Rössler J, Schweigerer L, Wilting J, Weich HA. 2007. Elevated expression of VEGFR-3 in lymphatic endothelial cells from lymphangiomas. BMC Cancer:in press.

Ny A, Koch M, Schneider M, Neven E, Tong RT, Maity S, Fischer C, Plaisance S, Lambrechts D, Heligon C, Terclavers S, Ciesiolka M, Kalin R, Man WY, Senn I, Wyns S, Lupu F, Brandli A, Vleminckx K, Collen D, Dewerchin M, Conway EM, Moons L, Jain RK, Carmeliet P. 2005. A genetic Xenopus laevis tadpole model to study lymphangiogenesis. Nat Med 11:998-1004.

Obergfell A, Judd BA, del Pozo MA, Schwartz MA, Koretzky GA, Shattil SJ. 2001. The molecular adapter SLP-76 relays signals from platelet integrin alphaIIbbeta3 to the actin cytoskeleton. J Biol Chem 276:5916-5923.

Oh SJ, Jeltsch MM, Birkenhager R, McCarthy JE, Weich HA, Christ B, Alitalo K, Wilting J. 1997. VEGF and VEGF-C: specific induction of angiogenesis and lymphangiogenesis in the differentiated avian chorioallantoic membrane. Dev Biol 188:96-109.

Oliver G, Alitalo K. 2005. The lymphatic vasculature: recent progress and paradigms. Annu Rev Cell Dev Biol 21:457-483.

Oliver G, Harvey N. 2002. A stepwise model of the development of lymphatic vasculature. Ann N Y Acad Sci 979:159-165; discussion 188-196.

Papoutsi M, Siemeister G, Weindel K, Tomarev SI, Kurz H, Schachtele C, Martiny-Baron G, Christ B, Marme D, Wilting J. 2000. Active interaction of human A375 melanoma cells with the lymphatics in vivo. Histochem Cell Biol 114:373-385. 
Papoutsi M, Tomarev SI, Eichmann A, Prols F, Christ B, Wilting J. 2001. Endogenous origin of the lymphatics in the avian chorioallantoic membrane. Dev Dyn 222:238251.

Parums DV, Cordell JL, Micklem K, Heryet AR, Gatter KC, Mason DY. 1990. JC70: a new monoclonal antibody that detects vascular endothelium associated antigen on routinely processed tissue sections. J Clin Pathol 43:752-757.

Pepper MS, Tille JC, Nisato R, Skobe M. 2003. Lymphangiogenesis and tumor metastasis. Cell Tissue Res 314:167-177.

Petrova TV, Makinen T, Makela TP, Saarela J, Virtanen I, Ferrell RE, Finegold DN, Kerjaschki D, Yla-Herttuala S, Alitalo K. 2002. Lymphatic endothelial reprogramming of vascular endothelial cells by the Prox-1 homeobox transcription factor. Embo J 21:4593-4599.

Popichenko D, Paululat A. 2004. Cell fate decisions in the Drosophila dorsal vessel depend on the multiadapter protein inscuteable. Genesis 40:218-222.

Prevo R, Banerji S, Ferguson DJ, Clasper S, Jackson DG. 2001. Mouse LYVE-1 is an endocytic receptor for hyaluronan in lymphatic endothelium. J Biol Chem 276:19420-19430.

Pullinger DB, Florey HW. 1937. Proliferation of lymphatics in inflammation. J Pathol Bacteriol 45:157-170.

Ranvier L. 1895. Développement des vaisseaux lymphatique des mammifères. Comptes Rendus de lÁcadémie des Sciences Paris 121:1105.

Regezi JA, MacPhail LA, Daniels TE, DeSouza YG, Greenspan JS, Greenspan D. 1993. Human immunodeficiency virus-associated oral Kaposi's sarcoma. A heterogeneous cell population dominated by spindle-shaped endothelial cells. Am J Pathol 143:240-249.

Reichert FL. 1926. The regeneration of the lymphatics. Arch Surg 13:871-881.

Religa P, Cao R, Bjorndahl M, Zhou Z, Zhu Z, Cao Y. 2005. Presence of bone marrowderived circulating progenitor endothelial cells in the newly formed lymphatic vessels. Blood 106:4184-4190.

Risau W. 1997. Mechanisms of angiogenesis. Nature 386:671-674.

Risau W, Flamme I. 1995. Vasculogenesis. Annu Rev Cell Dev Biol 11:73-91.

Rishi AK, Joyce-Brady M, Fisher J, Dobbs LG, Floros J, VanderSpek J, Brody JS, Williams MC. 1995. Cloning, characterization, and development expression of a rat lung alveolar type I cell gene in embryonic endodermal and neural derivatives. Dev Biol 167:294-306.

Rodriguez-Niedenfuhr M, Papoutsi M, Christ B, Nicolaides KH, von Kaisenberg CS, Tomarev SI, Wilting J. 2001. Prox1 is a marker of ectodermal placodes, 
endodermal compartments, lymphatic endothelium and lymphangioblasts. Anat Embryol (Berl) 204:399-406.

Rusznyák I, Földi M, Szabó G. 1969. Lymphologie. Physiologie und Pathologie der Lymphgefäße und des Lymphkreislaufes. Stuttgart: G. Fischer.

Rutgers JL, Wieczorek R, Bonetti F, Kaplan KL, Posnett DN, Friedman-Kien AE, Knowles DM, 2nd. 1986. The expression of endothelial cell surface antigens by AIDS-associated Kaposi's sarcoma. Evidence for a vascular endothelial cell origin. Am J Pathol 122:493-499.

Rutkowski JM, Boardman KC, Swartz MA. 2006. Characterization of lymphangiogenesis in a model of adult skin regeneration. Am J Physiol Heart Circ Physiol.

Sabin FR. 1902. On the origin of the lymphatic system from the veins and the development of the lymph hearts and thoracic duct in the pig. Amer J Anat 1:367-389.

Sabin FR. 1904. On the development of the superficial lymphatics in the skin of the pig. Amer J Anat 3:183-195.

Sabin FR. 1909. The lymphatic system in human embryos, with a consideration of the morphology of the system as a whole. Amer J Anat 9:43-91.

Sabin FR. 1920. Studies on the origin of blood-vessels and of red blood corpuscles as seen in the living blastoderm of chicks during the second day of incubation. Carnegie Contrib Embryol 272:214-262.

Sadler TW. 2003. Medizinische Embryologie. 10. Auflage. Stuttgart: Thieme.

Sala L. 1900. Sullo sviluppo dei cuori linfatici e dei dotti torici nell' embryone di pollo. Ric Lab Anat Norm Univ Roma 7:899-1000.

Salven P, Mustjoki S, Alitalo R, Alitalo K, Rafii S. 2003. VEGFR-3 and CD133 identify a population of CD34+ lymphatic/vascular endothelial precursor cells. Blood 101:168-172.

Sambrook J, Fritsch EF, Maniatis T. 1989. Molecular Cloning: A Laboratory Manual. Cold Spring Harbor, NY: Cold Spring Harbor Laboratory Press.

Sauter B, Foedinger D, Sterniczky B, Wolff K, Rappersberger K. 1998. Immunoelectron microscopic characterization of human dermal lymphatic microvascular endothelial cells. Differential expression of CD31, CD34, and type IV collagen with lymphatic endothelial cells vs blood capillary endothelial cells in normal human skin, lymphangioma, and hemangioma in situ. J Histochem Cytochem 46:165-176.

Schacht V, Ramirez MI, Hong YK, Hirakawa S, Feng D, Harvey N, Williams M, Dvorak AM, Dvorak HF, Oliver G, Detmar M. 2003. T1alpha/podoplanin deficiency disrupts normal lymphatic vasculature formation and causes lymphedema. Embo J 22:3546-3556. 
Schledzewski K, Falkowski M, Moldenhauer G, Metharom P, Kzhyshkowska J, Ganss R, Demory A, Falkowska-Hansen B, Kurzen H, Ugurel S, Geginat G, Arnold B, Goerdt S. 2006. Lymphatic endothelium-specific hyaluronan receptor LYVE-1 is expressed by stabilin-1+, F4/80+, CD11b+ macrophages in malignant tumours and wound healing tissue in vivo and in bone marrow cultures in vitro: implications for the assessment of lymphangiogenesis. J Pathol 209:67-77.

Schneider M, Othman-Hassan K, Christ B, Wilting J. 1999. Lymphangioblasts in the avian wing bud. Dev Dyn 216:311-319.

Scholzen T, Gerdes J. 2000. The Ki-67 protein: from the known and the unknown. J Cell Physiol 182:311-322.

Schoppmann SF, Birner P, Stockl J, Kalt R, Ullrich R, Caucig C, Kriehuber E, Nagy K, Alitalo K, Kerjaschki D. 2002. Tumor-associated macrophages express lymphatic endothelial growth factors and are related to peritumoral lymphangiogenesis. Am J Pathol 161:947-956.

Sebzda E, Hibbard C, Sweeney S, Abtahian F, Bezman N, Clemens G, Maltzman JS, Cheng L, Liu F, Turner M, Tybulewicz V, Koretzky GA, Kahn ML. 2006. Syk and Slp-76 mutant mice reveal a cell-autonomous hematopoietic cell contribution to vascular development. Dev Cell 11:349-361.

Shalaby F, Rossant J, Yamaguchi TP, Gertsenstein M, Wu XF, Breitman ML, Schuh AC. 1995. Failure of blood-island formation and vasculogenesis in Flk-1-deficient mice. Nature 376:62-66.

Skobe M, Hamberg LM, Hawighorst T, Schirner M, Wolf GL, Alitalo K, Detmar M. 2001a. Concurrent induction of lymphangiogenesis, angiogenesis, and macrophage recruitment by vascular endothelial growth factor-C in melanoma. Am J Pathol 159:893-903.

Skobe M, Hawighorst T, Jackson DG, Prevo R, Janes L, Velasco P, Riccardi L, Alitalo K, Claffey K, Detmar M. 2001b. Induction of tumor lymphangiogenesis by VEGF-C promotes breast cancer metastasis. Nat Med 7:192-198.

Srinivasan RS, Dillard ME, Lagutin OV, Lin FJ, Tsai S, Tsai MJ, Samokhvalov IM, Oliver G. 2007. Lineage tracing demonstrates the venous origin of the mammalian lymphatic vasculature. Genes Dev 21:2422-2432.

Stacker SA, Caesar C, Baldwin ME, Thornton GE, Williams RA, Prevo R, Jackson DG, Nishikawa S, Kubo H, Achen MG. 2001. VEGF-D promotes the metastatic spread of tumor cells via the lymphatics. Nat Med 7:186-191.

Uccini S, Sirianni MC, Vincenzi L, Topino S, Stoppacciaro A, Lesnoni La Parola I, Capuano M, Masini C, Cerimele D, Cella M, Lanzavecchia A, Allavena P, Mantovani A, Baroni CD, Ruco LP. 1997. Kaposi's sarcoma cells express the macrophage-associated antigen mannose receptor and develop in peripheral blood cultures of Kaposi's sarcoma patients. Am J Pathol 150:929-938. 
van der Putte SC. 1975a. The development of the lymphatic system in man. Adv Anat Embryol Cell Biol 51:3-60.

van der Putte SC. 1975b. The early development of the lymphatic system in mouse embryos. Acta Morphol Neerl Scand 13:245-286.

Weiss C, Jelkmann W. 1997. Physiologie des Menschen. Berlin: Springer.

Welsch U. 2006. Lehrbuch Histologie. München: Urban \& Fischer.

Wetterwald A, Hoffstetter W, Cecchini MG, Lanske B, Wagner C, Fleisch H, Atkinson M. 1996. Characterization and cloning of the E11 antigen, a marker expressed by rat osteoblasts and osteocytes. Bone 18:125-132.

Wigle JT, Harvey N, Detmar M, Lagutina I, Grosveld G, Gunn MD, Jackson DG, Oliver G. 2002. An essential role for Prox 1 in the induction of the lymphatic endothelial cell phenotype. Embo J 21:1505-1513.

Wigle JT, Oliver G. 1999. Prox1 function is required for the development of the murine lymphatic system. Cell 98:769-778.

Wilting J, Aref Y, Huang R, Tomarev SI, Schweigerer L, Christ B, Valasek P, Papoutsi M. 2006. Dual origin of avian lymphatics. Dev Biol 292:165-173.

Wilting J, Christ B. 1996. Embryonic angiogenesis: a review. Naturwissenschaften 83:153164.

Wilting J, Christ B, Weich HA. 1992. The effects of growth factors on the day 13 chorioallantoic membrane (CAM): a study of VEGF165 and PDGF-BB. Anat Embryol (Berl) 186:251-257.

Wilting J, Christ B, Yuan L, Eichmann A. 2003a. Cellular and molecular mechanisms of embryonic haemangiogenesis and lymphangiogenesis. Naturwissenschaften 90:433-448.

Wilting J, Eichmann A, Christ B. 1997. Expression of the avian VEGF receptor homologues Quek1 and Quek2 in blood-vascular and lymphatic endothelial and non-endothelial cells during quail embryonic development. Cell Tissue Res 288:207-223.

Wilting J, Hawighorst T, Hecht M, Christ B, Papoutsi M. 2005. Development of lymphatic vessels: tumour lymphangiogenesis and lymphatic invasion. Curr Med Chem 12:3043-3053.

Wilting J, Neeff H, Christ B. 1999. Embryonic lymphangiogenesis. Cell Tissue Res 297:111.

Wilting J, Papoutsi M, Becker J. 2004. The lymphatic vascular system: secondary or primary? Lymphology 37:98-106. 
Wilting J, Papoutsi M, Christ B, Nicolaides KH, von Kaisenberg CS, Borges J, Stark GB, Alitalo K, Tomarev SI, Niemeyer C, Rossler J. 2002. The transcription factor Prox 1 is a marker for lymphatic endothelial cells in normal and diseased human tissues. Faseb J 16:1271-1273.

Wilting J, Tomarev SI, Christ B, Schweigerer L. 2003b. Lymphangioblasts in embryonic lymphangiogenesis. Lymphat Res Biol 1:33-40.

Witte MH, Bernas MJ, Martin CP, Witte CL. 2001. Lymphangiogenesis and lymphangiodysplasia: from molecular to clinical lymphology. Microsc Res Tech 55:122-145.

Witte MH, Jones K, Wilting J, Dictor M, Selg M, McHale N, Gershenwald JE, Jackson DG. 2006. Structure function relationships in the lymphatic system and implications for cancer biology. Cancer Metastasis Rev 25:159-184.

Xin X, Yang S, Kowalski J, Gerritsen ME. 1999. Peroxisome proliferator-activated receptor gamma ligands are potent inhibitors of angiogenesis in vitro and in vivo. $\mathrm{J}$ Biol Chem 274:9116-9121.

Xu H, Chen M, Reid DM, Forrester JV. 2007. LYVE-1-positive macrophages are present in normal murine eyes. Invest Ophthalmol Vis Sci 48:2162-2171.

Yamaguchi TP, Dumont DJ, Conlon RA, Breitman ML, Rossant J. 1993. flk-1, an fltrelated receptor tyrosine kinase is an early marker for endothelial cell precursors. Development 118:489-498.

Yancopoulos GD, Davis S, Gale NW, Rudge JS, Wiegand SJ, Holash J. 2000. Vascularspecific growth factors and blood vessel formation. Nature 407:242-248.

Yaniv K, Isogai S, Castranova D, Dye L, Hitomi J, Weinstein BM. 2006. Live imaging of lymphatic development in the zebrafish. Nat Med 12:711-716. 


\section{Anhang}

\subsection{Abbildungs- und Tabellenverzeichnis}

Abb. 1: Querschnitte verschiedener Entwicklungsstadien des Mesoderms / der Somiten beim Menschen

Abb. 2: $\quad$ Schema der Gefäßentwicklung

Abb. 3: Entwicklung von Endothelzellen und Zellen der hämatopoetischen Reihe

Abb. 4: Theorien über die Entstehung von Lymphgefäßen

Abb. 5: Mausembryo des ET 10,5 und schematische Darstellung

Abb. 6: Schematische Darstellung eines Mausembryos des ET 9,5

Abb. 7: HE-Färbung von Paraffinschnitten von Mausembryonen der ET 11,5, 12,5 und 13,5

Abb. 8: Anti-Lyve-1-Färbung von Paraffinschnitten von Mausembryonen der ET 10,5 13,5

Abb. 9: Anti-Lyve-1 / LA102-Doppelfärbung an Kryoschnitten von Mausembryonen der ET 13,5 und 12,5

Abb. 10: Anti-Lyve-1 / CD31-Doppelfärbung an Kryoschnitten von Mausembryonen der ET 11,5 und 12,5

Abb. 11: Anti-Lyve-1 / CD45-Doppelfärbung an Kryoschnitten von Mausembryonen der ET 10,5, 12,5 und 13,5

Abb. 12: Anti-Lyve-1 / Prox1-Doppelfärbung an Kryoschnitten von Mausembryonen an ET 13,5

Abb. 13: Anti-Prox1 / LA102-Doppelfärbung an Kryoschnitten von Mausembryonen der ET 12,5 und 13,5

Abb. 14: Anti-Prox1 / CD31-Doppelfärbung an Kryoschnitten von Mausembryonen der ET 12,5 und 10,5

Abb. 15: Anti-Prox1 / CD45-Doppelfärbung an Kryoschnitten von Mausembryonen an ET 11,5

Abb. 16: Anti-CD11b / Prox1 bzw. Lyve-1-Doppelfärbungen an Kryoschnitten von Mausembryonen der ET 13,5 und 12,5

Abb. 17: Anti-F4/80 / Prox1 / Lyve-1-Dreifachfärbung an Kryoschnitten von Mausembryonen an ET 13,5

Abb. 18: Anti-Ki-67-Färbung an Paraffinschnitten von Mausembryonen an ET 12,5

Abb. 19: Anti-Ki-67 / Lyve-1-Doppelfärbung an Paraffinschnitten und Ki-67 / Prox1Doppelfärbung an Kryoschnitten von Mausembryonen der ET 11,5, 12,5 und 13,5

Abb. 20: Proliferationsraten von LECs in Mausembryonen der ET 12,5 und 13,5

Abb. 21: Anti-CD31 / Lyve-1-Färbung an Schnittkulturen von Mausembryonen

Abb. 22: Anti-CD31 / Lyve-1-Färbung an Schnittkulturen von Mausembryonen nach Zugabe von VEGF-C und ohne VEGF-C

Abb. 23: Auftrennung der extrahierten RNA in einem Agarosegel

Abb. 24: Nachweis von Lyve-1-, Prox1- und Podoplanin-mRNA mittels RT-PCR

Abb. 25: FACS-Analysen von separierten PBMCs, gefärbt mit dem Primärantikörper Lyve-1 und einem Alexa 488-konjugierten Sekundärantikörper

Abb. 26: Anti-Lyve-1 bzw. Prox1 / CD31-Doppelfärbungen von Blutausstrichen und Zytospins 
Abb. 27: Anti-Lyve-1 bzw. Prox1 / CD45-Doppelfärbungen von Blutausstrichen und Zytospins

Abb. 28: Anti-Lyve-1 / Podoplanin-Doppelfärbung von Zytospins

Abb. 29: Anti-Lyve-1 bzw. Prox1 / CD34-Doppelfärbungen von Zytospins

Abb. 30: Blut- (HUVECs) und Lymphendothelzellen (LECs) in vitro

Abb. 31: Relative PPAR $\gamma$-Expression von LECs und HUVECs

Abb. 32: Gelelektrophoretische Auftrennung von PCR-Produkten für den Nachweis des PPAR $\gamma$-Wildtyp- und Mutationsallels

Abb. 33: Anti-Lyve-1 / CD31-Färbung der Schnittkulturen von Wildtyp- und heterozygoten PPAR $\gamma$-Mäusen

Abb. 34: Makroskopischer und mikroskopischer Vergleich von PPAR $\gamma$-Wildtyp- und heterozygoten ET 13,5 Mäusen

Tabelle 1: Primärantikörper für Immunhistologische Untersuchungen

Tabelle 2: Gekoppelte Sekundärantikörper für Immunhistologische Untersuchungen und FACS-Analysen

Tabelle 3: Absolute und relative Anzahl von Ki-67-positiven LECs in Mausembryonen der ET 12,5 und 13,5 


\subsection{Publikationen}

\subsubsection{Originalpublikationen}

Buttler, K, Ezaki, T, Wilting, J. 2008. Proliferating mesodermal cells in murine embryos exhibiting macrophage and lymphendothelial characteristics. BMC Dev Biol 8:43

Kasten, P, Schnöink, G, Bergmann A, Papoutsi, M, Buttler, K, Rössler, J, Weich, HA, Wilting, J. 2007. Similarities and differences of human and experimental mouse lymphangiomas. Dev Dyn 236:2952-61

Wilting, J, Buttler, K, Schulte, I, Papoutsi, M, Schweigerer, L, Manner, J. 2007. The proepicardium delivers hemangioblasts but not lymphangioblasts to the developing heart. Dev Biol 305:451-459

Buttler, K, Kreysing, A, Kaisenberg, CS von, Schweigerer, L, Gale, N, Papoutsi, M, Wilting, J. 2006. Mesenchymal cells with leukocyte and lymphendothelial characteristics in muringe embryos. Dev Dyn 235:1554-62

\subsubsection{Buchbeiträge}

Wilting, J, Buttler, K, Rössler, R, Norgall, S, Schweigerer, L, Weich, HA, Papoutsi, M. Embryonic development and malformation of lymphatic vessels. In: Novartis Foundation Symposium No. 283 „,Vascular Development“. John Wiley, Chichester, 2007, pp 220-229

Wilting, J, Papoutsi, M, Buttler, K, Becker, J. Embryonic development of lymphovascular system and tumour lymphangiogenesis. In: Cancer metastasis and the lymphovascular system (ed. Leong S.P.L.) Springer, New York, 2007, pp 17-24

\subsubsection{Abstracts}

Wilting, J, Papoutsi, M, Buttler, K, Kreysing, A, Schweigerer, L. 2005. Embryonic development of the lymphatic system and tumor lymphangiogenesis. Eur J Lymphol 15:14

\subsubsection{Posterpräsentationen}

5. Internationales Kloster Seeon Meeting "Angiogenesis: Molecular Mechanisms and Functional Interactions", Kloster Seeon, 20.-23.09.2008: Lymphendothelial characteristics of peripheral blood mononuclear cells (PMBCs) of children.

Gordon Research Conference "Molecular mechanisms in lymphatic function and disease", Ventura, USA, 02. - 07.03.2008: Similarities and differences of human and experimental mouse lymphangiomas. 
2. Internationales Symposium "Cancer Metastasis and the Lymphovascular System: Basis for Rational Therapy", San Francisco, USA, 03. - 05.05.2007: Fluorescent imaging of the murine lymphatic system and postnatal lymphangiogenesis.

4. Internationales Kloster Seeon Meeting "Angiogenesis: Molecular Mechanisms and Functional Interactions", Kloster Seeon, 16. - 19.09.2006: Embryonic development and malformation of lymphatic vessels.

Internationales Symposium des Graduiertenkollegs 1034 "Pharmacogenomics: Genetic variation and pharmacogenomics in oncology", Göttingen, 14. - 15.07.2006: Precursor cells in normal and pathologic lymphangiogenesis.

3. Internationales Symposium des "German Priority Research Program SPP 1069, Angiogenesis", Kloster Seeon, 18. - 21.09.2004: Dual origin of avian lymphatics: comparison with murine embryos.

\subsubsection{Vorträge}

Teile dieser Arbeit wurden öffentlich als Vortrag auf folgender Tagung präsentiert (2. Chairman):

33. Kongress der „European Group of Lymphology“, Prag, 12. - 13.05.2007: Dual origin of lymphatic vessels in murine and avian embryos. 


\subsection{Danksagung}

Während der Durchführung dieser Arbeit, haben mir viele Personen unterstützend zur Seite gestanden. Bei ihnen möchte ich mich hiermit herzlich bedanken. Insbesondere gilt mein Dank Herrn Prof. Dr. E. A. Wimmer für die Bereitschaft, diese Arbeit zu betreuen und zu begutachten, sowie für Diskussionen und Anregungen im Fortgang meiner Arbeit. Herrn Prof. Dr. T. Pieler danke ich für die Übernahme des Korreferats.

Mein besonderer Dank gilt Herrn Prof. Dr. Jörg Wilting für die interessante und offen gestaltete Aufgabenstellung, die Raum für zahlreiche Ideen ließ. Neben der vielfältigen Unterstützung und intensiven Betreuung der Arbeit waren auch die Besuche nationaler und internationaler Kongresse sowie ein Labor-Auslandsaufenthalt, die duch ihn ermöglicht wurden, immer wieder motivierend.

Herrn Prof. Dr. M. Lakomek möchte ich dafür danken, dass ich den überwiegenden Teil meiner Versuche in den Laboren der Abteilung Pädiatrie I, Kinderheilkunde und Jugendmedizin, durchführen konnte. Beim Erlernen der Methoden war die fachliche Unterstützung von Dr. Maria Papoutsi, Dr. Martina Vockerodt und Dr. Jürgen Becker sehr hilfreich. Einen ganz besonderen Dank möchte ich auf diesem Wege Sonja Volland zukommen lassen, die nicht nur den Laboralltag erfrischt hat, sondern mir oftmals mit freundschaftlichem Rat zur Seite stand, wenn mal wieder ,,irgendetwas“ nicht so rund lief.

Dem Graduiertenkolleg 1034 „Die Bedeutung genetischer Polymorphismen in der Onkologie" danke ich für die Unterstützung und das vielfältige Ausbildungsprogrammm. Der Austausch mit den Kollegiaten war sehr hilfreich und freundschaftlich.

Herr Dr. L. Pardo vom MPI für experimentelle Medizin, Göttingen, und Frau B. Preitz aus der Abteilung Entwicklungsbiologie der Georg-August-Universität haben mir bei der konfokalen Laser-Scanning-Mikroskopie sehr geholfen. Vielen Dank dafür.

Die Arbeitsgruppe von Herrn Prof. Dr. Wahli von der Universität Lausanne in der Schweiz ermöglichte es mir, genetisch veränderte Mäuse zu untersuchen. Herzlichen Dank.

Meine „Finalphase“ in der Anatomie und Zellbiologie wurde durch die freundliche Aufnahme in die Abteilung und die Hilfsbereitschaft meiner Kolleginnen und Kollegen sehr erleichtert. Vielen Dank für die immerwährende Unterstützung, sei es im Laboralltag, beim Korrekturlesen dieser Arbeit oder in sonstigen scheinbar ausweglosen Situationen.

Meinen Eltern und meiner Schwester mit Familie möchte ich von ganzem Herzen für ihr bedingungsloses Verständnis und ihr Interesse an meiner Arbeit danken. Ständigen Rückhalt hat mir Peter gegeben. Er ermutigte mich stets aufs Neue, zuversichtlich zu sein. Danke! 


\section{Lebenslauf}

Angaben zur Person

Name:

Geburtsdatum / -ort:

Staatsangehörigkeit:

Familienstand:

Schulausbildung

1973 - 1977

$1977-1983$

$1983-1986$

Soziales Jahr

1986 - 1987

Beruflicher Werdegang

1987 - 1990

$1990-1996$

Wissenschaftlicher Werdegang $1996-2001$

2001

$2001-2003$

$2003-2004$

$2004-2008$
Kerstin Buttler

20.07.1967 in Hamburg

deutsch

ledig

Grundschule Jeddingen, Visselhövede Realschule Visselhövede, Visselhövede Gymnasiale Oberstufe der Berufsbildenden Schulen Rotenburg (Wümme), Rotenburg (Wümme)

Altenheim zur Mühle, Visselhövede

Berufsausbildung zur Verwaltungsfachangestellten bei der Stadt Visselhövede Verwaltungstätigkeiten beim Landkreis Verden / Aller und bei der Stadt Visselhövede

Biologie-Studium an der Universität Bremen Diplomarbeit bei Herrn Prof. Dr. W. Schloot, Zentrum für Hunangenetik, Universität Bremen, Titel der Arbeit: „Genetische Disposition bei der Entstehung Koronarer Herzstenosen“ Wissenschaftliche Mitarbeiterin der Adnagen AG, Hannover-Langenhagen Biowissenschaftliche Dokumentarin in der Abteilung Allgemeinmedizin der Medizinischen Hochschule Hannover Doktorarbeit bei Herrn Prof. Dr. J. Wilting, Anatomie und Zellbiologie, Universitätsmedizin der Georg-August-Universität Göttingen, Titel der Arbeit: ,,Vorläuferzellen des lymphatischen Endothels“ 